CENTRO UNIVERSITÁRIO DA FEI

JULIANA TACACIMA

OBTENÇÃO DE 5-HIDROXIMETIL-2-FURFURAL (HMF) A PARTIR DA DESIDRATAÇÃO CATALÍTICA DE AÇÚCARES

São Bernardo do Campo 

CENTRO UNIVERSITÁRIO DA FEI

JULIANA TACACIMA

\section{OBTENÇÃO DE 5-HIDROXIMETIL-2-FURFURAL (HMF) A PARTIR DA DESIDRATAÇÃO CATALÍTICA DE AÇÚCARES}

Dissertação de Mestrado apresentada ao Centro Universitário da FEI para obtenção do título de Mestre em Engenharia Química. Orientado pelo Prof. Dr. João Guilherme Rocha Poço. Coorientado pelo Prof. Dr. Silas Derenzo.

São Bernardo do Campo 
Tacacima, Juliana.

Obtenção de 5-hidroximetil-2-furfural (HMF) a partir da desidratação catalítica de açúcares / Juliana Tacacima. São Bernardo do Campo, 2017. 120 p. : il.

Dissertação - Centro Universitário FEI.

Orientador: Prof. Dr. João Guilherme Rocha Poço.

Coorientador: Prof. Dr. Silas Derenzo.

1. 5-hidroximetil-2-furfural. 2. desidratação de açúcares. 3. catálise heterogênea. I. Rocha Poço, João Guilherme, orient. II. Título. 
Título do Trabalho: Obtenção de 5-hidroximetil-2-furfural (HMF) a partir da desidratação catalítica de açúcares.

Área de Concentração: Engenharia Química

Orientador: Prof. Dr. João Guilherme Rocha Poço

Data da realização da defesa: 22/02/2017

Avaliação da Banca Examinadora:

São Bernardo do Campo, 22 / 02 / 2017.

\section{MEMBROS DA BANCA EXAMINADORA}

Prof. Dr. João Guilherme Rocha Poço

Prof. Dr. Dalmo Mandelli

Prof. Dr. Luis Fernando Novazzi
Ass.:

Ass. :

Ass.:

A Banca Julgadora acima-assinada atribuiu ao aluno o seguinte resultado:

APROVADO $\square \quad$ REPROVADO

\section{VERSÃO FINAL DA DISSERTAC̄ÃO}

APROVO A VERSÃO FINAL DA DISSERTAÇÃO EM QUE FORAM INCLUÍDAS AS RECOMENDAÇÕES DA BANCA

EXAMINADORA
Aprovação do Coordenador do Programa de Pós-graduação

Prof. Dr. Ricardo Belchior Torres 



\section{AGRADECIMENTOS}

Ao meu orientador, Prof. Dr. João Guilherme Rocha Poço, por acreditar no meu trabalho, pelas correções, incentivos e por todos os conhecimentos partilhados.

Ao meu coorientador, Prof. Dr. Silas Derenzo, pelo grande apoio, sugestões e conhecimentos partilhados.

Ao Centro Universitário da FEI e ao Instituto de Pesquisas Tecnológicas do Estado de São Paulo, por toda infraestrutura e disponibilidade de recursos essenciais no desenvolvimento deste trabalho.

A CAPES pela concessão da bolsa auxílio durante todo o curso.

Aos funcionários do Laboratório de Processos Químicos e Tecnológicos de Partículas, especialmente ao David Augusto de Freitas pela montagem do equipamento e pelo treinamento para a operação do reator Parr e a Vanessa Tiemi Kimura pelas dicas e conhecimentos compartilhados durante os experimentos com este reator.

Ao corpo docente da FEI pelos ensinamentos, especialmente à professora Dr. Andréia de Araujo Morandim Giannetti pelo auxílio com o HPLC.

Aos funcionários do Centro de Laboratórios de Químicos, pelos serviços que tornaram possível a execução dos experimentos na FEI.

A empresa Purolite ${ }^{\circledR}$, pelo fornecimento dos catalisadores utilizados nos experimentos.

A João Batista Ferreira Neto e Omar Ogusuku Alexandrino por permitirem a utilização do moinho de tungstênio.

A Douglas da Silva Santos e a Diego Zulkiewics Gomes pela realização da análise granulométrica no Malvern e análise no HPLC-MS, respectivamente.

Aos meus colegas da FEI, especialmente a Gabriela Peargentile, Renata Yagui e Ilidio Lazarieviez Antonio pela disposição em me ajudar nos experimentos finais de laboratório.

Aos meus amigos mestres, em especial, Ma. Fabiana dos Santos Lima, Ma. Ana Paula de Queiroz e Ma. Karinne Esteves Prado por todos os compartilhamentos de conhecimentos, todas as opiniões e todos os momentos de descontração.

A todos os familiares que sempre me apoiaram. 

"If you only do what you can do, you will never be more than you are now."

Master Shifu (Kung Fu Panda 3, 2016) 



\section{RESUMO}

O 5-hidroximetil-2-furfural (HMF) é um composto furânico considerado como uma importante plataforma química, pois pode ser obtido a partir de matérias-primas renováveis e tem ampla aplicação na indústria, agindo como um intermediário na produção de químicos finos, materiais poliméricos, biocombustíveis e fármacos. Por esse motivo, o presente projeto possui o intuito de estudar experimentalmente a reação de formação do HMF por catálise heterogênea, variando-se catalisadores e reagentes, com determinação de rendimento e seletividade para otimização e levantamento de dados cinéticos. Ensaios em reator batelada realizados em meio aquoso permitiram concluir que a frutose e a resina de troca iônica gel SGC650H apresentaram melhor desempenho que a glicose e a resina macroporosa CT275, respectivamente. $\mathrm{O}$ rendimento de HMF máximo de $20 \%$ em $3,5 \mathrm{~h}$ a $110{ }^{\circ} \mathrm{C}$ e a conversão de $84 \%$ após $7,5 \mathrm{~h}$ de reação indicaram que a reação não foi seletiva. A melhor forma de aumentar a seletividade do HMF é a utilização de solventes não aquosos, visto que a água degrada o produto em condições de alta temperatura e meio. Utilizando dimetilsulfóxido (DMSO) como solvente obtiveram-se rendimentos expressivamente maiores chegando a quase $100 \%$ em $3 \mathrm{~h}$ de reação a $110^{\circ} \mathrm{C}$. Além da utilização de reator batelada, ensaios em reator contínuo também foram realizados com frutose, DMSO e resina SGC650H como catalisador no leito recheado. A análise das reações com DMSO permitiu concluir que o aumento da temperatura e a redução do tamanho da partícula do catalisador favorecem a reação, ao contrário da concentração de alimentação da frutose. Considerando um modelo cinético de pseudo primeira ordem, obtiveram-se constantes cinéticas e parâmetros de Arrhenius, que variaram com a concentração de reagente alimentado. Essa variação mostrouse linear para a relação de Cremer-Constable o que indicou que o modelo foi insuficiente para caracterizar a reação. Testaram-se também modelos de taxas de reação de LangmuirHinshelwood (LHHW) com uma etapa limitante, porém não foi possível obter uma equação de taxa por esta abordagem.

Palavras-chave: 5-hidroximetil-2-furfural. Desidratação de açúcares. Catálise heterogênea. 



\begin{abstract}
5-hydroxymethyl-2-furfural (HMF) is a furanic compound considered as an important chemical platform once it is obtained from renewable raw materials and it has wide application in the industry, acting as an intermediate in the production of fine chemicals, polymer materials, biofuels and pharmaceuticals. Then, this project aimed an experimental study of the reaction of HMF formation by heterogeneous catalysis, varying catalysts and reagents, with determination of yield and selectivity for optimization, as well as kinetic data. Experiments in aqueous medium were carried out in a Parr reactor using a combination of a substrate (glucose or fructose) and a catalyst (macroporous or supergel ion exchange resins). The maximum HMF yield was $20 \%$ in $3.5 \mathrm{~h}$ and the conversion was $84 \%$ after $7.5 \mathrm{~h}$ in the reaction of fructose catalyzed by the supergel resin (named SGC650H) at $110{ }^{\circ} \mathrm{C}$, which indicated a poor performance towards HMF using water as solvent. This result is attributed to the HMF rehydration under high temperature conditions to produce levulinic and formic acids, so the best alternative to increase HMF selectivity is to use anhydrous solvents. Using dimethylsulfoxide (DMSO) as solvent, the yields significantly increased to almost $100 \%$ in $3 \mathrm{~h}$ reacting at $110{ }^{\circ} \mathrm{C}$. Besides conducted in batch reactions, experiments in continuous packed bed reactors were also performed with reaction systems containing fructose, DMSO and SGC650H resin. Analyzing the reactions performed with this system in both reactors, the increase in temperature and the reduction of the particle size of the catalyst favors the HMF formation, in contrast to the fructose feed concentration. Considering a pseudo first order kinetic model, the available data allowed to calculate rate constants and Arrhenius parameters, the latter varied with the concentration of reagent fed. This variation was linear in the CremerConstable diagram, which means that the model was insufficient to represent the reaction. Langmuir-Hinshelwood rate equations (LHHW) models were also tested by the rate determining step method, but none had adjusted to the data, and thus a rate law was not determined by the methods applied.
\end{abstract}

Keywords: 5-hidroxymethyl-2-furfural. Dehydration of sugars. Heterogeneous catalysis. 



\section{LISTA DE FIGURAS}

Figura 1 - Estruturas dos isômeros da $d$-frutose. 30

Figura 2 - Concentrações normalizadas dos isômeros da $d$-frutose em relação à concentração inicial de 0,02 M em função da temperatura em DMSO e água. ..... 31

Figura 3 - Alguns produtos químicos obtidos a partir da sacarose. ..................................... 32

Figura 4 - Ácido levulínico como uma plataforma química............................................. 33

Figura 5 - HMF como uma plataforma química. ........................................................... 34

Figura 6 - Formação do HMF com possíveis subprodutos.................................................. 35

Figura 7 - Desidratação da frutose para formação de HMF. .............................................. 36

Figura 8 - Possíveis rotas para o mecanismo de desidratação de hexoses. ........................... 41

Figura 9 - Mecanismo proposto para a rota cíclica da conversão catalítica da frutose a

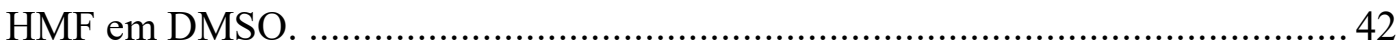

Figura 10 - Sistema reacional para experimentos em batelada........................................ 45

Figura 11 - Componentes internos do reator Parr............................................................ 46

Figura 12 - Representação do sistema experimental para reação contínua. ........................... 47

Figura 13 - Sistema reacional para realização dos ensaios em reator contínuo....................... 48

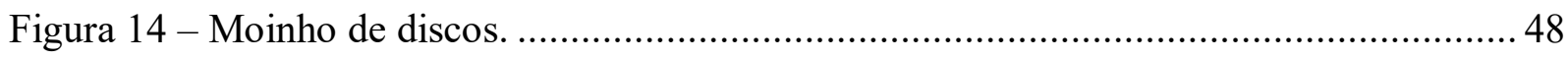

Figura 15 - Diagrama de blocos do procedimento experimental....................................... 50

Figura 16 - Taxa inicial em função da concentração inicial de reagente para diferentes

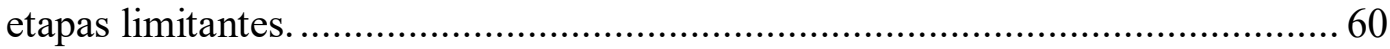

Figura 17 - Gráficos de Arrhenius e de Van’t Hoff para a desidrogenação do etanol............. 62 Figura 18 - Concentrações normalizadas em função do tempo de reação para o ensaio a $110{ }^{\circ} \mathrm{C}$ com alimentação de frutose, resina gelular SGC650H e água.

Figura 19 - Concentrações normalizadas em função do tempo de reação para o ensaio a $110{ }^{\circ} \mathrm{C}$ com alimentação de frutose, resina macroporosa CT275 e água.

Figura 20 - Concentrações normalizadas em função do tempo de reação para o ensaio a $110^{\circ} \mathrm{C}$ com alimentação de glicose, resina gel SGC650H e água. 65

Figura 21 - Concentrações normalizadas em função do tempo de reação para o ensaio a $110{ }^{\circ} \mathrm{C}$ com alimentação de glicose, resina macroporosa CT275 e água.

Figura 22 - Área percentual em relação ao HMF dos picos em função do tempo de reação para o ensaio a $110{ }^{\circ} \mathrm{C}$ com alimentação de $1,5 \%$ de frutose, DMSO e 
Figura 23 - Gráficos para comparação de resultados utilizando diferentes solventes: água e DMSO.

Figura 24 - Concentração de HMF em função do tempo de reação para ensaios com alimentação de $1,5 \%(\mathrm{~m} / \mathrm{m})$ de frutose em DMSO a diferentes temperaturas.

Figura 25 - Concentração de HMF em função do tempo de reação para ensaios com alimentação de 3,0 \% (m/m) de frutose em DMSO a diferentes temperaturas. .... 70

Figura 26 - Concentração de HMF em função do tempo de reação para ensaios com alimentação de 4,5 \% (m/m) de frutose em DMSO a diferentes temperaturas. .... 70

Figura 27 - Concentração de HMF em função do tempo de reação para ensaios com alimentação de 13,5\% (m/m) de frutose em DMSO a diferentes temperaturas.... 71

Figura 28 - Rendimento de HMF em função do tempo de reação para ensaios a $90{ }^{\circ} \mathrm{C}$ com diferentes concentrações de alimentação do reagente.

Figura 29 - Rendimento em HMF em função do tempo de reação para ensaios a $100{ }^{\circ} \mathrm{C}$ com diferentes concentrações de alimentação do reagente.

Figura 30 - Rendimento em HMF em função do tempo de reação para a $110{ }^{\circ} \mathrm{C} \mathrm{com}$ diferentes concentrações de alimentação do reagente.

Figura 31 - Colorações das amostras com diferentes concentrações de frutose alimentada. ... 74

Figura 32 - Distribuições granulométricas obtidas pelo analisador de tamanho de partículas

Malvern Mastersizer 2000.

Figura 33 - Rendimento de HMF em função do tempo de reação para ensaios a $90{ }^{\circ} \mathrm{C}$ com diferentes granulometrias da SGC650H como catalisador.

Figura 34 - Gráfico linearizado da conversão em função do tempo de reação em diferentes temperaturas.

Figura 35 - Regressão linear da equação de Arrhenius para os ensaios com diferentes concentrações de alimentação de frutose.

Figura 36 - Diagrama de Cremer-Constable mostrando o efeito de compensação dos resultados para o reator em batelada.

Figura 37 - Efeito de compensação dos resultados obtidos para o reator batelada.

Figura 38 - Gráfico da taxa inicial de reação em função da concentração inicial de frutose. .. 81

Figura 39 - Gráficos de Arrhenius e de Van’t Hoff para reação na superfície limitante, sem dissociação do reagente.

Figura 40 - Conversão da frutose em função do tempo médio de residência em reator contínuo a diferentes temperaturas. 
Figura 41 - Conversão da frutose em função do tempo médio de residência em reator contínuo para ensaios com diferentes alimentações de frutose e DMSO.

Figura 42 - Gráfico linearizado da conversão em função do tempo de permanência em reator contínuo a diferentes temperaturas.

Figura 43 - Efeito de compensação dos resultados obtidos para os reatores batelada e contínuo.

Figura 44 - Gráficos para comparação de resultados para diferentes tipos de reator.

Figura 45 - Cromatogramas de uma amostra de DMSO puro analisado pela coluna Aminex $\mathrm{HPX}-87 \mathrm{H}^{\circledR}$

Figura 46 - Cromatograma de uma amostra de DMSO puro analisado pela coluna Shimpack CLC-ODS (M) ${ }^{\circledR}$ com o detector UV-Vis a $266 \mathrm{~nm}$.

Figura 47 - Curvas de calibração do HMF para a coluna Aminex HPX87H ${ }^{\circledR}$ e detectores

I.R. e UV-Vis a $210 \mathrm{~nm}$ utilizados nos ensaios com água.

Figura 48 - Curva de calibração do HMF para a coluna Shim-pack CLC-ODS (M) ${ }^{\circledR}$ utilizada nos ensaios com DMSO.

Figura 49 - Comparação entre dados experimentais e valores calculados para a concentração de HMF no ensaio a $90{ }^{\circ} \mathrm{C}$ com alimentação de $1,5 \%(\mathrm{~m} / \mathrm{m})$ de frutose.

Figura 50 - Comparação entre dados experimentais e valores calculados para a concentração de HMF no ensaio a $100{ }^{\circ} \mathrm{C}$ com alimentação de $1,5 \%$ (m/m) de frutose.

Figura 51 - Comparação entre dados experimentais e valores calculados para a concentração de HMF no ensaio a $110^{\circ} \mathrm{C}$ com alimentação de $1,5 \%(\mathrm{~m} / \mathrm{m})$ de frutose.

Figura 52 - Comparação entre dados experimentais e valores calculados para a concentração de HMF no ensaio a $90{ }^{\circ} \mathrm{C}$ com alimentação de $3,0 \%(\mathrm{~m} / \mathrm{m})$ de frutose.

Figura 53 - Comparação entre dados experimentais e valores calculados para a concentração de HMF no ensaio a $100{ }^{\circ} \mathrm{C}$ com alimentação de $3,0 \%(\mathrm{~m} / \mathrm{m})$ de frutose.

Figura 54 - Comparação entre dados experimentais e valores calculados para a concentração de HMF no ensaio a $110{ }^{\circ} \mathrm{C}$ com alimentação de $3,0 \%(\mathrm{~m} / \mathrm{m})$ de frutose. 
Figura 55 - Comparação entre dados experimentais e valores calculados para a concentração de HMF no ensaio a $90{ }^{\circ} \mathrm{C}$ com alimentação de $4,5 \%(\mathrm{~m} / \mathrm{m})$ de frutose

Figura 56 - Comparação entre dados experimentais e valores calculados para a concentração de $\mathrm{HMF}$ no ensaio a $100{ }^{\circ} \mathrm{C}$ com alimentação de 4,5 \% (m/m) de frutose

Figura 57 - Comparação entre dados experimentais e valores calculados para a concentração de HMF no ensaio a $110{ }^{\circ} \mathrm{C}$ com alimentação de $4,5 \%(\mathrm{~m} / \mathrm{m})$ de frutose

Figura 58 - Comparação entre dados experimentais e valores calculados para a concentração de HMF no ensaio a $90{ }^{\circ} \mathrm{C}$ com alimentação de $13,5 \%$ (m/m) de frutose

Figura 59 - Comparação entre dados experimentais e valores calculados para a concentração de HMF no ensaio a $100{ }^{\circ} \mathrm{C}$ com alimentação de 13,5 \% (m/m) de frutose.

Figura 60 - Comparação entre dados experimentais e valores calculados para a concentração de HMF no ensaio a $110{ }^{\circ} \mathrm{C}$ com alimentação de $13,5 \%$ (m/m) de frutose. 


\section{LISTA DE TABELAS}

Tabela 1 - Especificações das substâncias utilizadas nos experimentos. 43

Tabela 2 - Especificações das resinas utilizadas como catalisadores nos experimentos......... 44

Tabela 3 - Descrição dos reagentes utilizados na preparação das soluções padrões. ............. 44

Tabela 4 - Especificações das colunas utilizadas para HPLC. .............................................. 49

Tabela 5 - Parâmetros para realização dos ensaios preliminares. ........................................ 51

Tabela 6 - Parâmetros dos ensaios com DMSO em reator batelada. ................................... 52

Tabela 7 - Parâmetros para realização dos ensaios em reator contínuo. ................................ 53

Tabela 8 - Valores de diluição das amostras para análise cromatográfica em HPLC............. 54

Tabela 9 - Conversão e rendimentos máximos obtidos nos ensaios a $110^{\circ} \mathrm{C}$ com utilização de frutose como reagente e água como solvente. .............................................6 64

Tabela 10 - Comparação entre os valores experimentais ${ }^{a}$ e uma referência bibliográfica ${ }^{b}$ com utilização de frutose como reagente e água como solvente.

Tabela 11 - Conversão e rendimentos máximos obtidos nos ensaios com utilização de glicose como reagente e água como solvente.

Tabela 12 - Características da resina SGC650H em diferentes granulometrias. 75

Tabela 13 - Constantes de velocidade e parâmetros de Arrhenius da reação global de formação de HMF obtidos pelo método integral.

Tabela 14 - Comparação entre os parâmetros de Arrhenius para a reação de pseudo primeira ordem obtidas pelo método de Euler e pelo método integral

Tabela 15 - Equações para as leis de velocidade baseados no modelo LHHW. 81

Tabela 16 - Constantes cinéticas calculadas pelo modelo para reação na superfície limitante, sem adsorção da água e reação global irreversível.

Tabela 17 - Constantes de velocidade e parâmetros de Arrhenius para a reação global de formação de HMF obtidos a partir do método integral no reator contínuo. 86

Tabela 18 - Equações para comparação entre reatores batelada e contínuo. 88

Tabela 19 - Propriedades do HMF. 101

Tabela 20 - Tempos de retenção das soluções padrões analisadas. 106

Tabela 21 - Coeficientes das curvas de calibração para a coluna Aminex HPX-87H ${ }^{\circledR}$ utilizada nos ensaios preliminares.

Tabela 22 - Área do pico referente à respectiva concentração analisada e área relativa para a coluna Shim-pack CLC-ODS (M) ${ }^{\circledR}$ utilizada nos ensaios com DMSO. 



\section{LISTA DE SÍMBOLOS}

\begin{tabular}{|c|c|c|}
\hline$a_{j}$ & constantes de uma equação linear & \\
\hline$A_{m}$ & área superficial específica em relação à massa & $\mathrm{cm}^{2} / \mathrm{g}$ \\
\hline$C_{c a t}$ & concentração de catalisador em massa & $\mathrm{g}_{\text {cat }} / \mathrm{L}$ \\
\hline$C_{i}$ & concentração da espécie $i$ & $\mathrm{~mol} / \mathrm{L}$ \\
\hline$C_{i_{0}}$ & concentração de alimentação da espécie $i$ & $\mathrm{~mol} / \mathrm{L}$ \\
\hline$D_{p}$ & diâmetro médio das partículas & $\mathrm{cm}$ ou $\mu \mathrm{m}$ \\
\hline$E_{A}$ & energia de ativação & $\begin{array}{l}\mathrm{J} / \mathrm{mol} \text { ou } \\
\mathrm{kJ} / \mathrm{mol}\end{array}$ \\
\hline$F_{i_{0}}$ & vazão molar inicial da espécie $i$ & $\mathrm{~mol} / \mathrm{h}$ \\
\hline$k$ & constante de velocidade da reação & $\mathrm{h}^{-1}$ ou $\min ^{-1}$ \\
\hline$k_{\text {ads.i, }} k_{r . s .}$ & $\begin{array}{l}\text { constantes de taxa da reação para reação catalítica de primeira } \\
\text { ordem }\end{array}$ & $\begin{array}{l}\mathrm{L} \cdot \mathrm{g}_{\mathrm{cat}}{ }^{-1} \cdot \mathrm{h}^{-1} \mathrm{ou} \\
\mathrm{L} \cdot \mathrm{g}_{\mathrm{cat}}{ }^{-1} \cdot \mathrm{min}^{-1}\end{array}$ \\
\hline$K_{a d s . i}, K_{r . s .}$ & constantes de equilíbrio para a reação catalítica & $\mathrm{L} / \mathrm{mol}$ \\
\hline$k^{\prime}$ & $\begin{array}{l}\text { constante de velocidade da reação em termos da massa de } \\
\text { catalisador }\end{array}$ & $\begin{array}{l}\mathrm{L} \cdot \mathrm{g}_{\mathrm{cat}}{ }^{-1} \cdot \mathrm{h}^{-1} \text { ou } \\
\mathrm{L} \cdot \mathrm{g}_{\mathrm{cat}}{ }^{-1} \cdot \mathrm{min}^{-1}\end{array}$ \\
\hline$k^{\prime}{ }_{0}$ & constante pré-exponencial de Arrhenius & $\begin{array}{l}\mathrm{L} \cdot \mathrm{g}_{\text {cat }}{ }^{-1} \cdot \mathrm{h}^{-1} \mathrm{ou} \\
\mathrm{L} \cdot \mathrm{g}_{\text {cat }}{ }^{-1} \cdot \mathrm{min}^{-1}\end{array}$ \\
\hline$m_{i}$ & massa da espécie $i$ & $\mathrm{~g}$ \\
\hline$n$ & ordem da reação & \\
\hline$N_{i}$ & quantidade molar da espécie $i$ & mol \\
\hline$n_{i}$ & molaridade da espécie $i$ & $\mathrm{~mol} / \mathrm{L}$ \\
\hline$n_{0}$ & molaridade de alimentação no reator & $\mathrm{mol} / \mathrm{L}$ \\
\hline$n_{t}$ & $\begin{array}{l}\text { molaridade total no instante } t \text { dos componentes participantes na } \\
\text { reação, exceto catalisador e solvente }\end{array}$ & $\mathrm{mol} / \mathrm{L}$ \\
\hline$R$ & constante universal dos gases ideais & $\mathrm{J} \cdot \mathrm{mol}^{-1} \cdot \mathrm{K}^{-1}$ \\
\hline$r_{i}$ & velocidade ou taxa de reação em termos de $i$ & $\begin{array}{l}\mathrm{mol} \cdot \mathrm{L}^{-1} \cdot \mathrm{h}^{-1} \mathrm{ou} \\
\mathrm{mol} \cdot \mathrm{L}^{-1} \cdot \mathrm{min}^{-1}\end{array}$ \\
\hline$r_{a d s . i,} r_{r . s .}$ & $\begin{array}{l}\text { velocidades ou taxas de reação por unidade de massa de } \\
\text { catalisador }\end{array}$ & 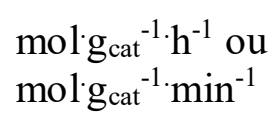 \\
\hline
\end{tabular}




$\begin{array}{lll}r_{i}^{\prime} & \begin{array}{l}\text { velocidade global da reação em termos de } i \text { baseada na massa } \\ \text { de catalisador }\end{array} & \begin{array}{l}\mathrm{mol} \cdot \mathrm{g}_{\mathrm{cat}}{ }^{-1} \cdot \mathrm{h}^{-1} \mathrm{ou} \\ \mathrm{mol}^{1} \mathrm{~g}_{\mathrm{cat}}{ }^{-1} \cdot \mathrm{min}^{-1}\end{array} \\ S & \text { seletividade da reação de formação do HMF } & \% \\ T & \text { tempo de reação } & \mathrm{h} \text { ou min } \\ V & \text { temperatura de reação } & \mathrm{K} \\ v_{0} & \text { volume reacional } & \mathrm{L} \\ W & \text { vazão volumétrica de alimentação no reator contínuo } & \mathrm{mL} / \mathrm{min} \\ X & \text { massa de catalisador em base seca } & \mathrm{gcat} \\ x_{j} & \text { conversão da frutose } & \% \\ y & \text { variável independente de uma equação linear } & \\ Y & \text { variável dependente de uma equação linear } & \%\end{array}$

\section{Símbolos gregos}

$\begin{array}{lll}\Delta t & \text { passo, variação de tempo } & \mathrm{h} \text { ou min } \\ \rho_{\text {meio }} & \text { densidade do meio reacional } & \mathrm{g} / \mathrm{L} \\ \rho_{p} & \text { densidade das partículas sólidas } & \mathrm{g} / \mathrm{cm}^{3} \\ \tau & \text { tempo de residência médio ou de permanência no reator } & \mathrm{h} \text { ou min }\end{array}$

\section{Subscritos}

$A, R, S \quad$ componentes de reação

ads adsorção

cat catalisador

F $\quad$ frutose

G glicose

$H \quad$ HMF

HF ácido fórmico

$H L \quad$ ácido levulínico 


$\begin{array}{ll}i & \text { componente } i \text { da reação } \\ I & \text { inerte } \\ j & j \text {-ésimo componente } \\ m & \text { massa } \\ \text { meio } & \text { meio reacional } \\ p & \text { partícula } \\ r . s . & \text { reação na superfície } \\ t & \text { no instante } t \text { da reação } \\ W & \text { água } \\ 0 & \text { condição inicial ou de alimentação }\end{array}$

\section{Sobrescritos}

BTR reator batelada

PBR reator tubular contínuo de leito recheado

$T \quad$ no instante $t$ da reação

$t+\Delta t \quad$ no instante $t+\Delta t$ da reação

baseado na massa de catalisador 



\section{SUMÁRIO}

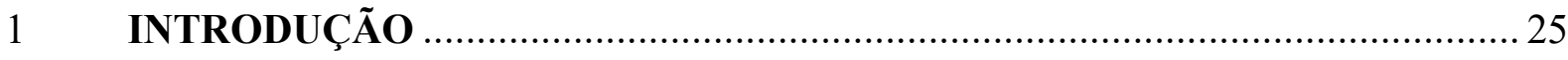

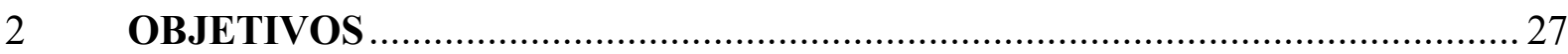

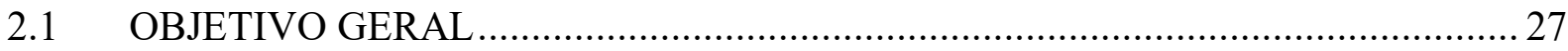

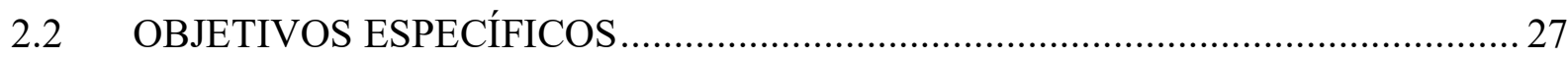

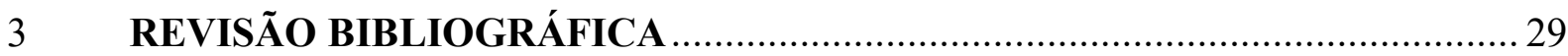

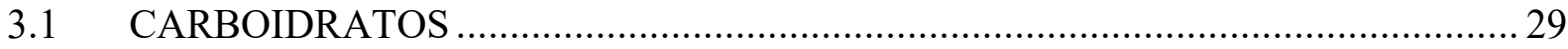

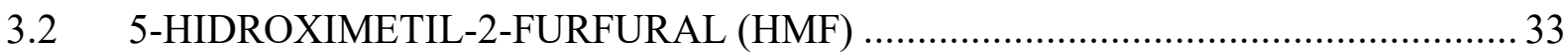

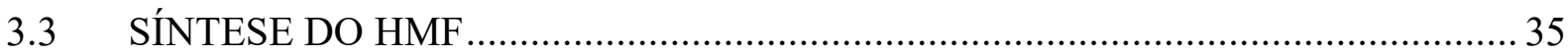

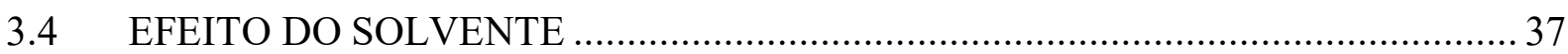

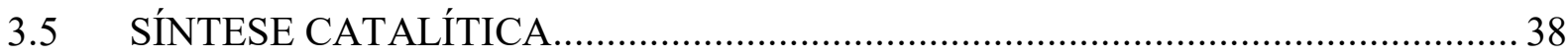

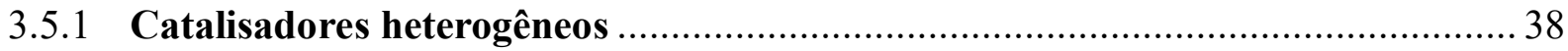

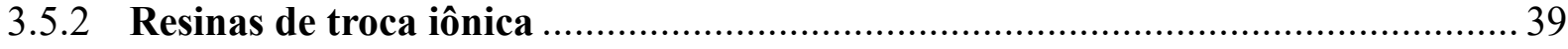

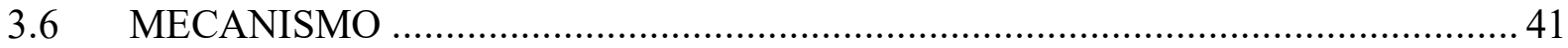

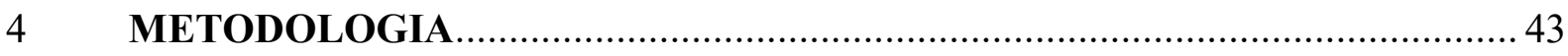

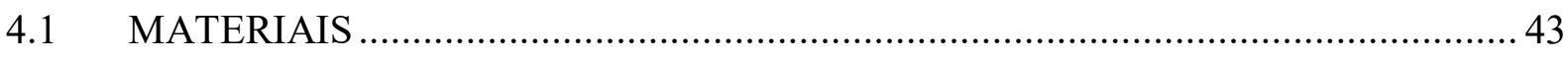

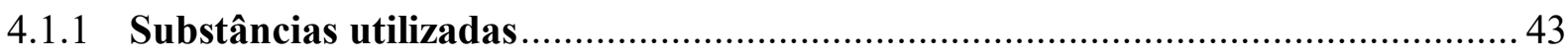

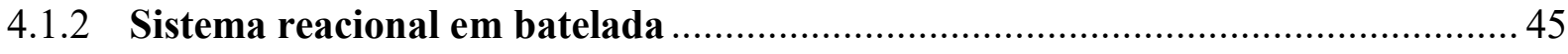

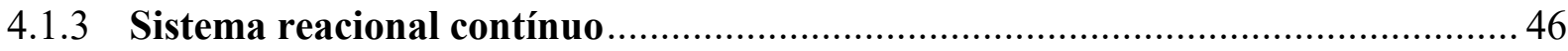

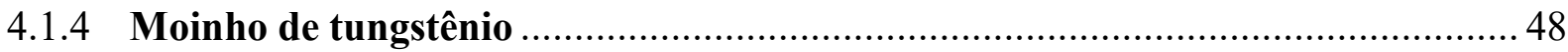

4.1.5 Analisador de tamanho de partículas por difração laser .................................... 49

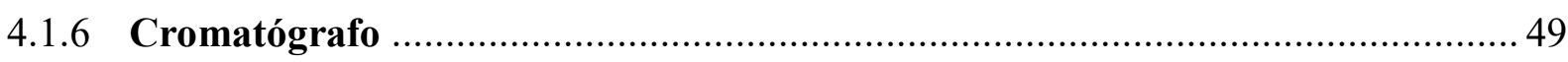

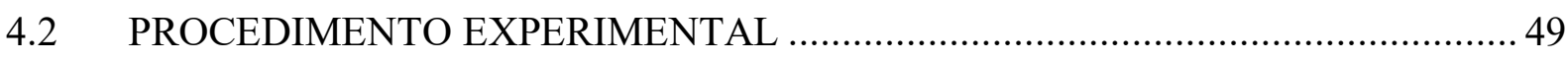

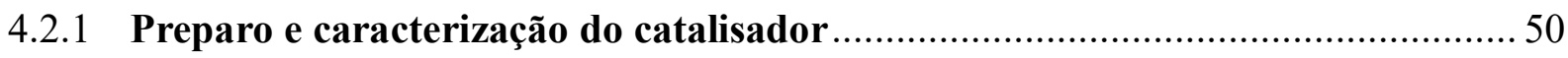

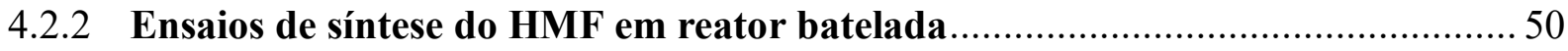

4.2.3 Ensaios de síntese do HMF em reator contínuo …........................................ 52

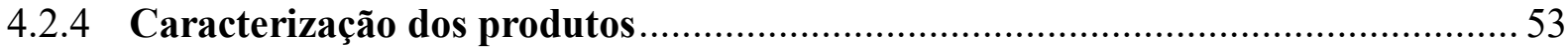

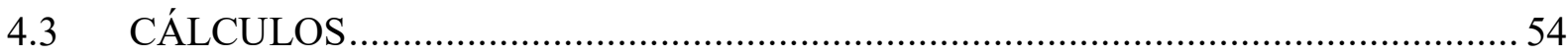

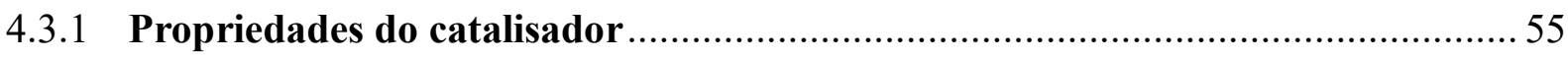

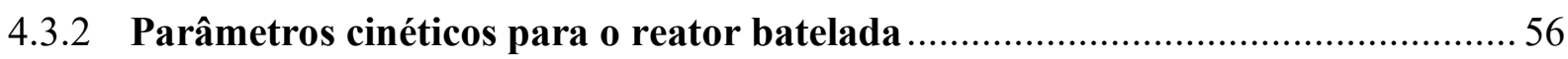

4.3.3 Parâmetros cinéticos para o reator contínuo ..................................................... 58

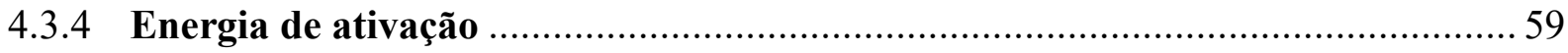

4.3.5 Parâmetros cinéticos para reação com aquecimento no reator batelada ............. 59 


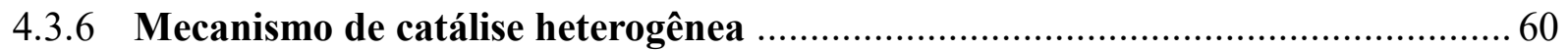

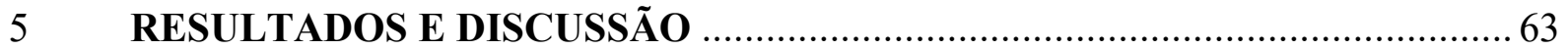

5.1 ENSAIOS EM REATOR BATELADA COM ÁGUA COMO SOLVENTE .............63

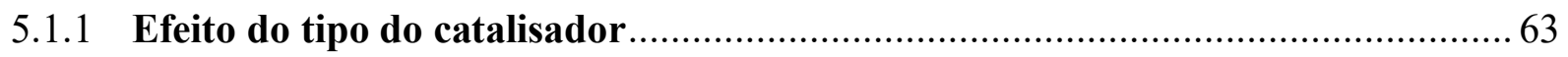

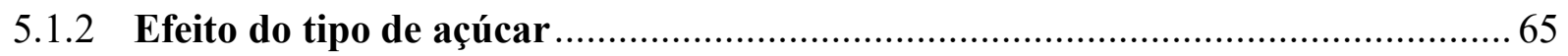

5.2 ENSAIOS EM REATOR BATELADA COM DMSO COMO SOLVENTE .............67

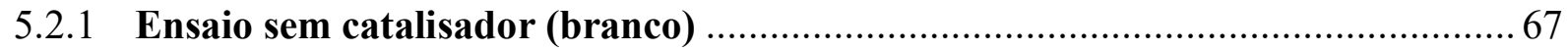

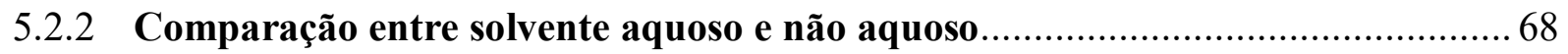

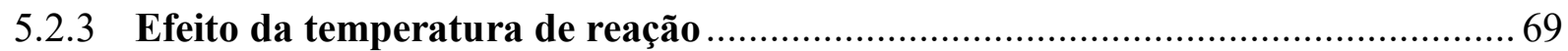

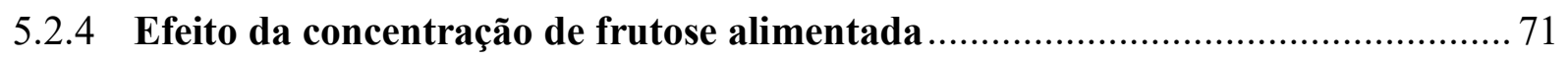

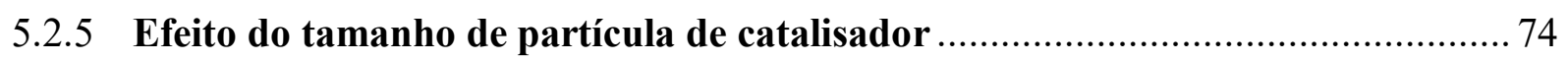

5.2.6 Análise cinética da reação pelo método integral.................................................. 76

5.2.7 Análise cinética da reação considerando o aquecimento ..................................... 79

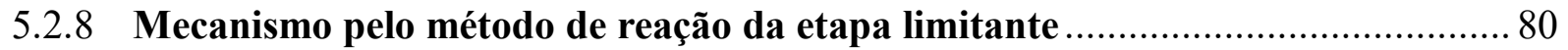

5.3 ENSAIOS EM REATOR CONTÍNUO COM DMSO COMO SOLVENTE.............. 83

5.3.1 Efeitos da temperatura de reação e concentração de alimentação ....................... 83

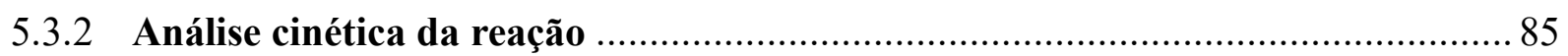

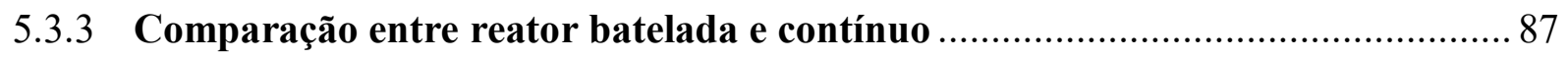

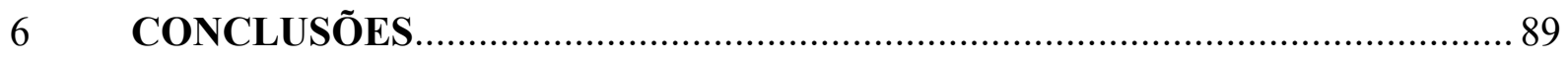

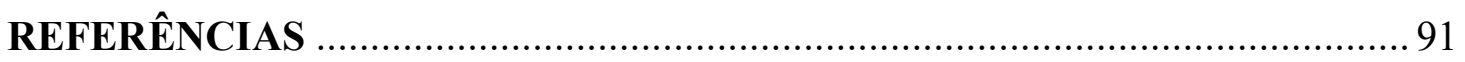

APÊNDICE A - RESUMO DAS PROPRIEDADES DO 5-HIDROXIMETIL-

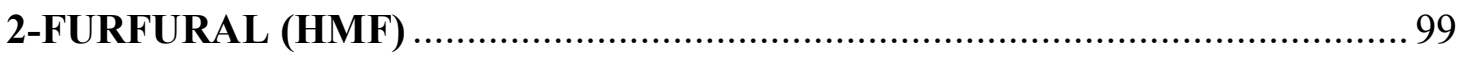

APÊNDICE B - CURVAS DE CALIBRAÇÃO PARA A ANÁLISE POR

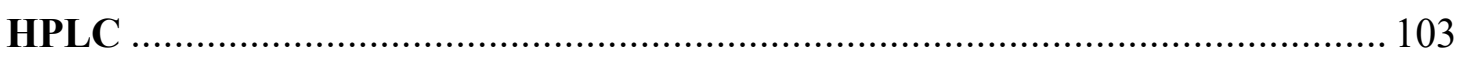

APÊNDICE C - GRÁFICOS DOS DADOS SIMULADOS POR

OTIMIZAÇÃ

ANEXO A - TABELA DOS GRUPOS QUE COMPÕEM EQUAÇÕES

CINÉTICAS CATALISADAS POR SÓLIDOS ............................................. 117 


\section{INTRODUÇÃO}

Nos últimos anos, houve uma crescente preocupação com questões ambientais tais como o aquecimento global provocado pelo agravamento do efeito estufa, cujo principal responsável é o aumento significativo das emissões de gases do efeito estufa (GEE) para a atmosfera desde o início da revolução industrial. Segundo o Painel Intergovenamental sobre Mudanças Climáticas (IPCC), essas emissões apresentaram um aumento de $75 \%$ entre 1970 e 2010. O dióxido de carbono $\left(\mathrm{CO}_{2}\right)$ é o GEE com maior crescimento nas emissões de aproximadamente $78 \%$ no mesmo período e representando $76 \%$ do total de emissões antropogênicas em 2010 (IPCC, 2014). A elevação da concentração desse gás na atmosfera deve-se ao fato de ele ser o produto principal da queima de combustíveis fósseis associado às devastações florestais que diminuem a abstração natural do gás da atmosfera por fotossíntese.

Em sua análise sobre os compromissos feitos no Acordo de Paris, a Agência Internacional de Energia (IEA), na edição do World Energy Outlook de 2016 chegou à conclusão que a demanda por combustíveis fósseis, especialmente o petróleo, continuará a crescer até 2040, justificado pela falta de alternativas plausíveis à sua utilização. Por isso, reforçam a necessidade do desenvolvimento de tecnologias renováveis, expandindo seu uso nos setores industrial, de construção e transporte (IEA, 2016).

Uma alternativa é a utilização de biomassa, considerada atrativa por ser um recurso renovável abundante na natureza, produto da fixação do $\mathrm{CO}_{2}$, com quantidade estimada existente na Terra na ordem de 1,8 trilhão de toneladas. O Brasil apresenta situação privilegiada para produção de biomassa, devido ao solo e às condições climáticas adequadas, situando-se na faixa tropical do planeta com agroindústria ativa e grandes dimensões de terras cultivadas ou cultiváveis (AGÊNCIA NACIONAL DE ENERGIA ELÉTRICA - ANEEL, 2008). Além de seu potencial para a produção de energia e biocombustíveis, a biomassa também é precursora para insumos químicos, empregando o conceito de biorrefinaria e química verde. Esta última, também conhecida como química sustentável, é definida pela Agência de Proteção Ambiental dos Estados Unidos - EPA (2016) como o planejamento de produtos e processos químicos com redução ou eliminação de emissões de substâncias nocivas ao meio ambiente.

Uma biorrefinaria é uma unidade de extração a partir da biomassa de carboidratos, óleos, lignina e outros compostos para produzir vários produtos, como combustíveis, materiais com maior valor agregado e energia (WERPY; PETERSEN, 2004). Durante este processo de transformação, há as substâncias intermediárias ou precursoras a estes produtos 
finais. Uma plataforma química é um intermediário com potencial para sintetizar uma vasta variedade de materiais, como solventes, combustíveis, fármacos, polímeros etc, ou seja, servem como blocos de construção (do termo em inglês, building block) para a obtenção destes compostos químicos com alto valor agregado.

Um desses intermediários químicos sintetizados a partir de biomassa é o 5 hidroximetil-2-furfural (HMF), um derivado furânico reconhecido como uma importante plataforma química devido ao seu potencial industrial para produção biocombustíveis, solventes, resinas e outros precursores de biopolímeros, fármacos etc. A hidrogenação seletiva do HMF produz o 2,5-dimetilfurano (DMF), um exemplo de biocombustível com propriedades parecidas com o etanol e maior miscibilidade que o diesel. A oxidação seletiva do HMF pode formar o ácido 2,5-furanodicarboxílico (FDCA), este último com potencial para substituir o ácido tereftálico como monômero para produção de poliésteres. Já a hidrólise do HMF forma o ácido levulínico, um importante building block para sintetizar polímeros de acrilato e aditivos de combustíveis, como o $\gamma$-valerolactona, 2-metil-tetrahidrofurano e levulinato de etila (CRISCI et al, 2010).

Diante deste quadro, o presente projeto propôs o estudo da síntese do HMF a partir de matérias-primas de fontes renováveis, analisando os efeitos dos tipos de reagente e catalisador, bem como da temperatura e das concentrações dos componentes durante a reação para o levantamento de dados cinéticos. 


\section{OBJETIVOS}

\subsection{OBJETIVO GERAL}

O presente projeto foi elaborado com o objetivo geral de sintetizar o 5-hidroximetil-2furfural (HMF) por reação catalítica heterogênea utilizando carboidratos como matéria-prima.

\subsection{OBJETIVOS ESPECÍFICOS}

Visando melhorar o rendimento e a seletividade do processo, definiram-se como objetivos específicos:

a) comparar diferentes carboidratos como reagentes (frutose e glicose);

b) selecionar resinas ácidas como catalisador;

c) avaliar o efeito de solvente aquoso ou não aquoso sobre a reação;

d) estudar o efeito da temperatura na reação e levantamento de dados cinéticos;

e) estudar comparativamente reatores batelada e tubular contínuo;

f) estudar o efeito da temperatura e da concentração de alimentação do reator para obtenção de uma lei de velocidade para catálise heterogênea. 


\section{REVISÃO BIBLIOGRÁFICA}

A dependência mundial por combustíveis fósseis aumentou drasticamente ao longo dos anos, por serem as principais fontes de energia e insumos químicos. $\mathrm{O}$ aumento na demanda desses recursos, as previsões para o esgotamento de suas reservas, a elevação dos custos de extração, bem como uma crescente preocupação com questões ambientais são os principais fatores que influenciam a busca por tecnologias que reduzam essa dependência (KUNZ, 1993; VAN PUTTEN et al., 2013).

Diante desse cenário, diversos países têm empregado o conceito de biorrefinaria, visando à utilização de fontes renováveis para produção de energia, matérias-primas classificadas como commodities e intermediários da química fina.

Ferreira, Rocha e Silva (2009) destacaram a biomassa como um recurso natural atrativo, uma vez que é economicamente viável, renovável, facilmente disponível e abundante na natureza, especialmente em países tropicais como o Brasil. A biomassa refere-se às matérias orgânicas obtidas de forma renovável, apresentando composição complexa na qual seus constituintes básicos são carboidratos, lignina, proteínas, lipídios como por exemplo celulose, amido, óleos, terpenos etc. Essas matérias-primas biológicas possuem elevado potencial energético quando utilizadas em processos de combustão, gaseificação e fermentação em biodigestores. Além disso, a biomassa é uma importante fonte de carboidratos, e estes podem ser utilizados tanto para fins alimentares como para a produção de insumos químicos e intermediários da química fina, uma vez que os açúcares formam a maior fonte natural de carbono.

\subsection{CARBOIDRATOS}

Carboidrato é um termo genérico sinônimo de açúcar que originalmente definia moléculas compostas apenas por carbono e água em proporção 1:1. Atualmente abrange monossacarídeos, oligossacarídeos, polissacarídeos e substâncias derivadas que podem conter grupos amino, tiol ou outros heteroátomos (ULLMANN'S, 2011).

Os monossacarídeos são os carboidratos que apresentam constituições mais simples, não possuindo ligações glicosídicas e assim não sofrem hidrólise. Esses açúcares podem ser aldoses ou cetoses e são classificados de acordo com seu número de carbonos, que pode variar de dois a oito átomos, sendo que os mais comuns contêm seis ou cinco carbonos, respectivamente hexoses ou pentoses (ULLMANN'S, 2011). 
As hexoses são os monossacarídeos mais abundantes na natureza e comumente representadas na forma de cadeia linear, mas se apresentam predominantemente em estruturas cíclicas quando em soluções aquosas. As principais são a $d$-glicose e a $d$-frutose quando o assunto é a obtenção de insumos químicos e intermediários da química fina (TONG; MA; LI, 2010).

A $d$-frutose é uma ceto-hexose com o sabor mais doce obtido naturalmente e largamente utilizado como adoçante, que pode ser sintetizado por reações como as de isomerização da glicose e hidrólise da sacarose ou da inulina. Em solução aquosa, a frutose apresenta-se em quatro tautômeros cíclicos mostrados na Figura 1 (FERREIRA; ROCHA; SILVA, 2009), sendo que suas concentrações dependem da temperatura e do solvente, como visto na Figura 2. Em altas temperaturas, a frutofuranose do tipo $\beta\left(\mathrm{F}_{5-\beta}\right)$ é a forma predominante e apresenta concentração relativa maior em DMSO que em água ou metanol, cujos comportamentos são explicados pelo efeito de solvatação e pela orientação dos grupos $\mathrm{OH}$ do soluto, que determina a estabilidade do anel na presença de fortes interações com o solvente (KIMURA; NAKAHARA; MATUBAYASI, 2013).

Figura 1 - Estruturas dos isômeros da $d$-frutose.

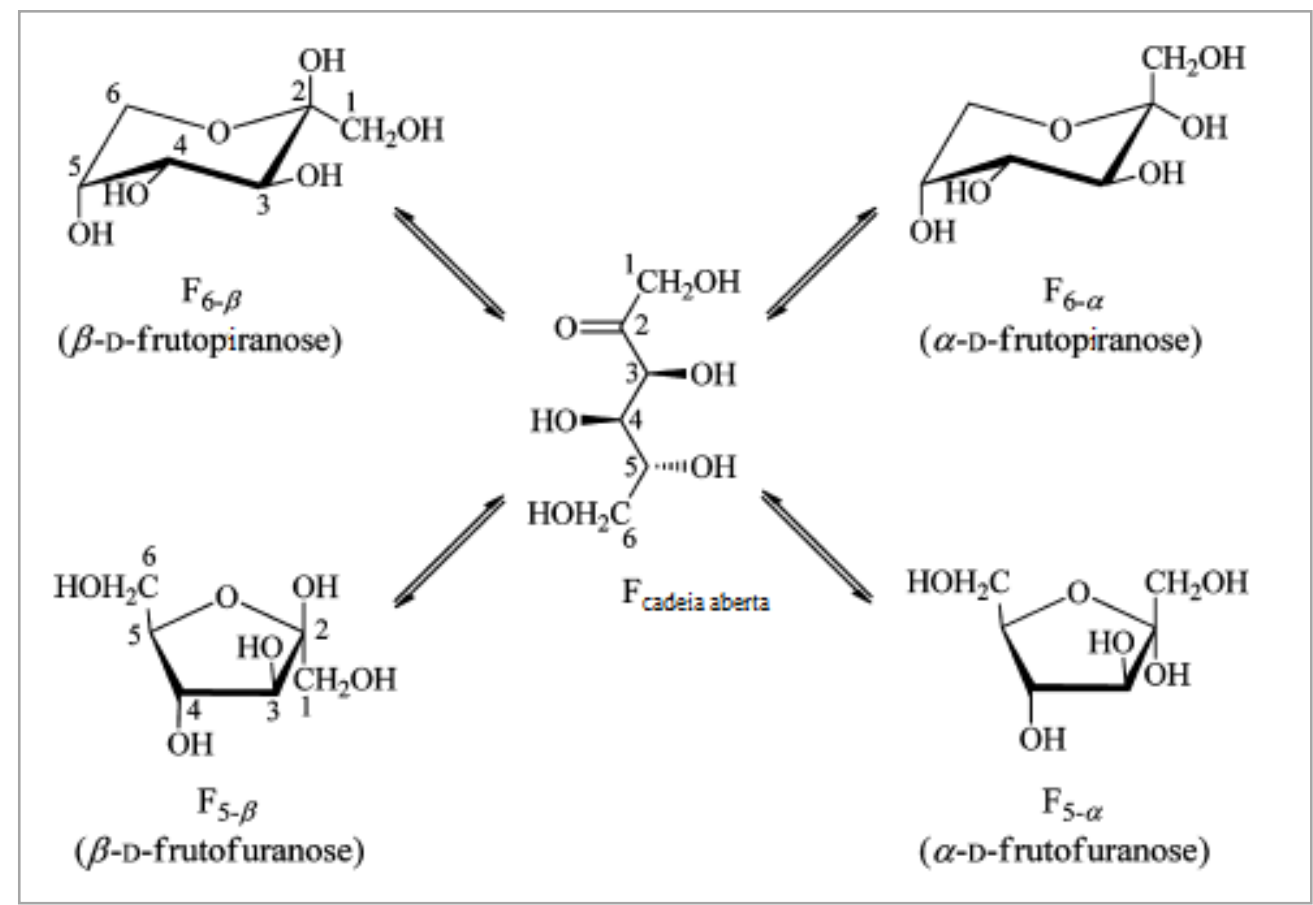

Fonte: Autora “adaptado de” Kimura, Nakahara e Matubayasi, 2013. 
Figura 2 - Concentrações normalizadas dos isômeros da $d$-frutose em relação à concentração inicial de 0,02 M em função da temperatura em DMSO e água.

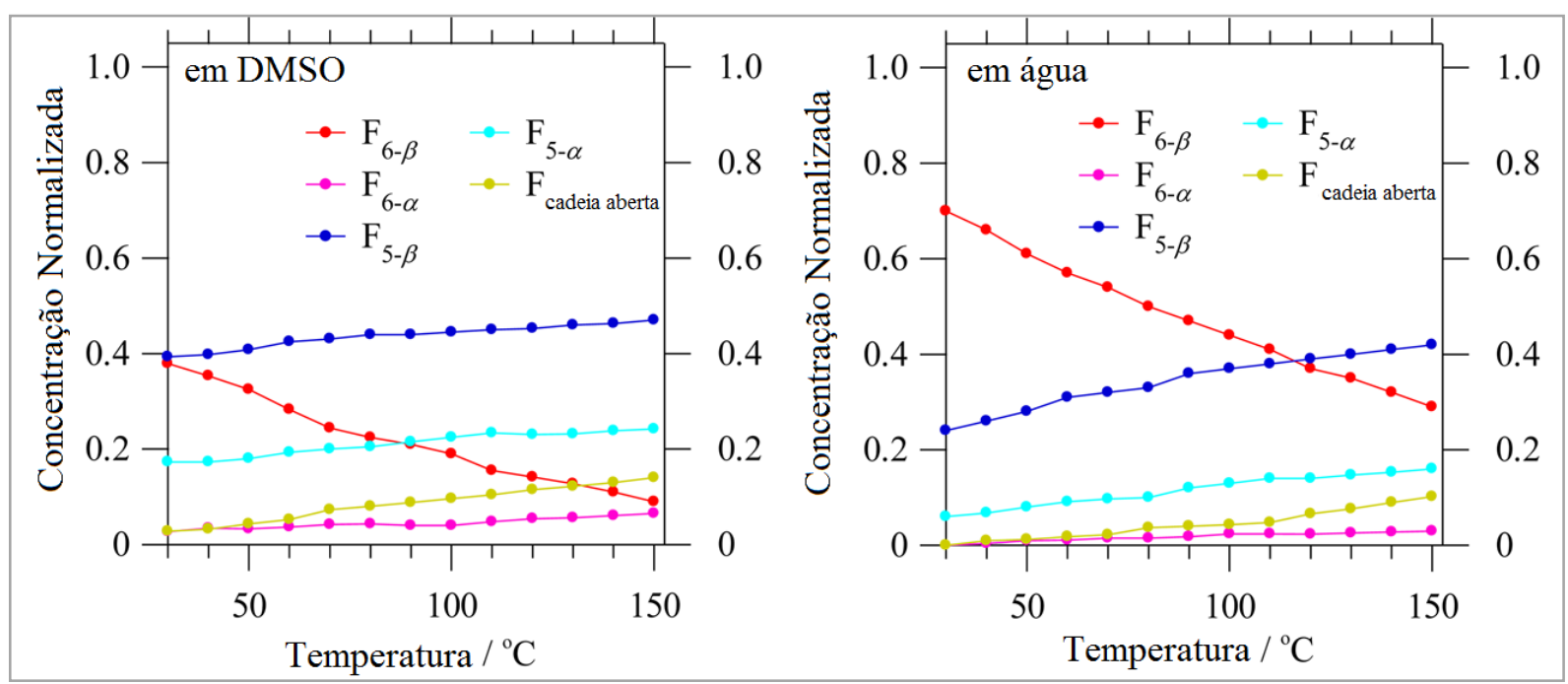

Fonte: Autora "adaptado de" Kimura, Nakahara e Matubayasi, 2013.

Segundo Ferreira, Rocha e Silva (2009), a obtenção de commodities e intermediários da química fina por fontes de carboidratos parte da transformação da biomassa em açúcares com baixas massas moleculares, como monossacarídeos e dissacarídeos. Esse processo de transformação desses sacarídeos para substâncias com maior valor agregado requer a diminuição do número de átomos de oxigênio das estruturas moleculares do açúcar. Entre as opções para a redução do teor de oxigênio está a reação de desidratação da molécula, que possibilita a produção de uma variedade de compostos com alto potencial para produção de combustíveis, tais como furanos e ácido levulínico (TAKAGAKI; NISHIMURA; EBITANI, 2012; VAN PUTTEN et al., 2013).

A Figura 3 mostra um exemplo da variedade de produtos de baixa massa molecular que podem ser obtidos em escala industrial a partir de um carboidrato, no caso a sacarose. 
Figura 3 - Alguns produtos químicos obtidos a partir da sacarose.

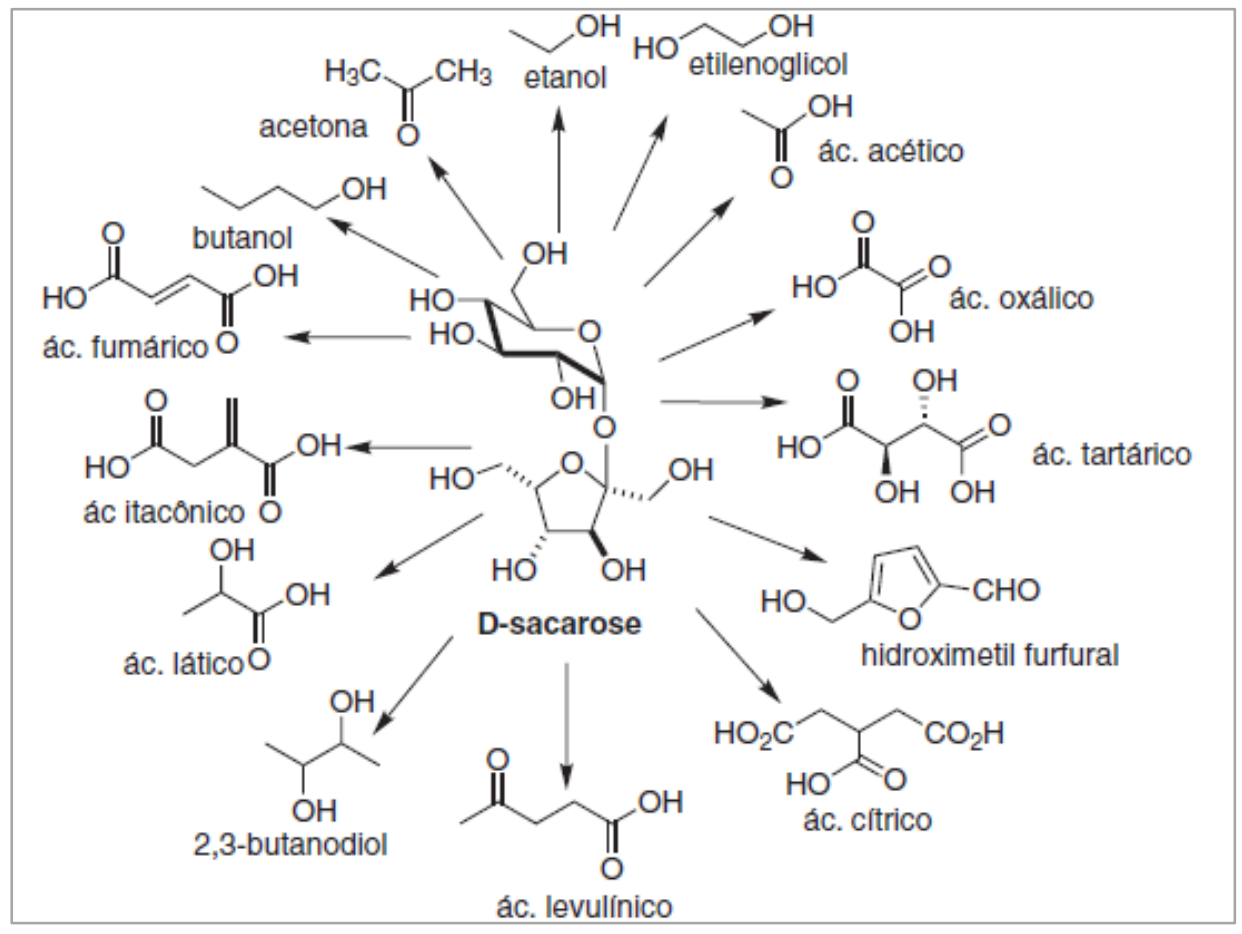

Fonte: Autora "adaptado de" Ferreira, Rocha e Silva, 2009.

Além de sua utilidade alimentar, as principais aplicações da D-frutose são as produções de hidroximetilfurfural (HMF) e ácido levulínico, ambos considerados como importantes plataformas químicas. O ácido levulínico, formado pela hidrólise ácida do HMF, é uma matéria-prima versátil para produção de diversos produtos como apresentados na Figura 4. Já o HMF é um importante precursor para intermediários de elevado potencial industrial, incluindo o ácido levulínico, 2,5-dimetilfurano (DMF), ácido 2,5furandicarboxílico (FDCA) entre outros apresentados na Figura 5, página 34 (FERREIRA; ROCHA; SILVA, 2009). 
Figura 4 - Ácido levulínico como uma plataforma química.

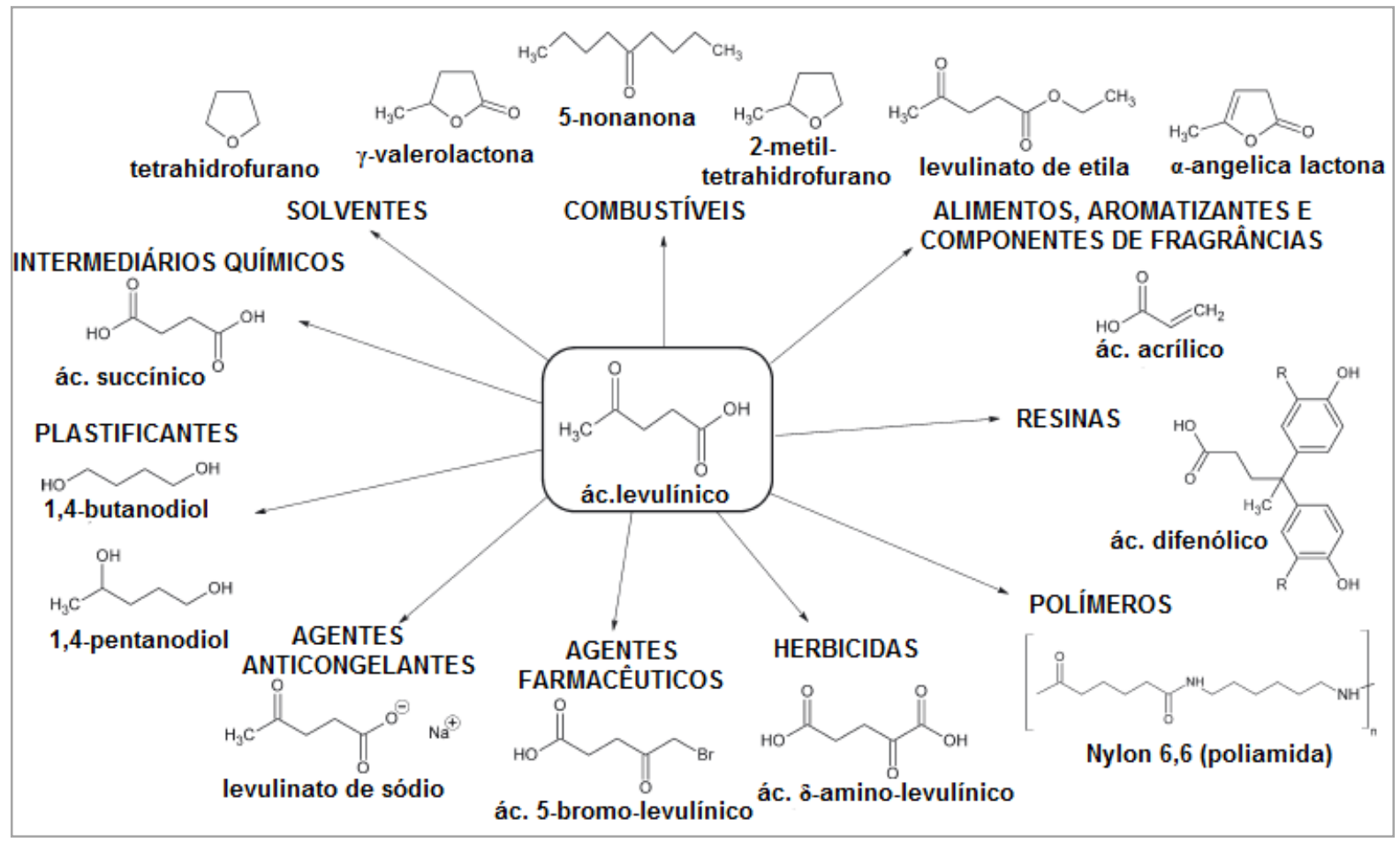

Fonte: Autora “adaptado de” Rackemann e Doherty, 2011.

\subsection{5-HIDROXIMETIL-2-FURFURAL (HMF)}

O 5-hidroximetil-2-furfural ou hidroximetilfurfural (HMF), cuja nomenclatura IUPAC é 5-hidroximetil-2-furaldeído e fórmula molecular $\mathrm{C}_{6} \mathrm{H}_{6} \mathrm{O}_{3}$, é um monômero furânico de seis carbonos, solúvel em água, possui elevado ponto de ebulição e é relativamente instável podendo degradar-se a ácidos levulínico e fórmico (KIRK; OTHMER, 1963). Um resumo das propriedades do HMF é apresentado no Apêndice A.

Naturalmente formado por decomposição térmica de hexoses, o HMF pode ser encontrado na dieta humana como um intermediário na caramelização e em reações de Maillard que ocorrem em alimentos. Como um produto derivado de biomassa, é apontado como uma importante plataforma química do tipo furano, que apresenta vantagens frente a outras plataformas como o ácido levulínico e o bioetanol, devido às altas seletividades obtidas em sua síntese a partir da frutose, e por manter em sua estrutura os seis átomos de carbono presentes na matéria-prima (VAN PUTTEN et al., 2013).

Kunz (1993) utiliza o termo "químico básico" para o HMF por ser formado a partir de matérias-primas dos setores primários e convertido em intermediários que serão transformados em produtos finais como químicos finos, materiais poliméricos, biocombustíveis, fármacos, solventes, entre outros. É considerado como um importante 
"bloco de construção" (tradução para o termo building block) para a indústria sustentável, devido ao seu potencial para ampla aplicação como um precursor de intermediários da química fina, como é possível observar pela Figura 5.

Figura 5 - HMF como uma plataforma química.

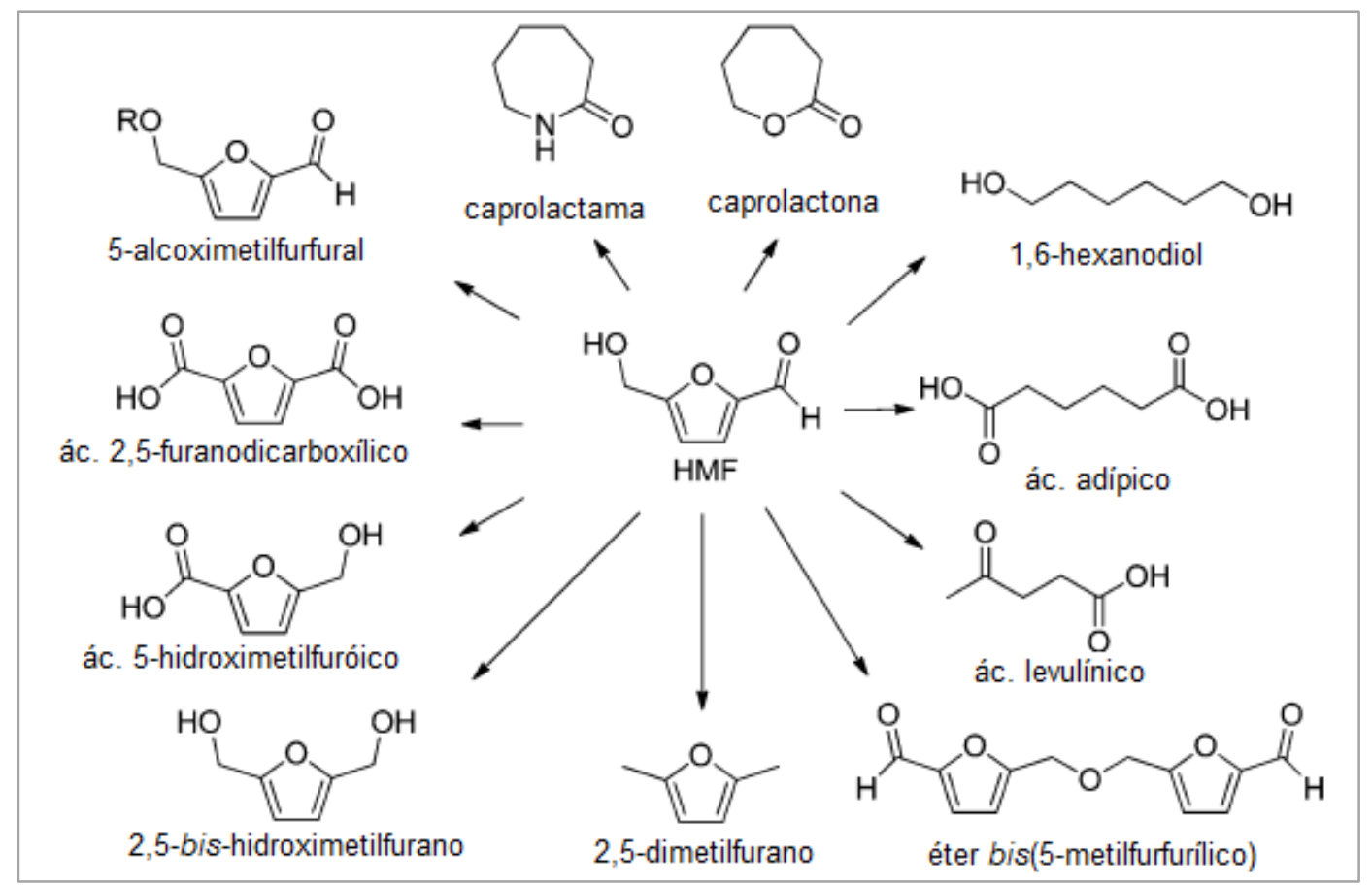

Fonte: Autora "adaptado de" van Putten et al., 2013.

Além do ácido levulínico, destaca-se outro building block derivado do HMF: o ácido 2,5-furanodicarboxílico ou FDCA, que pode ser obtido por oxidação seletiva do HMF, possuindo alto potencial para substituir o ácido tereftálico por ser intermediário para produção de biopolímeros e de ácido succínico (WERPY; PETERSEN, 2004; TONG; MA; LI, 2010; TAKAGAKI; NISHIMURA; EBITANI, 2012).

Além do FDCA, outros derivados furânicos do HMF possuem potencial industrial para a produção de poliaminas e poliésteres, como o ácido 5-hidroximetilfuróico, o 2,5-bishidroximetilfurano, o 2,5-diformil-furano ou 2,5-furano-dicarbaldeído (FDC), 1,6-hexanodiol, 1,6-hexanodiamina e (KUNZ, 1993; FERREIRA; ROCHA; SILVA, 2009; TAKAGAKI; NISHIMURA; EBITANI, 2012).

Outras aplicações como síntese de surfactantes e solventes pode ser citada para o intermediário 2,5-bis-hidroximetilfurano (KUNZ, 1993); e a obtenção de biocombustíveis como o 2,5-dimetilfurano ou DMF, é imiscível em água e menos volátil em relação ao etanol, de modo que o torna adequado para combustível de transporte (TONG; MA; LI, 2010). 


\subsection{SÍNTESE DO HMF}

O HMF é um produto obtido naturalmente da degradação térmica de açúcares, mas também pode ocorrer por desidratação de hexoses ou de carboidratos baseados em frutose como sacarose e inulina -, assim como pela hidroximetilação de furfural com formaldeído (ERTL et al., 2008).

Devido ao seu potencial como plataforma química, sua síntese com altos rendimento e seletividade torna-se desejável, o que é possível pela reação de desidratação de hexoses por catalisadores ácidos em meio aquoso ou orgânico. Entretanto, a catálise ácida promove também a formação de subprodutos como polímeros solúveis e huminas insolúveis, ou mesmo a subsequente hidrólise formando os ácidos levulínico e fórmico, como representado na Figura 6, os quais contribuem para a diminuição da seletividade da reação de síntese do HMF (CARLINI et al., 1999).

Figura 6 - Formação do HMF com possíveis subprodutos.

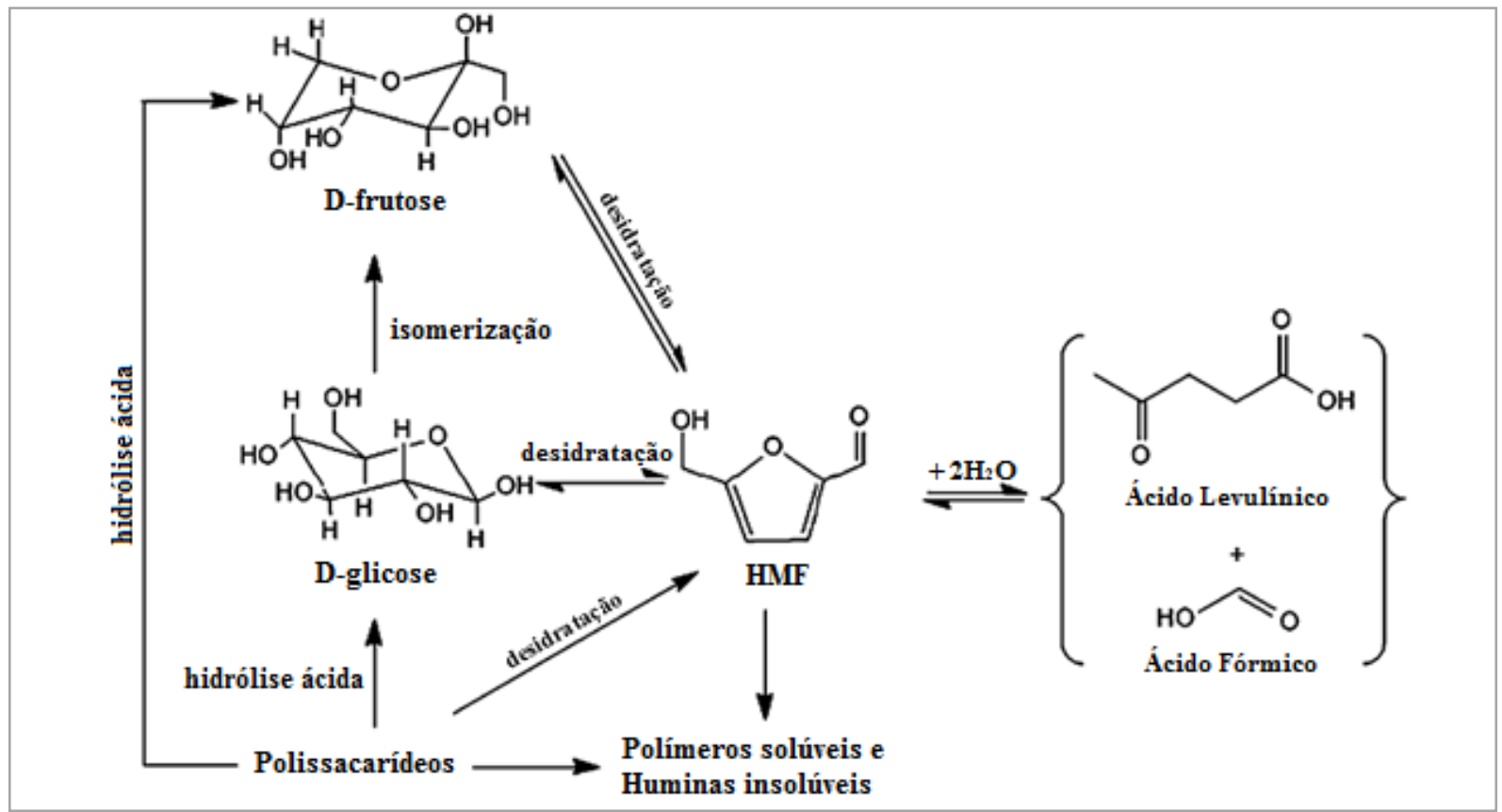

Fonte: Autora “adaptado de” Jiang et al., 2012.

Subprodutos de condensação, oligomerização e polimerização como os polímeros solúveis e as huminas insolúveis são formados a partir da reação entre o reagente e produtos da desidratação (HMF), por este motivo, altas concentrações de substrato aumentam a probabilidade de formação desses subprodutos. As huminas são polímeros sólidos insolúveis, cujas estruturas complexas tornam-nos difíceis de identificar, porém podem ser verificados 
através da mudança de coloração de marrom a preta (PATIL; LUND, 2011). Além da diminuição da seletividade, estes polímeros podem obstruir e depositar-se na superfície de catalisadores heterogêneos, reduzindo suas atividades catalíticas.

A rota geral de desidratação de sacarídeos em meio ácido segue a eliminação do equivalente a três moléculas de água, como representado na Figura 7. Nos casos em que se utiliza dissacarídeos e polissacarídeos - por exemplo sacarose, inulina e celulose - como matéria-prima, é preciso realizar uma despolimerização inicial por hidrólise (ANTAL; MOK; RICHARDS, 1990; SIMEONOV; AFONSO, 2013).

Figura 7 - Reação de desidratação da frutose para formação de HMF.

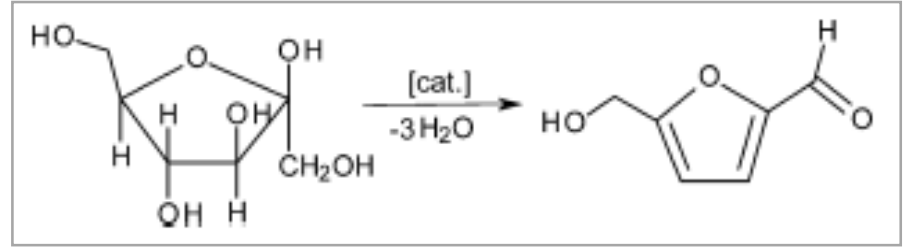

Fonte: Stark et al., 2012.

Apesar da glicose ser o monossacarídeo mais abundante na natureza e, portanto, a melhor opção do ponto de vista econômico, sua utilização como substrato durante a formação do HMF apresenta menor eficiência produtiva quando comparada à frutose (TAKAGAKI; NISHIMURA; EBITANI, 2012). Isso ocorre devido à estabilidade da estrutura cíclica formada por seis átomos na glicose - denominada piranose - quando comparada ao ciclo de cinco átomos na frutose - furanose, o que resulta em um menor grau de enolização responsável pela formação do HMF (KUSTER, 1990; ZAKRZEWSKA; BOGEL-ŁUKASIK; BOGEL-ŁUKASIK, 2011). Assim, a isomerização inicial da glicose para frutose é uma reação importante a ser considerada para melhorar a produção do HMF.

A reação de isomerização de hexoses ocorre em meio alcalino com catalisadores básicos ou ácidos de Lewis, mas comercialmente a frutose é obtida a partir da glicose por catálise enzimática utilizando a $d$-xilose isomerase, que resulta em uma mistura com 42:50 de glicose:frutose no equilíbrio, um processo considerado caro (MOREAU et al., 2000). Segundo a literatura, os ácidos de Lewis (como $\mathrm{ZnCl}_{2}, \mathrm{AlCl}_{3}$ e $\mathrm{BF}_{3}$ ) são utilizados para realizar a isomerização de glicose a frutose, enquanto os ácidos de Brønsted como catalisadores (pentóxido e fosfato de nióbio, por exemplo) são responsáveis pela reação de desidratação da frutose (JAIN et al., 2015; ASGHARI; YOSHIDA, 2006). Por este motivo, sistemas de catalisadores contendo esses dois tipos de sítios ácidos são reportados na 
literatura para a conversão one-pot de HMF partindo da glicose, tais como resinas de troca iônica e hidrotalcita, fosfato de nióbio mesoporoso, MCM-41 dopado com alumínio, zeólitas, entre outros (TAKAGAKI; NISHIMURA; EBITANI, 2012; ZHANG Y. et al., 2015)

\subsection{EFEITO DO SOLVENTE}

O solvente é um fator determinante para a reação de conversão de frutose a HMF, pois promove fluidez e contato entre reagente e catalisador. A escolha do meio reacional deve levar em conta propriedades de solvatação, já que economicamente recomenda-se trabalhar com altas concentrações do soluto, que pode aumentar a probabilidade de formação de huminas, dependendo do solvente (KUSTER, 1990). Os solventes comumente empregados são: água, metanol, dimetilsulfóxido (DMSO), misturas orgânica/aquosa, líquidos iônicos e sistemas bifásicos orgânico/aquoso (KIMURA; NAKAHARA; MATUBAYASHI, 2013).

A utilização de solvente aquoso é a mais vantajosa do ponto de vista econômico, é menos tóxica e não inflamável. No entanto, a água também atua como reagente deslocando o equilíbrio inverso da desidratação da frutose para HMF e facilitando a hidrólise deste a ácido levulínico. Além disso a maioria dos sólidos ácidos perde sua atividade catalítica e estabilidade em meio aquoso (KUSTER, 1990).

Em contrapartida, solventes anidros como dimetilformamida (DMF), acetonitrila, DMSO e líquidos iônicos geralmente promovem maiores rendimentos e menores formações de huminas e produtos de hidrólise como os ácidos fórmico e levulínico, porém envolvem problemas ambientais e de toxicidade. Além do maior custo do solvente em si, são necessárias maiores diluições do substrato, devido à sua baixa capacidade de solubilização do reagente, o que diminui a produtividade e dificulta a purificação do HMF, visto também que estes solventes possuem elevado ponto de ebulição (CARLINI et al., 1999). O DMSO pode sofrer ainda decomposição resultando na formação de subprodutos tóxicos. Já os líquidos iônicos possuem aplicação em larga escala limitada por seu elevado custo e pela sua facilidade de desativação em água (GALLO et al., 2013).

Utilizando sistemas bifásicos, a reação de desidratação ocorre na fase aquosa com o catalisador e deve estar saturada com $\mathrm{NaCl}$ para diminuir a solubilidade do HMF em água. A fase orgânica (como octanol, metil-isobutilcetona, dioxano, entre outros) comporta-se como agente de extração do HMF, inibindo a degradação do mesmo pelo catalisador, porém é preciso uma alta diluição devido ao seu coeficiente de partição desfavorável e assim necessitando um tempo maior de aquecimento (GALLO et al., 2013). 


\subsection{SÍNTESE CATALÍTICA}

A catálise ácida para obtenção do HMF pode ser realizada em sistemas homogêneos e heterogêneos, mas no geral, o emprego de catalisadores heterogêneos fornece seletividades maiores em relação aos homogêneos, além de apresentarem menores toxicidade, corrosividade e demanda, bem como facilidade de separação, reciclo e adaptação para sistemas contínuos em larga escala.

Os principais catalisadores homogêneos utilizados são: ácidos minerais, ácidos orgânicos, líquidos iônicos, ácidos de Lewis e sais (ASGHARI; YOSHIDA, 2006).

Musau e Munavu (1987) estudaram a reação de desidratação da frutose utilizando dimetilsulfóxido (DMSO) como solvente e catalisador, conseguindo um rendimento de $92 \%$ de $\mathrm{HMF}$ ao realizar a reação a $150{ }^{\circ} \mathrm{C}$.

Ranoux et al. (2013) estudaram síntese do HMF em $190^{\circ} \mathrm{C}$ sem adição inicial de catalisador em meio aquoso neutro e observaram que a reação é autocatalítica, devido à formação de subprodutos ácidos. Os autores chegaram à conversão de 70 \% e seletividade de $61 \%$, concluindo que a alta seletividade observada foi devido à pequena formação gradual de ácido fórmico e que este é um catalisador mais efetivo que o ácido levulínico.

Compostos heteropoliácidos são catalisadores ativos que podem ser homogêneos ou heterogêneos. Por exemplo o ácido dodecatungstofosfórico $\left(\mathrm{H}_{3} \mathrm{PW}_{12} \mathrm{O}_{40}\right)$, considerado como um superácido, é solúvel em solventes polares; enquanto os seus sais com substituição dos prótons por cátions monovalentes de tamanho maior, como $\mathrm{Cs}^{+}, \mathrm{NH}_{4}^{+}, \mathrm{K}^{+}, \mathrm{e}^{+}$, formam sólidos ácidos porosos e insolúveis em água. Fan et al. (2011), Zhao et al. (2011) e Shimizu, Uozumi e Satsuma (2009) reportaram elevadas seletividades a HMF chegando a 94,7 \% para alta concentração de frutose $(30-50 \% \mathrm{~m} / \mathrm{m})$ ao utilizar esses catalisadores heterogêneos, no caso o $\mathrm{Cs}_{2,5} \mathrm{H}_{0,5} \mathrm{PW}$, sob condições de operação amenas a $115^{\circ} \mathrm{C}$. As vantagens destes catalisadores heterogêneos são suas tolerâncias a altas concentrações do substrato e a possibilidade de reciclo.

\subsubsection{Catalisadores heterogêneos}

Catalisadores baseados em nióbio $(\mathrm{Nb})$ possuem elevadas propriedades ácidas que são preservadas mesmo em solventes polares. O pentóxido de nióbio, também designado ácido nióbico, apresenta alta acidez de Brønsted, enquanto o fosfato de nióbio possui alta proporção de sítios ácidos de Lewis/Brønsted (CARNITI et al., 2006). Este, por sua vez, pode ser obtido 
por tratamento daquele com ácido fosfórico (ARMAROLI et al., 2000). Entretanto, a utilização do ácido nióbico possui a desvantagem de perder rapidamente sua atividade catalítica, provavelmente devido à deposição de huminas insolúveis sobre a superfície do catalisador (CARNITI; GERVASINI; MARZO, 2011).

Zeólitas são aluminosilicatos com estrutura microporosa, comumente utilizados como adsorventes, peneiras moleculares e catalisadores. Esses catalisadores, quando comerciais, como o ZSM-5, podem ser obtidos na forma de amônio ( $\left.\mathrm{NH}_{4}-\mathrm{ZSM}-5\right)$ e convertido à forma protonada (H-ZSM-5) por calcinação. Este, por sua vez, apresenta elevada acidez devido à alta proporção entre sílica e alumina (O’NEILL et al., 2009).

Materiais mesoporosos possuem maiores áreas superficiais e diâmetros de poro, quando comparados a zeólitas cristalinas e, à princípio, têm potencial para aplicações em reações catalíticas em escala industrial (DAL SANTO et al., 2010). De modo generalizado, são sintetizados por conformação de uma matriz cristalina em líquido formando um complexo molecular composto por espécies inorgânicas moleculares e moléculas orgânicas anfifílicas, os surfactantes, responsáveis pelo direcionamento da estrutura (HUO; MARGOLESE; STUCKY, 1996). A família M41S - como MCM-41, MCM-48 e MCM-50 - de silicatos e aluminosilicatos, por exemplo, são materiais considerados peneiras moleculares e apresentam grandes áreas superficiais, poros monodispersos de (2-50) $\mathrm{nm}$ de diâmetro e sistema de canais regulares e bem definidos (JIAN-WEN et al., 2008). Muitos estudos reportam que o MCM-41 não demonstra atividade catalítica satisfatória, contudo, há a possibilidade de incorporação de compostos ativos em sua estrutura por síntese direta ou por métodos pós-síntese (GUCBILMEZ; DOGUA; BALCI, 2005).

\subsubsection{Resinas de troca iônica}

Resinas de troca iônica são materiais de matriz orgânica macromolecular composta por cadeias irregulares de hidrocarbonetos hidrofóbicos interconectados por crosslinks. Possuem grupos iônicos hidrofílicos, como $\mathrm{SO}_{3}^{-}, \mathrm{COO}^{-}$e $\mathrm{NH}_{2}{ }^{+}$, incorporados, cujas cargas são balanceadas por íons de sinal oposto chamados contra-íons, que se movimentam livremente pela matriz e podem ser substituídos por outros íons de mesma carga. Tipicamente na forma de gel, são insolúveis em qualquer solvente e não são destruídos por eles, porém podem expandir e inchar devido à elasticidade da matriz, diferentemente da estrutura rígida das zeólitas. 
A atividade catalítica das resinas de troca iônica em meios líquidos é análoga à catálise homogênea por eletrólitos dissolvidos (por exemplo $\mathrm{H}^{+}, \mathrm{OH}^{-}, \mathrm{Hg}^{2+}, \mathrm{CN}^{-}$), estes, por sua vez, podem ser utilizados como contra-íons nas resinas, servindo como catalisadores.

As vantagens de sua utilização são a separação por decantação ou filtração, possibilidade de operação contínua em colunas, obtenção de produto com maior pureza, já que reações paralelas são menos significantes, e em alguns casos há possibilidade de isolar intermediários de reação. Entretanto, suas aplicações são restritas a estabilidade química (agentes oxidantes fortes podem quebrar crosslinks) e térmica, além do custo maior (HELFFERICH, 1989).

Segundo Kuster (1990), ao utilizar resinas de troca iônica como catalisador, deve-se evitar a formação de huminas insolúveis, recomendando a utilização de DMSO ou sistemas bifásicos para extração contínua do HMF do meio reacional. Kimura, Nakahara e Matubayasi (2013), Simeonov e Afonso (2013), Chinnappan et al. (2014) e Lansalot-Matras e Moreau (2003) reportaram elevados rendimentos entre $80 \%$ e $97 \%$ a HMF ao utilizar Amberlyst-15 e DMSO como solvente, visto que a menor concentração de água no meio reacional reduz a reação consecutiva de hidrólise do produto desejado.

Shimizu, Uozumi e Satsuma (2009) estudaram a reação a $120{ }^{\circ} \mathrm{C}$ com DMSO como solvente e diferentes tipos de catalisadores, como resinas de troca iônica (Amberlyst-15), sólidos heteropoliácidos e zeólitas. Neste estudo, utilizaram técnicas de remoção da água no meio reacional por redução da pressão, chegando a um aumento no rendimento para HMF de $49 \%$ para $97 \%$ com o catalisador $\mathrm{FePW}_{12} \mathrm{O}_{40}$ e de $51 \%$ para $97 \%$ com a zeólita H-BEA, ao realizar-se uma evacuação branda do sistema, operando em 0,97 bar. A resina Amberlyst-15 foi tratada com DMSO para redução da água adsorvida e também apresentou um aumento no rendimento com a redução da pressão de $76 \%$ para $92 \%$, apesar de não ser tão expressivo quanto os dois primeiros, pois são sólidos que retém água. Ao utilizar essa resina moída com diâmetros de partícula entre $0,150 \mathrm{~mm}$ e $0,053 \mathrm{~mm}$, os autores notaram que a remoção da água adsorvida no catalisador foi mais eficiente conseguindo um rendimento de $100 \%$ para concentração de frutose de $3 \%(\mathrm{~m} / \mathrm{m})$, o que também pode ser justificado pelos processos de transferência de massa e dessorção de produtos que resultam em maiores conversões e menores formações de subprodutos. 


\subsection{MECANISMO}

O processo de desidratação da D-frutose para formação do HMF é complexo e, no geral, envolve etapas de isomerização, desidratação, fragmentação, reversão e condensação. Evidências experimentais para o estabelecimento do mecanismo para a reação de síntese do HMF por desidratação de hexose ainda são insuficientes, de modo que não há consenso na literatura. Diversos mecanismos são sugeridos e podem ser divididos em duas linhas gerais: na primeira, a reação ocorre com intermediários acíclicos, já a segunda ocorre com o ciclo frutofuranose intacto (VAN PUTTEN et al., 2013), ambas representadas na Figura 8.

Figura 8 - Possíveis rotas para o mecanismo de desidratação de hexoses.

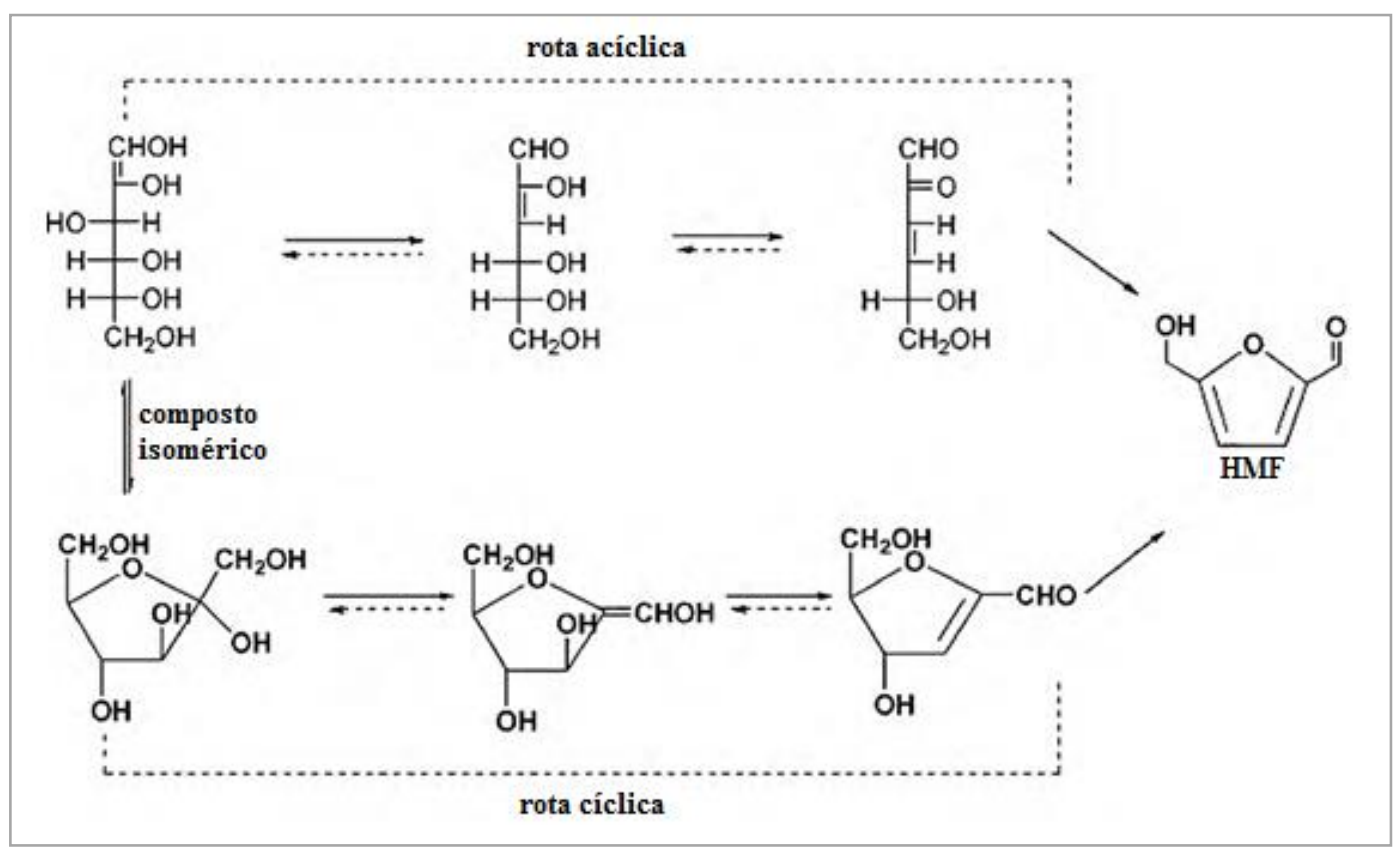

Fonte: Autora “adaptado de" Tong, Ma e Li, 2010.

Moreau et al. (1996) estudaram a desidratação da frutose para formação de HMF a $165{ }^{\circ} \mathrm{C}$ catalisada por zeólitas em solvente bifásico de água e metil-isobutilcetona (MIBK) encontrando uma equação de taxa condizente ao modelo de Langmuir-Hinshelwood que não sofre influência do produto e do solvente. Cinética de primeira ordem foi observada em baixas coberturas do catalisador até um ponto de saturação, a partir do qual cinética de ordem zero é observada. Além disso, obtiveram valores para a energia de ativação de $141 \mathrm{~kJ} / \mathrm{mol}$ para formação e de $64 \mathrm{~kJ} / \mathrm{mol}$ para o consumo do HMF como intermediário para a síntese do ácido levulínico. Por fim, os autores propuseram uma rota acíclica assumindo a formação de 1,2- 
enodiol como etapa limitante, baseado na observação de pequenas quantidades de glicose e manose e até mesmo de furfural e hidroxiacetilfurano formados em reações paralelas.

Trabalhos mais recentes como os de Amarasekara, Williams e Ebede (2008), Kimura, Nakahara e Matubayasi (2013) e Zhang J. et al. (2016) realizaram estudos por RMN e propuseram uma rota cíclica, que basicamente reportaram a formação de três intermediários de reação em DMSO ou água: 3,4-dihidroxi-2-dihidroximetil-5-hidroximetiltetrahidrofurano (Int. 1 na Figura 9), forma enol 2-hidroximetil-5-hidroximetileno-tetrahidrofurano-3,4-diol ou forma ceto 4-hidroxi-5-hidroximetil-tetrahidrofurano-2-carbaldeído (Int. 2 na Figura 9) e 4hidroxi-5-hidroximetil-4,5-dihidrofurano-2-carbaldeído (Int. 3 na Figura 9), ambos compostos cíclicos de cinco membros, de modo que a reação provavelmente se inicia com o isômero $\beta$ furanose da D-frutose.

Amarasekara, Williams e Ebede (2008) destacaram o terceiro intermediário como a espécie chave para a reação e, assim como Zhang J. et al. (2016), não conseguiram identificar o segundo intermediário em qualquer de suas formas (Int. 2 na Figura 9) por RMN, o que sugere um consumo maior que sua produção, nas condições de reação adotadas pelos autores.

Figura 9 - Mecanismo proposto para a rota cíclica da conversão catalítica da frutose a HMF em DMSO.

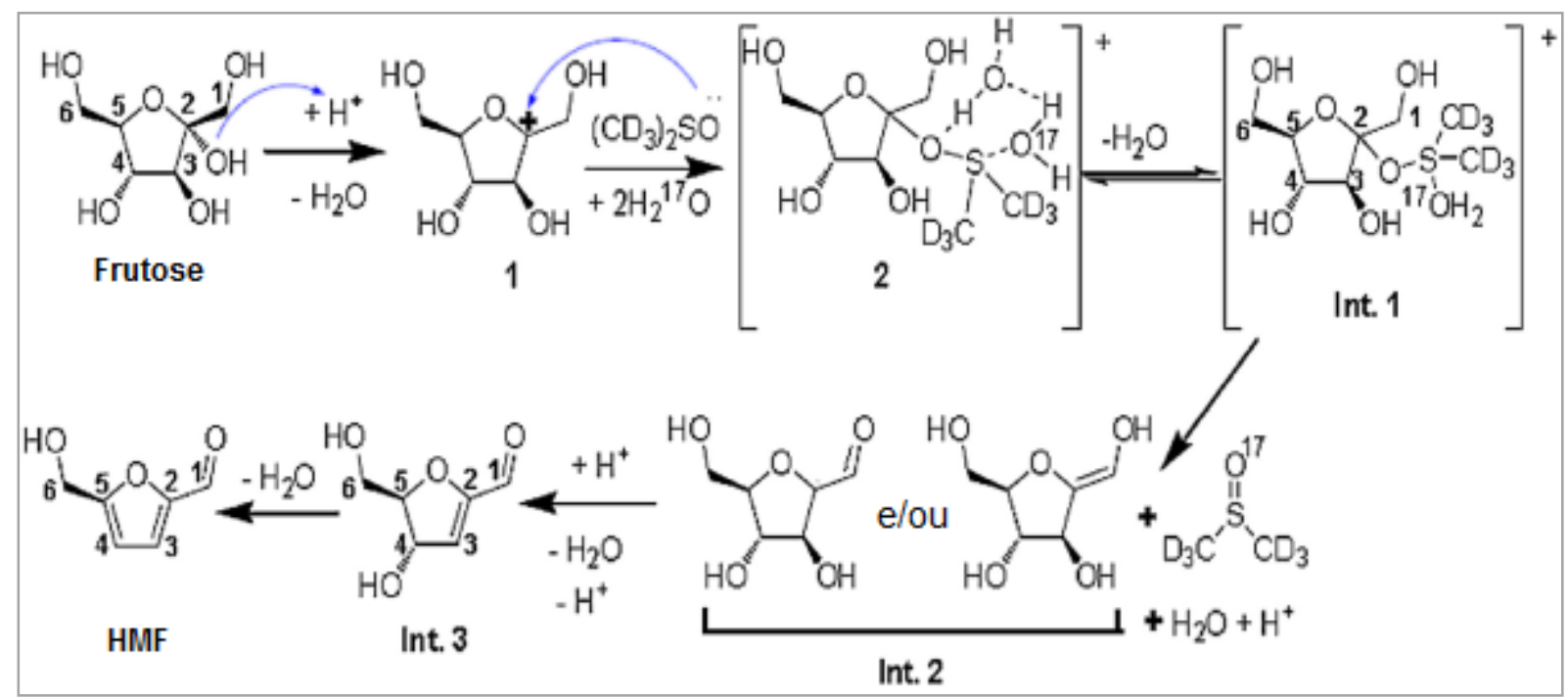

Fonte: Autora "adaptado de" Zhang J. et al., 2016. 


\section{METODOLOGIA}

O desenvolvimento experimental foi realizado utilizando as infraestruturas proporcionadas pelo Centro de Laboratórios Químicos (CLQ) do Centro Universitário da FEI e do Laboratório de Processos Químicos e Tecnológicos de Partículas (LPP) do Instituto de Pesquisas Tecnológicas do Estado de São Paulo (IPT).

Neste capítulo, são apresentadas as descrições dos materiais utilizados e métodos adotados para o desenvolvimento deste trabalho.

\subsection{MATERIAIS}

Os materiais necessários à execução dos experimentos, como reagentes, solventes e catalisadores, além dos equipamentos utilizados são apresentados a seguir.

\subsubsection{Substâncias utilizadas}

A síntese do HMF nos experimentos foi desenvolvida utilizando: frutose ou glicose como reagente; água deionizada ou dimetilsulfóxido (DMSO) como solvente; nitrogênio para inertização da reação; e resinas de troca iônica do tipo fortemente catiônica SGC650H ou CT275 como catalisadores. Uma descrição geral dessas substâncias é apresentada na Tabela 1, sendo que as especificações dos catalisadores estão apresentadas na Tabela 2.

Tabela 1 - Especificações das substâncias utilizadas nos experimentos.

\begin{tabular}{|c|c|c|c|}
\hline Nome & Fabricante & Lote & Propriedades relevantes \\
\hline D-Frutose & Synth $^{\circledR}$ & $\begin{array}{l}170227 \\
185956\end{array}$ & $\begin{array}{l}\text { CAS: 57-48-7 } \\
\text { Fórmula química: } \mathrm{C}_{6} \mathrm{H}_{12} \mathrm{O}_{6} \\
\text { Massa molar: } 180,16 \mathrm{~g} / \mathrm{mol}\end{array}$ \\
\hline D-Glicose & Synth $^{\circledR}$ & 191196 & $\begin{array}{l}\text { CAS: 50-99-7 } \\
\text { Fórmula química: } \mathrm{C}_{6} \mathrm{H}_{12} \mathrm{O}_{6} \\
\text { Massa molar: } 180,16 \mathrm{~g} / \mathrm{mol}\end{array}$ \\
\hline DMSO & Synth $^{\circledR}$ & $\begin{array}{l}197880 \\
198971\end{array}$ & $\begin{array}{l}\text { CAS: 67-68-5 } \\
\text { Fórmula química: } \mathrm{C}_{2} \mathrm{H}_{6} \mathrm{OS} \\
\text { Massa molar: } 78,13 \mathrm{~g} / \mathrm{mol} \\
\text { Massa específica: } 1,100 \mathrm{~g} / \mathrm{mL}^{\mathrm{a}}\end{array}$ \\
\hline Nitrogênio & Air Liquide ${ }^{\circledR}$ & 1477 & $\begin{array}{l}\text { CAS: } 7727-37-9 \\
\text { Fórmula química: } \mathrm{N}_{2} \\
\text { Massa molar: } 28,01 \mathrm{~g} / \mathrm{mol}\end{array}$ \\
\hline
\end{tabular}

Fonte: Autora. 
Tabela 2 - Especificações das resinas utilizadas como catalisadores nos experimentos.

\begin{tabular}{|c|c|c|}
\hline Resina: & $\mathrm{CT}_{275^{\mathrm{a}}}$ & $\mathrm{SGC650H}^{\mathrm{b}}$ \\
\hline Fabricante: & Purolite $^{(B)}$ & Purolite $^{\circledR}$ \\
\hline Lote: & $490 \mathrm{~T} / 13 / 5$ & $1150 \mathrm{~S} / 13 / 6$ \\
\hline Matriz: & macroporosa & supergel \\
\hline Aparência & partículas esféricas & partículas esféricas \\
\hline Grupo funcional: & ácido sulfônico & ácido sulfônico \\
\hline Forma iônica: & $\mathrm{H}^{+}$ & $\mathrm{H}^{+}$ \\
\hline Capacidade total: & 5,2 eq/kg (mín.) & 2,0 eq/L (mín.) \\
\hline Peso específico: & 1,2 & 1,21 \\
\hline Umidade: & $(51-59) \%$ & $(46-50) \%$ \\
\hline Diâmetro médio: & $(425-1200) \mu \mathrm{m}$ & $(650 \pm 50) \mu \mathrm{m}$ \\
\hline Área específica: & $(20-35) \mathrm{m}^{2} / \mathrm{g}$ & \\
\hline Volume de poros: & $(0,4-0,6) \mathrm{mL} / \mathrm{g}$ & \\
\hline Diâmetro médio dos poros: & $(600-750) \AA$ & \\
\hline Limite de temperatura & $130^{\circ} \mathrm{C}$ & $130^{\circ} \mathrm{C}$ \\
\hline $\begin{array}{l}\text { a Purolite }(2016 \mathrm{a}) \\
\mathrm{b} \text { Purolite }(2016 \mathrm{~b})\end{array}$ & & \\
\hline
\end{tabular}

A identificação dos componentes nos meios reacionais foi realizada por cromatografia líquida de alta eficiência (HPLC), que foram comparadas com soluções padrões preparadas a partir das substâncias apresentadas na Tabela 3.

Tabela 3 - Descrição dos reagentes utilizados na preparação das soluções padrões.

\begin{tabular}{|c|c|c|c|c|c|}
\hline Nome & $\begin{array}{l}\text { Fórmula } \\
\text { química }\end{array}$ & $\begin{array}{c}\text { Massa molar } \\
(\mathrm{g} / \mathrm{mol})\end{array}$ & CAS & Fabricante & Lote \\
\hline D-Frutose & $\mathrm{C}_{6} \mathrm{H}_{12} \mathrm{O}_{6}$ & 180,16 & $57-48-7$ & $\begin{array}{c}\text { Sigma } \\
\text { Aldrich }^{\circledR} \\
\end{array}$ & SLBJ8832V \\
\hline D-Glicose & $\mathrm{C}_{6} \mathrm{H}_{12} \mathrm{O}_{6}$ & 180,16 & $50-99-7$ & $\begin{array}{c}\text { Sigma } \\
\text { Aldrich }^{\circledR} \\
\end{array}$ & SLBK4621V \\
\hline HMF & $\mathrm{C}_{6} \mathrm{H}_{6} \mathrm{O}_{3}$ & 126,11 & $67-47-0$ & $\begin{array}{c}\text { Sigma } \\
\text { Aldrich }^{\circledR} \\
\end{array}$ & STBF6986V \\
\hline $\begin{array}{c}\text { Ácido } \\
\text { Levulínico }\end{array}$ & $\mathrm{C}_{5} \mathrm{H}_{8} \mathrm{O}_{3}$ & 116,12 & $123-76-2$ & $\begin{array}{c}\text { Sigma } \\
\text { Aldrich }^{\circledR} \\
\end{array}$ & MKBT7708V \\
\hline $\begin{array}{c}\text { Ácido } \\
\text { Fórmico } \\
\end{array}$ & $\mathrm{CH}_{2} \mathrm{O}_{2}$ & 46,03 & $64-18-6$ & Dinâmica $^{\circledR}$ & 72806 \\
\hline Furfural & $\mathrm{C}_{5} \mathrm{H}_{4} \mathrm{O}_{2}$ & 96,08 & $98-01-1$ & $\begin{array}{c}\text { Sigma } \\
\text { Aldrich }^{\circledR} \\
\end{array}$ & SHBF9497V \\
\hline
\end{tabular}

Fonte: Autora. 


\subsubsection{Sistema reacional em batelada}

Os ensaios em batelada foram realizados em um sistema montado no IPT e mostrado na Figura 10.

Figura 10 - Sistema reacional para experimentos em batelada.

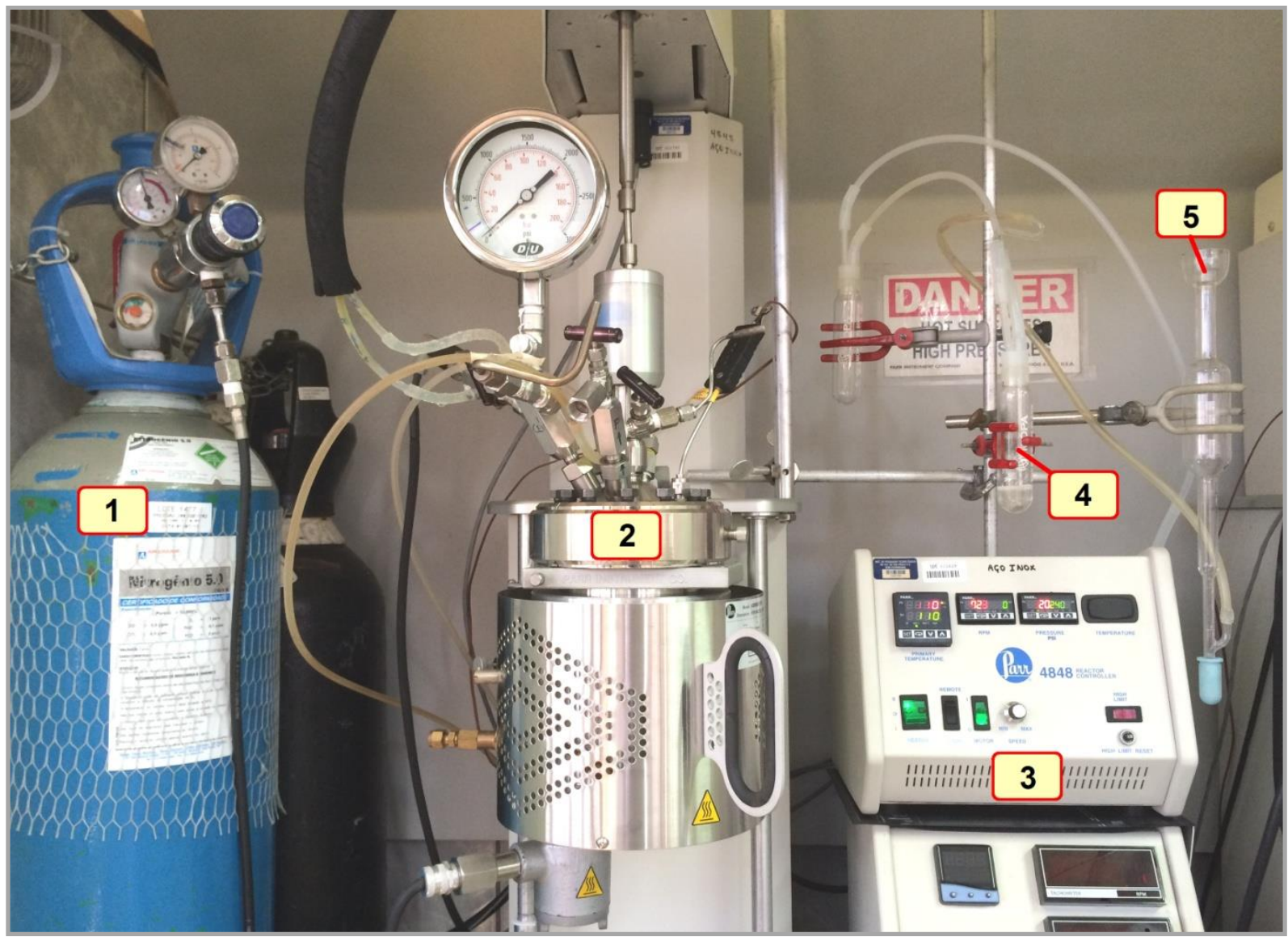

Fonte: Autora.

Legenda: 1 - cilindro de nitrogênio; 2 - reator Parr; 3 - controlador; 4 - borbulhador de glicerina; 5 bolhômetro.

O reator de aço inox do tipo autoclave com capacidade de $1 \mathrm{~L}$ modelo 4520 foi fabricado pela Parr Instrument Company ${ }^{\circledR}$ equipado com aquecedor acoplado e controlador de temperatura e agitação modelo 4848. Os demais componentes do sistema reacional consistiram em um cilindro de gás nitrogênio da Air Liquide ${ }^{\circledR}$; tubulação de saída do reator ligado a um borbulhador de glicerina para evitar o retorno de ar atmosférico e um bolhômetro para medição da vazão de gás. Além disso, utilizaram-se dois banhos termostáticos: um do modelo ECO RE $415 \mathrm{~S}$ fabricado pela Lauda ${ }^{\circledR}$ para resfriamento do selo do transducer, e um do modelo HP- 4 fabricado pela Julabo ${ }^{\circledR}$ apenas para circulação de fluido na temperatura ambiente no selo do agitador. 
Os componentes internos do reator são apresentados na Figura 11, mostrando o agitador com dois impelidores do tipo turbina com seis pás planas inclinadas; o tubo pescador para amostragem e alimentação de gás com tela na extremidade para impedir entrada de catalisador no mesmo; o orifício superior para saída de gás e alívio manual da pressão; a válvula de segurança para alívio da pressão e o poço do termopar.

Figura 11 - Componentes internos do reator Parr.

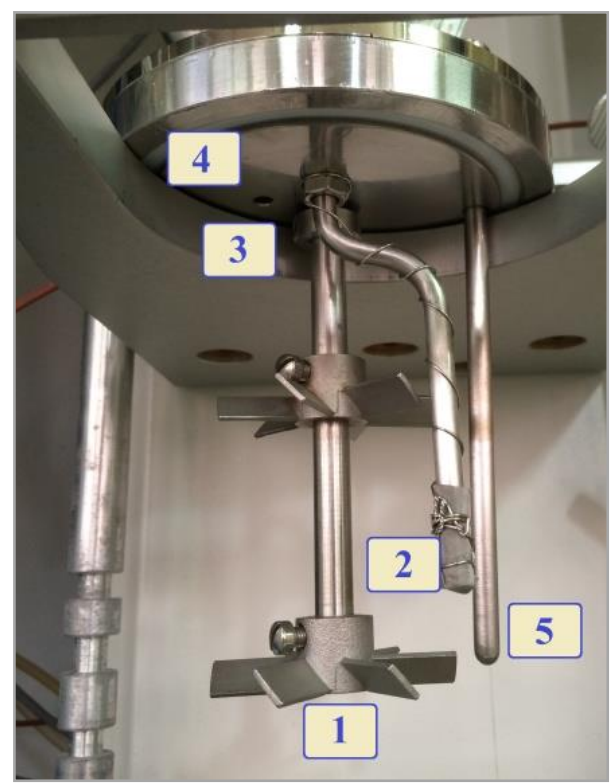

Fonte: Autora.

Legenda: 1 - agitador; 2 - tubo pescador; 3 - saída de gás; 4 - válvula de segurança; 5 - poço do termopar.

\subsubsection{Sistema reacional contínuo}

Os ensaios em reator contínuo foram realizados no Centro Universitário da FEI em um sistema montado conforme esquematizado na Figura 12. 
Figura 12 - Representação do sistema experimental para reação contínua.

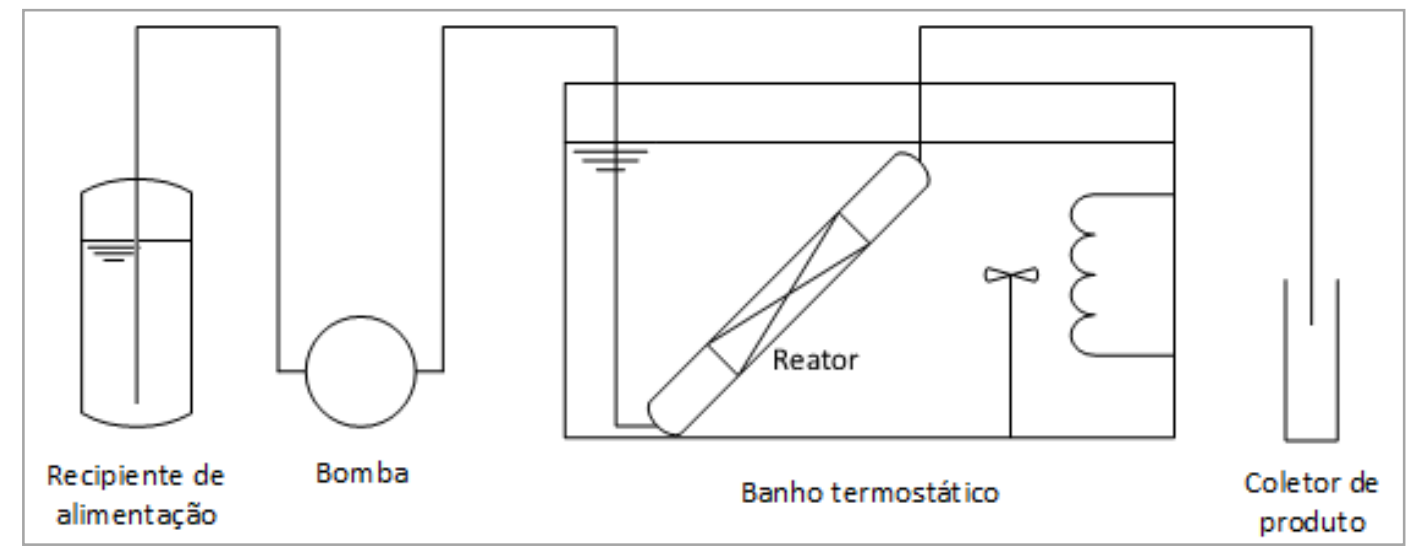

Fonte: Autora.

O reator tubular de leito recheado (PBR do termo em inglês Packed Bed Reactor) consistiu em um tubo de aço inox com anilha, flange e dois adaptadores para redução de 1/2" para 1/8" em cada extremidade. As medidas desse tubo eram de $82 \mathrm{~mm}$ de comprimento, diâmetro externo de $1 / 2$ " e interno de $10 \mathrm{~mm}$, sendo que o catalisador ficava retido no reator por telas de aço e lã de vidro nas extremidades. A massa de catalisador contida foi de aproximadamente 5,3110 g de SGC650H em base úmida (b.u.).

A vazão do sistema era controlada pela bomba dosadora de diafragma modelo KNF SIMDOS 02. As tubulações eram de teflon e tinham diâmetro externo de 1/8", com adaptadores de plástico nas extremidades para conexão à bomba, e com flange e anilha para conectar ao reator.

Os ensaios realizados nas temperaturas reacionais de $80{ }^{\circ} \mathrm{C}$ e $90{ }^{\circ} \mathrm{C}$ foram controlados pelo banho termostático modelo Julabo F25-ME, onde o reator se manteve submerso no fluido de aquecimento aquoso a uma inclinação que proporcionasse um fluxo ascendente dentro do reator. $\mathrm{O}$ volume de fluido de aquecimento era de $5 \mathrm{~L}$, com um nível de $14 \mathrm{~cm}$, proporcionando assim uma inclinação de $50^{\circ}$ do reator. $\mathrm{O}$ sistema experimental montado para os ensaios em reator contínuo é apresentado na Figura 13. 
Figura 13 - Sistema reacional para realização dos ensaios em reator contínuo.

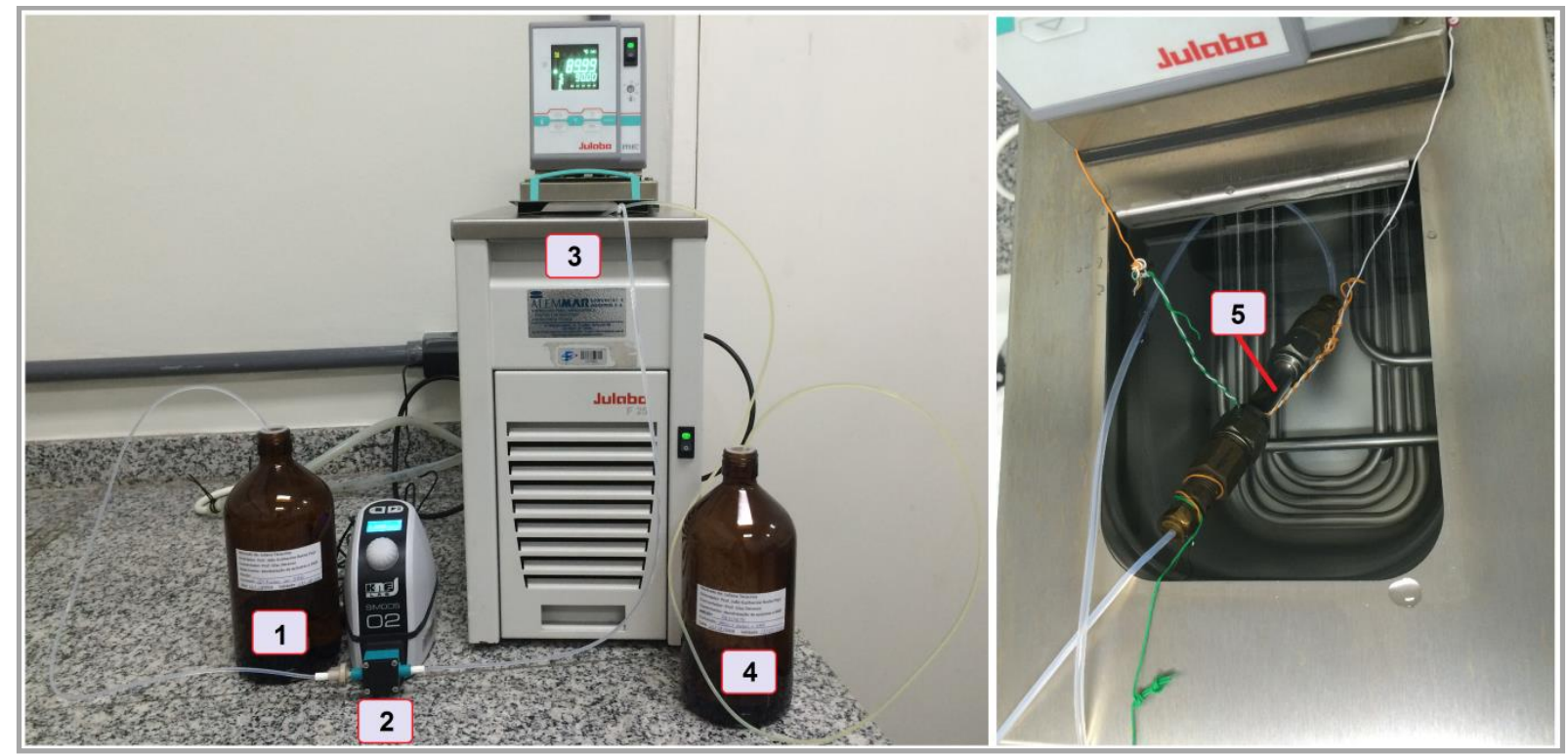

Fonte: Autora.

Legenda: 1 - recipiente com a solução de alimentação; 2 - bomba KNF SIMDOS 02; 3 - banho termostático Julabo F25; 4 - recipiente para coleta do produto; 5 - reator tubular de leito recheado.

Já para os ensaios com as temperaturas reacionais de $100{ }^{\circ} \mathrm{C}$ e $110^{\circ} \mathrm{C}$ não foi possível utilizar o banho com fluido aquoso, de modo que a temperatura do reator foi controlada pelo aparelho de banho maria microprocessado da Quimis ${ }^{\circledR}$, modelo Q215M, com óleo de silicone como fluido de aquecimento. O reator foi mantido submerso horizontalmente nesse banho.

\subsubsection{Moinho de tungstênio}

Alguns experimentos utilizaram o catalisador moído, nestes casos, a resina passou pelo processo de moagem em um moinho de discos de tungstênio fabricado pela KawasakiSieb Technik ${ }^{\circledR}$ apresentado na Figura 14.

Figura 14 - Moinho de discos.

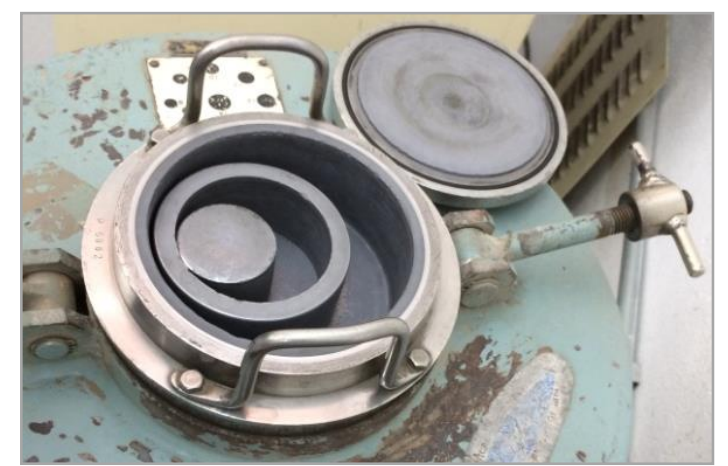

Fonte: Autora. 


\subsubsection{Analisador de tamanho de partículas por difração laser}

A determinação da distribuição granulométrica dos catalisadores foi realizada por difração de raios laser em um medidor de tamanho de partículas Malvern Mastersizer 2000, equipamento fabricado pela Malvern Instruments $\operatorname{Ltd}^{\circledR}$.

\subsubsection{Cromatógrafo}

O equipamento de cromatografia líquida de alta eficiência (CLAE, ou HPLC do inglês High-Performance Liquid Chromatography) utilizado foi fabricado pela Shimadzu ${ }^{\circledR}$, cujos componentes eram: degaseificador DGU-20A3, duas bombas LC-20AD, forno CTO-20A para a coluna com injetora manual de $20 \mu \mathrm{L}$, detector de ultravioleta na faixa visível (UV-Vis) SPD-20A, detector de índice de refração (I.R.) RID-10A e um módulo de comunicação CBM20A usada como interface para um computador, que, por meio do programa LCsolution, possibilitou o controle de parâmetros, bem como a aquisição e o tratamento dos dados.

As colunas utilizadas foram a Aminex HPX-87H da Bio-Rad ${ }^{\circledR}$ para análise de açúcares e ácidos orgânicos e a coluna analítica Shim-pack CLC-ODS (M), uma coluna de fase reversa C18 da Shimadzu ${ }^{\circledR}$. As especificações das colunas utilizadas são apresentadas na Tabela 4.

Tabela 4 - Especificações das colunas utilizadas para HPLC.

\begin{tabular}{|c|c|c|}
\hline Coluna: & Shim-pack CLC-ODS (M) ${ }^{\circledR a}$ & Aminex HPX-87H ${ }^{\circledR b}$ \\
\hline Fase estacionária: & Grupo octadecil & $\overline{\text { Resina iônica na forma } \mathrm{H}^{+}}$ \\
\hline Tamanho das partículas: & $5 \mu \mathrm{m}$ & $9 \mu \mathrm{m}$ \\
\hline Dimensões: & $15 \mathrm{~cm} \mathrm{X} \mathrm{4,6} \mathrm{mm}$ & $300 \mathrm{~mm} \mathrm{X} \mathrm{7,8} \mathrm{mm}$ \\
\hline Poro: & $100 \AA$ & \\
\hline Temperatura máxima: & $50^{\circ} \mathrm{C}$ & $65^{\circ} \mathrm{C}$ \\
\hline Pressão máxima: & 343 bar ou $350 \mathrm{~kg} / \mathrm{cm}^{2}$ & 1500 psi ou $105 \mathrm{~kg} / \mathrm{cm}^{2}$ \\
\hline pH ótimo: & 2 a 7,5 & 1 a 3 \\
\hline \multicolumn{3}{|c|}{$\begin{array}{l}\text { a Universidade Federal do Espírito Santo (2013) } \\
\text { b Bio-Rad Laboratories Inc. (2015) }\end{array}$} \\
\hline
\end{tabular}

\subsection{PROCEDIMENTO EXPERIMENTAL}

O desenvolvimento experimental do presente projeto seguiu o procedimento geral representado no diagrama de blocos mostrado na Figura 15 e detalhados nos itens subsequentes. 
Figura 15 - Diagrama de blocos do procedimento experimental.

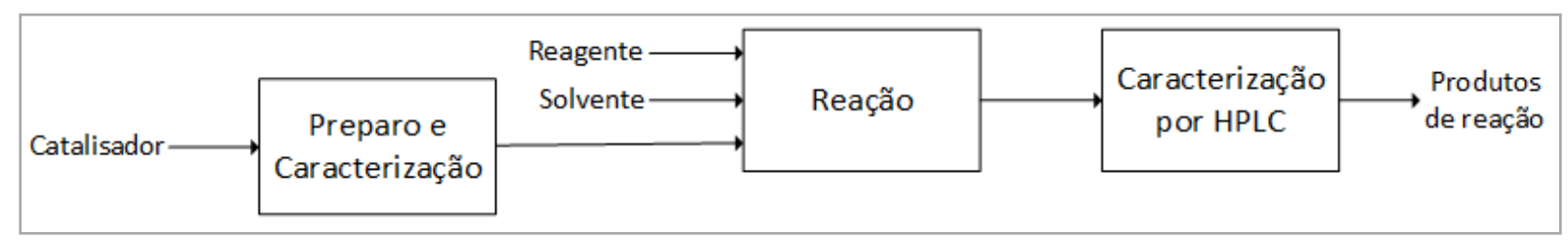

Fonte: Autora.

\subsubsection{Preparo e caracterização do catalisador}

A maioria dos ensaios utilizou catalisadores úmidos com especificações do fabricante e sem tratamento prévio. Porém, a análise cinética da reação foi realizada em base seca, de modo que foram necessários dados de massa para seu cálculo a partir da base úmida do fabricante. Tais dados foram as massas de catalisador úmido, seco e empacotado com água destilada obtidas ao pesar determinada quantidade do catalisador bruto (massa úmida), transferi-la para uma proveta calibrada e medir a massa do catalisador empacotado com água destilada. Por fim, o conteúdo da proveta foi transferido para um béquer e seco em estufa a $85^{\circ} \mathrm{C}$ durante $20 \mathrm{~h}$, anotando a massa seca de catalisador.

$\mathrm{O}$ procedimento de moagem do catalisador utilizou $80 \mathrm{~g}$ do catalisador comercial bruto separado em duas frações. Cada fração foi moída no moinho de discos de tungstênio durante $20 \mathrm{~s}$ e, após juntar as duas frações, a amostra moída foi seca em estufa a $65^{\circ} \mathrm{C}$ durante $48 \mathrm{~h}$.

Os diâmetros médios das partículas de catalisador nas duas formas estudadas (comercial e moída) foram obtidos por análise granulométrica realizada no analisador de tamanho de partículas Malvern Mastersizer 2000.

\subsubsection{Ensaios de síntese do HMF em reator batelada}

Baseado na metodologia aplicada por Kimura et al. (2013); Kimura et al. (2014a) e Kimura et al. (2014b), os ensaios para a obtenção do HMF foram executados variando-se os seguintes parâmetros: temperatura de reação, tipo e concentração de açúcar, tipo de catalisador e granulometria.

Os ensaios em batelada iniciavam-se com a pesagem de reagente, catalisador e solvente para alimentação no reator Parr e, após seu devido fechamento, realizava-se um teste de estanqueidade pressurizando-o com gás nitrogênio até atingir 40 psi (aproximadamente 
3 bar). Caso a pressão fosse mantida após $15 \mathrm{~min}$, o reator era despressurizado seguido pela injeção de gás nitrogênio numa vazão adequada e constante durante 20 min para a remoção de oxigênio do meio reacional sob agitação com velocidade aproximada de $700 \mathrm{rpm}$.

Após a inertização do meio reacional, o reator era pressurizado a 10 psi com nitrogênio, de modo a facilitar posteriores amostragens. Feito isso, iniciava-se o aquecimento com a definição do set-point da temperatura de reação a qual seria mantida pelo controlador. Anotou-se a variação da temperatura, de modo que o tempo de aquecimento dos ensaios variou de 20 min a 45 min até que o meio reacional atingisse a temperatura de reação definida, que se considerou como o tempo inicial da reação.

Alíquotas de aproximadamente $5 \mathrm{~mL}$ foram retiradas no decorrer da reação, descartando-se um volume inicial de aproximadamente $4,5 \mathrm{~mL}$ estagnado no tubo pescador. As alíquotas eram identificadas com seu respectivo tempo de reação e armazenadas em geladeira. Decorrido um certo tempo de reação, o controlador de temperatura era desligado, o reator era desconectado do sistema e resfriado em banho de água até atingir temperatura próxima à ambiente.

Após resfriado, o reator era aberto para a retirada de seu conteúdo, que era então filtrado com peneira Tyler $325(0,045 \mathrm{~mm})$ e papel de filtro para separação do catalisador bruto e centrifugado para os ensaios com catalisador moído. O sólido era lavado com água destilada e armazenado, enquanto o filtrado era armazenado em geladeira para posterior caracterização.

Os ensaios preliminares consistiram na análise da reação em meio aquoso, com parâmetros apresentados na Tabela 5 .

Tabela 5 - Parâmetros para realização dos ensaios preliminares.

\begin{tabular}{lcc}
\hline \hline \multicolumn{1}{c}{ Parâmetro } & Descrição & Valor \\
\hline \hline Massa de solvente: & Água deionizada & $400 \mathrm{~g}$ \\
\hline Massa de reagente: & $\begin{array}{l}\text { D-glicose } \\
\text { D-frutose }\end{array}$ & $4 \mathrm{~g}$ \\
\hline Massa de catalisador: & $\begin{array}{c}\text { SGC650H bruta } \\
\text { CT275 bruta }\end{array}$ & $40 \mathrm{~g}$ \\
\hline Temperatura de reação: & & $110^{\circ} \mathrm{C}$ \\
\hline \hline
\end{tabular}

Fonte: Autora.

Após os ensaios preliminares, foi possível selecionar o reagente e o catalisador mais produtivos para a obtenção do HMF, foram eles: frutose e resina gel SGC650H. Já o solvente foi escolhido com base na literatura, em que se encontrou o DMSO como um solvente recomendado ao utilizar resinas de troca iônica como catalisador. 
A análise da reação catalisada pela resina SGC650H para desidratação da frutose com DMSO atuando como solvente foi realizada com os parâmetros apresentados na Tabela 6 .

Tabela 6 - Parâmetros dos ensaios com DMSO em reator batelada.

\begin{tabular}{lcc}
\hline \hline \multicolumn{1}{c}{ Parâmetro } & Descrição & Valor \\
\hline \hline Massa de solvente: & DMSO & $330 \mathrm{~g}$ \\
\hline & & $5 \mathrm{~g}(1,5 \% \mathrm{~m} / \mathrm{m})$ \\
Massa de reagente: & D-frutose & $10 \mathrm{~g}(3,0 \% \mathrm{~m} / \mathrm{m})$ \\
& & $15 \mathrm{~g}(4,5 \% \mathrm{~m} / \mathrm{m})$ \\
& & $45 \mathrm{~g}(13,5 \% \mathrm{~m} / \mathrm{m})$ \\
\hline \multirow{2}{*}{ Massa de catalisador: } & SGC650H bruta & $0 \mathrm{~g}(\mathrm{branco})$ \\
& SGC650H moída & $30 \mathrm{~g}$ \\
Temperatura de reação: & & $90^{\circ} \mathrm{C}$ \\
& & $100^{\circ} \mathrm{C}$ \\
\hline \hline
\end{tabular}

Fonte: Autora.

\subsubsection{Ensaios de síntese do HMF em reator contínuo}

Devido à alta temperatura de ebulição do DMSO, sua utilização como solvente permitiu realizar ensaios à pressão atmosférica em reator contínuo, verificada a pressão máxima de 19 psi (aproximadamente 1,31 bar) nos experimentos em reator batelada.

Primeiramente as soluções de alimentação eram preparadas misturando determinadas massas de reagente e solvente para corresponder às concentrações estudadas. Os ensaios em reator contínuo necessitaram do condicionamento prévio do mesmo, para isto, ligava-se a bomba durante aproximadamente 20 min alimentando solvente puro no sistema a uma vazão de $1 \mathrm{~mL} / \mathrm{min}$, com o reator já na temperatura de reação. Após a mudança para a solução de alimentação, o início de cada ensaio era considerado ao ligar-se a bomba, retirando três amostras após aproximadamente três tempos de residência, para assegurar que o sistema se encontrava em regime estacionário. Terminadas as amostragens, a bomba era desligada e sua vazão era redefinida para dar início a outro ensaio com mesma temperatura de reação e concentração de alimentação, porém vazão diferente. Encerradas as aquisições dessas amostras com diferentes vazões, realizava-se novamente a limpeza do sistema com bombeamento de solvente puro. O mesmo procedimento era realizado variando-se os parâmetros de temperatura e concentração da solução de alimentação.

A análise da reação em reator contínuo de leito catalítico com alimentação de solução de frutose em DMSO foi realizada com os parâmetros apresentados na Tabela 7. 
Tabela 7 - Parâmetros para realização dos ensaios em reator contínuo.

\begin{tabular}{l|c|c|c|c}
\hline \hline \multicolumn{1}{c|}{ Parâmetro } & \multicolumn{4}{c}{ Valor } \\
\hline \hline \multirow{2}{*}{ Concentração de alimentação: } & \multicolumn{4}{c}{$4,5 \%(\mathrm{~m} / \mathrm{m})$} \\
& \multicolumn{4}{c}{$80^{\circ} \mathrm{C}$} \\
& \multicolumn{4}{c}{$10{ }^{\circ} \mathrm{C}$} \\
Temperatura de reação: & \multicolumn{4}{c}{$100^{\circ} \mathrm{C}$} \\
& \multicolumn{4}{c}{$110^{\circ} \mathrm{C}$} \\
\hline Vazão (mL/min): & 1,000 & 0,500 & 0,250 & 0,125 \\
\hline Tempos de amostragem (min): & 10 & 36 & 60 & 120 \\
& 20 & 45 & 72 & 150 \\
& 30 & & 90 & 180 \\
\hline \hline
\end{tabular}

Fonte: Autora.

\subsubsection{Caracterização dos produtos}

A determinação dos produtos da reação de síntese do HMF em meio aquoso foi realizada por HPLC utilizando a coluna Aminex HPX-87H ${ }^{\circledR}$ com ácido sulfúrico $5 \mathrm{mM}$ como eluente, vazão de $0,6 \mathrm{~mL} / \mathrm{min}$, operando a $60^{\circ} \mathrm{C}$. Os detectores utilizados foram de UV-Vis a $210 \mathrm{~nm}$ e índice de refração (I.R.), ambos operando a $40{ }^{\circ} \mathrm{C}$ e dispostos em série. $\mathrm{O}$ primeiro foi empregado para análise de HMF e furfural, enquanto o segundo, para as substâncias restantes (açúcares e ácidos orgânicos). Antes da injeção das amostras, estas eram retiradas da geladeira e, após atingir temperatura ambiente eram filtradas com filtro de seringa de $0,20 \mu \mathrm{m}$.

Segundo a pesquisa bibliográfica realizada, todos os trabalhos com análise por HPLC com a coluna Aminex $\mathrm{HPX} 87 \mathrm{H}^{\circledR}$ utilizaram um detector de índice de refração, como por exemplo, Moreau, Finiels e Vanoye (2006), Carniti, Gervasini e Marzo (2011), Ohara et al. (2010), Rasrendra et al. (2012) e Lucas et al. (2013). Alguns autores como Ordomsky et al. (2012), Kruger, Nikolakis e Vlachos (2014) e Swift et al. (2016) empregaram os dois detectores: índice de refração e ultravioleta. Já Yuan et al. (2011) e Zhang Y. et al. (2015) utilizaram cada detector para análises diferentes: HMF no detector de UV-Vis e glicose, frutose e ácido levulínico no I.R. No presente trabalho, eluições nos dois detectores foram realizadas em série, porém os dados considerados para HMF e furfural foram obtidos pelo detector de UV-Vis, o restante, pelo detector de I.R.

O método utilizado para a cromatografia nos ensaios preliminares em meio aquoso não foi adequado para a determinação dos produtos de síntese em DMSO como solvente, devido à sua interferência no sinal do HMF nos cromatogramas. Em trabalhos como os de Chinnappan et al. (2014), Fang et al. (2014), Liu et al. (2015), Teimouri et al. (2015) e Xu et al. (2015), a estratégia para caracterização do HMF foi a utilização de uma coluna de fase reversa com 
detector UV-Vis a $280 \mathrm{~nm}$ para minimizar o sinal do DMSO no cromatograma. A utilização do detector de índice de refração não foi adequada ao estudo, pois o sinal do solvente ainda interferia na análise dos produtos.

Para a determinação dos produtos da reação com DMSO como solvente, foi necessária uma preparação inicial das amostras obtidas dos experimentos, de modo que estas foram mantidas à temperatura ambiente, diluídas com água destilada em quantidade adequada para atingir a sensibilidade do detector e filtradas com filtro de seringa de $0,20 \mu \mathrm{m}$.

A análise do HMF sintetizado em DMSO foi realizada por HPLC com a coluna Shimpack CLC-ODS $(\mathrm{M})^{\circledR}$ de fase reversa operando a $30^{\circ} \mathrm{C}$, vazão binária de eluente a $1,2 \mathrm{~mL} / \mathrm{min}$ de acetonitrila e ácido acético $1 \%(\mathrm{~m} / \mathrm{m})$ na proporção de 20:80. O detector de UV-Vis a $266 \mathrm{~nm}$ operando a $40{ }^{\circ} \mathrm{C}$ apresentou sensibilidade baixa ao solvente DMSO e alta ao produto HMF, de modo que foram necessárias diluições das amostras com água segundo a Tabela 8.

Tabela 8 - Valores de diluição das amostras para análise cromatográfica em HPLC.

\begin{tabular}{cccc}
\hline $\begin{array}{c}\text { Concentração de } \\
\text { alimentação }\end{array}$ & Diluição & $\begin{array}{c}\text { Volume de amostra } \\
(\boldsymbol{\mu L})\end{array}$ & Volume de água $(\boldsymbol{\mu L})$ \\
\hline \hline $1,5 \%(\mathrm{~m} / \mathrm{m})$ & 50 vezes & 200 & 4800 \\
\hline $3,0 \%(\mathrm{~m} / \mathrm{m})$ & 100 vezes & 100 & 4900 \\
\hline $4,5 \%(\mathrm{~m} / \mathrm{m})$ & 200 vezes & 50 & 9950 \\
\hline $13,5 \%(\mathrm{~m} / \mathrm{m})$ & 400 vezes & 25 & 9975 \\
\hline \hline
\end{tabular}

Fonte: Autora.

\subsection{CÁlCULOS}

A reação de desidratação da frutose para formação de HMF apresentada na Figura 7 foi representada pela Equação (1) e as principais reações secundárias conhecidas, pelas Equações (2) e (3), baseadas na Figura 6, página 31.

$$
\begin{gathered}
F \rightarrow H+3 W \\
H+2 W \rightarrow H L+A F \\
F \rightarrow G
\end{gathered}
$$

em que $F$ representa a frutose; $H$, o HMF; $W$, a água; $H L$, o ácido levulínico; $H F$, o ácido fórmico; e $G$, a glicose.

As curvas de calibração apresentadas no Apêndice B foram elaboradas por regressão linear da área do pico no cromatograma pela concentração das soluções padrões. 
Com os dados de concentração de cada amostra obtidos da curva de calibração, a concentração normalizada foi definida em relação ao reagente alimentado segundo a Equação (4).

$$
\text { Concentração normalizada }=\frac{(\text { espécie analisada })}{(\text { reagente alimentado })}
$$

O rendimento $(Y)$ de HMF foi calculado pela Equação (5):

$$
Y[\%]=\frac{(\text { HMF formado })}{\text { (reagente alimentado })} \cdot 100=\frac{C_{H}}{C_{F_{0}}} \cdot 100
$$

sendo $C_{i_{0}}$ e $C_{i}$ simbolizando as concentrações molares da espécie $i$ em mol/L no início da reação e em determinado instante de tempo diferente do inicial, respectivamente.

A seletividade $(S)$ do HMF foi definida pela Equação (6).

$$
S[\%]=\frac{(\text { HMF formado })}{\text { (reagente convertido })} \cdot 100=\frac{C_{H}}{C_{F_{0}}-C_{F}} \cdot 100
$$

A conversão $(X)$ de reagente foi definida pela Equação (7), porém foi calculada pela Equação (8) quando não havia dados da concentração do reagente ao longo do tempo, considerando assim, a estequiometria da reação e que não houve reações secundárias da frutose, de modo que a seletividade $S$ do HMF foi admitida como $100 \%$.

$$
\begin{gathered}
X[\%]=\frac{(\text { reagente convertido })}{(\text { reagente alimentado })} \cdot 100=\frac{C_{F_{0}}-C_{F}}{C_{F_{0}}} \cdot 100=\frac{Y}{S} \cdot 100 \\
X=Y=\frac{C_{\mathrm{H}}}{C_{F_{0}}} \cdot 100
\end{gathered}
$$

O balanço material foi calculado segundo a Equação (9) pelas molaridades $\left(n_{i}\right)$ dos componentes analisados pela cromatografia, baseado na estequiometria das reações (1), (2) e (3). Já o erro do balanço de molar foi definido pela Equação (10).

$$
\begin{gathered}
n_{0}=n_{t}=n_{\text {frutose }}+n_{\text {glicose }}+n_{H M F}+\frac{n_{\text {ác.levulínico }}+n_{\text {ác.fórmico }}}{2} \\
\text { Erro }=\frac{\left|n_{0}-n_{t}\right|}{n_{0}} \cdot 100
\end{gathered}
$$

sendo $n_{0}$ a molaridade de reagente alimentado e $n_{t}$, a soma das molaridades das espécies analisadas em determinado instante $t$ da reação.

\subsubsection{Propriedades do catalisador}

A conversão da massa úmida do catalisador em sua forma bruta para sua massa seca foi realizada através de um coeficiente (11). 


$$
\text { Razão mássica }=\frac{m_{\text {base seca }}}{m_{\text {base úmida }}}
$$

com $m_{i}$ simbolizando a massa em gramas do catalisador sob a base $i$ em questão.

A área superficial específica em relação à massa $\left(A_{m}\right)$ dada $\mathrm{em} \mathrm{cm}^{2} / \mathrm{g}$ pôde ser calculada pela Equação (12), admitindo que as partículas são esféricas e uniformes.

$$
A_{m}=\frac{6}{D_{p} \cdot \rho_{p}}
$$

em que $D_{p}$ é o diâmetro médio das partículas em $\mathrm{cm}$; e $\rho_{p}$, a densidade das partículas em $\mathrm{g} / \mathrm{cm}^{3}$ (GOMIDE, 1980).

\subsubsection{Parâmetros cinéticos para o reator batelada}

O método de cálculo descrito a seguir foi realizado para o intervalo de tempo em que a temperatura já havia atingido seu set-point, a partir do qual não se considerou os efeitos de sua variação.

O balanço molar do reagente limitante em um reator batelada (BTR do termo em inglês Batch Tank Reactor) considerando mistura perfeita é dado pela Equação (13).

$$
\frac{d N_{F}}{d t}=r_{\mathrm{F}} \cdot V
$$

em que $N_{F}$ representa a quantidade molar do reagente limitante (no caso, a frutose) no tempo $t$ de reação; $V$, o volume reacional; e $r_{F}$, a velocidade ou taxa da reação. Lembrando que $N_{\mathrm{F}}=V \cdot C_{F}$.

Analogamente, a velocidade global da reação baseada na massa de catalisador $\left(r_{F}^{\prime}\right)$ pode ser calculada pela Equação (14) (LEVENSPIEL, 2000).

$$
r_{F}^{\prime}\left[\frac{\text { mol }_{\mathrm{F} \text { reagido }}}{g_{\text {catalisador }} \cdot h}\right]=\frac{1}{W} \cdot \frac{d N_{F}}{d t}
$$

onde $W$ representa a massa do catalisador heterogêneo em gramas (base seca).

A retirada de alíquotas implicou na variação do volume reacional durante o tempo, mas para facilitar os cálculos, propôs-se que o volume reacional era constante e que a concentração de catalisador $\left(C_{c a t}\right)$, calculada pela Equação (15), aumentava com o tempo similarmente a um reator semi-batelada com fluxo de alimentação de catalisador.

$$
C_{c a t}\left[\frac{\text { g catalisador }}{\mathrm{L}}\right]=\frac{W \cdot \rho_{\text {meio }}}{\left(m_{\text {meio }, 0}-m_{\text {alíquotas }}\right)}
$$

em que $\rho_{\text {meio }}$ é a densidade do meio reacional em $\mathrm{g} / \mathrm{L}$, aproximadamente igual à do solvente (DMSO), supondo que os solutos não interferem significativamente neste parâmetro; 
e $m_{\text {meio, } 0}, m_{\text {alíquotas }}$ representam, respectivamente, as massas em gramas do solvente alimentado e da soma das alíquotas retiradas, sendo esta última uma função do tempo.

As leis de velocidade da reação foram definidas pelas Equações (16) e (17), considerando uma reação pseudo homogênea.

$$
\begin{aligned}
& r_{F}=-k \cdot C_{\mathrm{F}}^{n} \\
& r_{\mathrm{F}}{ }^{\prime}=-k^{\prime} \cdot C_{F}^{n}
\end{aligned}
$$

onde $k$ e $k^{\prime}$ simbolizam as constantes de velocidade da reação e $n$, a ordem da reação.

Combinando as leis de velocidade com os balanços molares, têm-se as equações diferenciais ordinárias de primeira ordem (18) e (19).

$$
\begin{gathered}
\frac{d C_{F}}{d t}=-k \cdot C_{F}^{n} \\
\frac{d C_{\mathrm{F}}}{d t}=-k^{\prime} \cdot C_{c a t} \cdot C_{F}^{n}
\end{gathered}
$$

As Equações (18) e (19) mostram que as constantes de velocidade estão correlacionadas pela concentração do catalisador, da mesma forma que as taxas de velocidade da reação como mostrado pelas Equações (20) e (21).

$$
\begin{aligned}
k & =k^{\prime} \cdot C_{c a t} \\
r_{F} & =r_{F}{ }^{\prime} \cdot C_{c a t}
\end{aligned}
$$

A resolução da Equação (19) foi realizada pelo método de ajuste integral análogo ao utilizado por Milcent e Corrêa (1991), que estudaram a reação de inversão da sacarose em reator de leito recheado com catalisador de resina de troca iônica. Tratando a reação como de pseudo primeira ordem e integrando a equação para $n=1$ em termos da conversão $\left(C_{F}=C_{F_{0}} \cdot(1-X)\right)$, obtém-se a Equação (22).

$$
-\ln (1-X)=k \cdot t
$$

Segundo a Equação (22), a curva de $-\ln (1-X)$ em função de $t$ apresenta um comportamento linear. Milcent e Corrêa (1991) ignoraram os desvios para altos tempos de permanência no reator que não se ajustaram ao modelo e consideraram apenas os dados iniciais que apresentaram tendência linear, de modo que a inclinação no ponto inicial equivale a constante cinética $k$. No presente trabalho, essa inclinação foi calculada pela derivada da equação da linha de tendência no ponto inicial, de modo que a constante cinética foi obtida pela Equação (23).

$$
k=\left(\frac{d[-\ln (1-X)]}{d t}\right)_{t=0}
$$

As constantes de velocidade foram calculadas em Excel ${ }^{\circledR}$ construindo-se os gráficos de $-\ln (1-X)$ versus $t$ e ajustando uma linha de tendência aos dados. A escolha do tipo de 
regressão da linha de tendência foi a linear ou a polinomial, de acordo com a inclinação em $t=0$ visualmente mais apropriada.

\subsubsection{Parâmetros cinéticos para o reator contínuo}

Os balanços molares para os reatores tubular (PFR do termo em inglês Plug Flow Reactor) e de leito recheado (PBR) nas formas diferenciais são dados pelas Equações (24) e (25), respectivamente em termos da conversão $X$ (FOGLER, 2014).

$$
\begin{aligned}
& F_{F_{0}} \cdot \frac{d X}{d V}=-r_{F} \\
& F_{F_{0}} \cdot \frac{d X}{d W}=-r_{F}^{\prime}
\end{aligned}
$$

em que $F_{F_{0}}$ representa a vazão molar inicial do reagente limitante em mol/h; $V$, o volume do reator; $W$, a massa de catalisador no leito em base seca; $r_{F}$ e $r_{F}^{\prime}$, as velocidades da reação em termos do reagente.

As leis de velocidade da reação definidas pelas Equações (16) e (17), página 57, foram combinadas respectivamente às Equações (24) e (25), resultando nas Equações (26) e (27).

$$
\begin{aligned}
& \frac{d X}{d \tau}=-k \cdot C_{\mathrm{F}_{0}}^{n-1} \cdot(1-X)^{n} \\
& \frac{d \mathrm{X}}{d\left(\frac{W}{F_{F_{0}}}\right)}=-k^{\prime} \cdot C_{F_{0}}^{n} \cdot(1-X)^{n}
\end{aligned}
$$

em que $\tau$ é o tempo de residência médio ou permanência no reator dado por $\tau=V / v_{0}$, assumindo vazão volumétrica $v_{0}$ constante ao longo do leito.

A determinação dos parâmetros cinéticos da reação foi possível o método de ajuste integral aplicado por Milcent e Corrêa (1991), tratou os dados para uma reação de pseudo primeira ordem em reator tubular (PFR), de modo que a Equação (26) para $n=1$ resultou na Equação (28).

$$
-\ln (1-X)=k \cdot \tau
$$

Ignorando os desvios para altos tempos de permanência no reator que não se ajustaram ao modelo, ajustando-se uma linha de tendência linear ou polinomial aos dados iniciais do gráfico de $-\ln (1-X)$ versus $\tau$ no Excel $^{\circledR}$ definindo a intersecção na origem dos eixos. A constante de velocidade foi obtida então pela Equação (23), página 57. 


\subsubsection{Energia de ativação}

Com os valores das constantes cinéticas foi possível calcular a energia de ativação $\left(E_{A}\right)$ da reação pela equação de Arrhenius (29), linearizada na forma (30).

$$
\begin{aligned}
k^{\prime} & =k_{0}^{\prime} \cdot e^{-\frac{E_{A}}{R \cdot T}} \\
\ln k^{\prime} & =\ln k_{0}^{\prime}-\frac{E_{A}}{R} \cdot \frac{1}{T}
\end{aligned}
$$

sendo $k_{0}^{\prime}$ a constante pré-exponencial; $T$, a temperatura absoluta de reação; e $R$, a constante universal dos gases ideais $\left(8,3145 \mathrm{~J} \cdot \mathrm{mol}^{-1} \cdot \mathrm{K}^{-1}\right)$.

\subsubsection{Parâmetros cinéticos para reação com aquecimento no reator batelada}

Agora considerando a variação de temperatura a partir do início do aquecimento do reator batelada, foi possível calcular iterativamente a energia de ativação $\left(E_{A}\right)$ e a constante pré-exponencial $\left(k_{0}^{\prime}\right)$, utilizando os que foram obtidos pelo método integral como valor inicial. Para isso, calcularam-se as constantes cinéticas $k^{\prime}$ pela equação de Arrhenius (29) e a taxa de reação pela Equação (31) em que as variáveis eram uma função do tempo t. A ordem de reação foi admitida como $n=1$.

$$
r_{F}(t)=-k^{\prime}(t) \cdot C_{c a t}(t) \cdot C_{F}(t)
$$

A concentração do reagente só era conhecida na alimentação do reator, de modo que, no decorrer da reação, foi simulada em planilha eletrônica no Excel ${ }^{\circledR}$ por otimização segundo a Equação (32), estipulando um $\Delta t$ uniforme.

$$
C_{F}^{t+\Delta t}=C_{F}^{t}-k^{\prime t} \cdot C_{c a t}^{t} \cdot C_{F}^{t} \cdot \Delta t
$$

cujas expressões $t$ e $t+\Delta t$ sobrescritas são índices para identificação e não operação de potenciação.

Apenas os dados para o HMF foram analisados experimentalmente, então novamente admitiu-se que não houve reações secundárias, de modo que a concentração de HMF foi calculada pela Equação (33) para os valores simulados.

$$
C_{H}^{t}=C_{F_{0}}-C_{F}^{t}
$$

Os valores obtidos na simulação foram ajustados aos dados experimentais pelo método dos mínimos quadrados, em que a soma dos desvios elevados à segunda potência (34) é minimizada através da ferramenta solver do Excel ${ }^{\circledR}$ pelo método GRG Não Linear ao variar os parâmetros estudados $\left(E_{A}\right.$ e $\left.k_{0}^{\prime}\right)$. 


$$
\text { Erro }=\sum\left(C_{H}^{\text {experimental }}-C_{H}^{\text {simulado }}\right)^{2} \cdot P
$$

sendo $P$ um valor de peso variando para cada dado experimental, com o intuito de obter um ajuste visualmente coerente. Por exemplo, no ponto inicial em que o meio reacional atingiu a temperatura de reação, adotou-se $P=10$, para que o ajuste fosse mais preciso nesse ponto.

\subsubsection{Mecanismo de catálise heterogênea}

As leis de velocidade da reação definidas pelas Equações (16) e (17), página 57, consideram a reação como pseudo homogênea. A cinética de catálise heterogênea utiliza os mesmos princípios de concentração e temperatura, porém outros fatores também são essenciais e devem ser acrescentados à equação como a formação de um complexo na superfície, ou a influência de fenômenos de transporte.

Seguindo uma metodologia descrita por Froment, Bischoff e De Wilde (2011), a determinação da equação de taxa pela abordagem de Langmuir-Hinshelwood popularizado por Hougen-Watson (LHHW) pode ser iniciada com a discussão do mecanismo de reação admitindo que não é limitada por difusão e observando o comportamento do gráfico da taxa de reação inicial em função da concentração inicial do reagente, que pode dar indicativos da etapa limitante da reação: adsorção, dessorção ou reação na superfície, de acordo com as curvas apresentadas na Figura 16.

Figura 16 - Taxa inicial em função da concentração inicial de reagente para diferentes etapas limitantes.

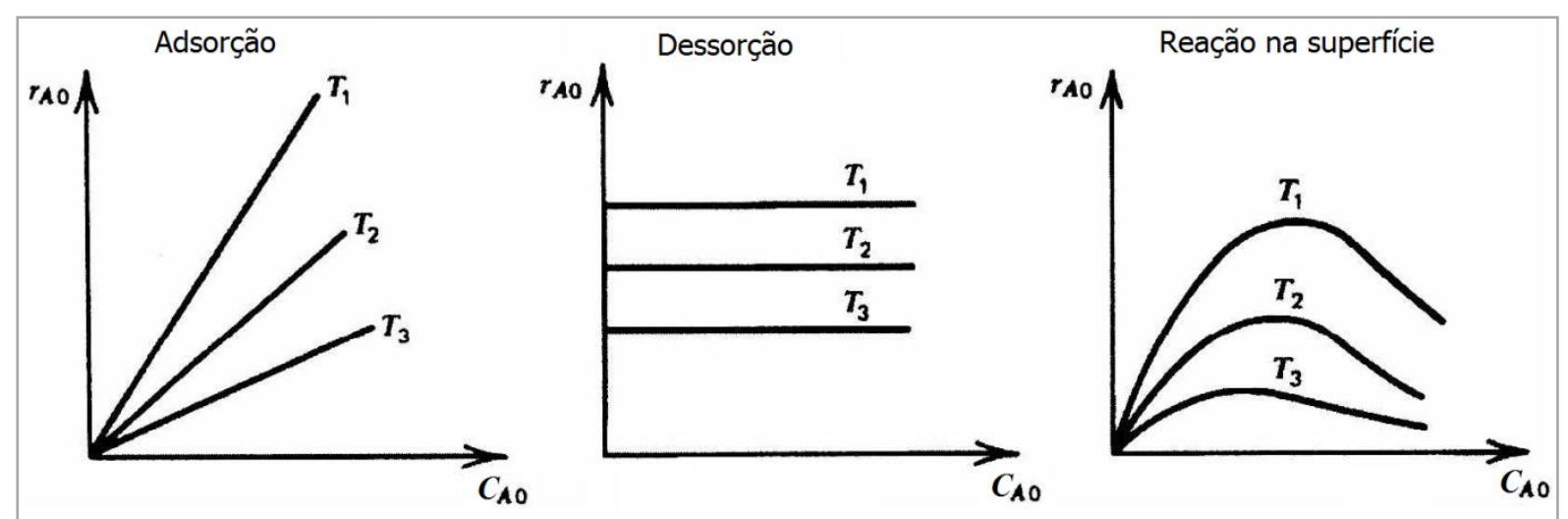

Fonte: Autora "adaptado de" Froment, Bischoff e De Wilde, 2011.

Legenda: $r_{A_{0}}$ simbolizando a velocidade inicial da reação em termos de $A ; C_{A_{0}}$, a concentração molar inicial da espécie $A$; e $T$, a temperatura de reação. 
O desenvolvimento de uma lei de velocidade para a reação global envolve a seleção de um mecanismo que descreva cada etapa da reação, cujas leis de velocidade são tratadas como elementares. Admitindo que uma dessas etapas é limitante, as concentrações das espécies adsorvidas podem ser obtidas manipulando-se as expressões das etapas não limitantes e, combinando-as com a expressão da etapa limitante e com o balanço de sítios na superfície do catalisador, obtém-se uma possível equação de taxa para a reação global.

Várias equações cinéticas podem ser encontradas, dependendo das hipóteses assumidas, mas estão sempre na forma da Equação (35), cujos termos podem ser encontrados na literatura como mostrado no Anexo A.

$$
\text { taxa de reação }=\frac{(\text { termo cinético }) \cdot(\text { força }- \text { motriz ou deslocamento do equilíbrio })}{(\text { termo de adsorção })}
$$

As possíveis leis de velocidade podem ser transformadas em equações na forma da Equação (36).

$$
y=a_{0}+a_{1} \cdot x_{1}+a_{2} \cdot x_{2}+a_{3} \cdot x_{3}+\cdots
$$

em $y$ que é a variável dependente; $x_{j}$, as variáveis independentes em termos das concentrações das espécies que adsorvem na superfície; e $a_{j}$, são constantes compostas pelos parâmetros da lei de velocidade.

Se os dados experimentais são ajustados pelas leis de velocidade na forma da Equação (36), as constantes podem ser determinadas por regressão linear múltipla. Interpretações estatísticas são necessárias para determinar se os ajustes são significativos. Os coeficientes obtidos também podem ser avaliados se os dados se ajustarem em retas características nos gráficos de Arrhenius para os coeficientes de taxa e de Van’t Hoff para os coeficientes de adsorção como exemplificado na Figura 17. 
Figura 17 - Gráficos de Arrhenius e de Van’t Hoff para a desidrogenação do etanol.

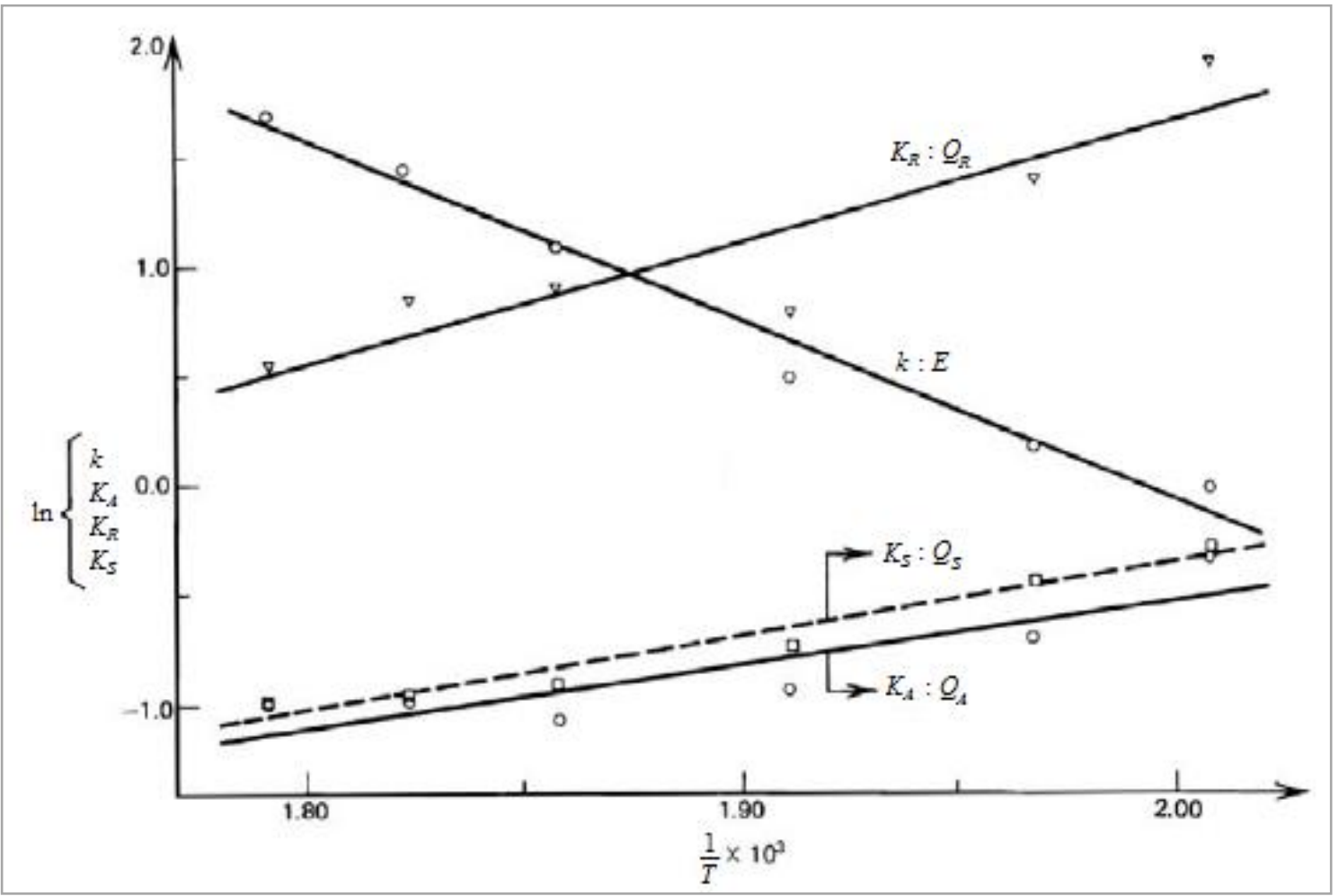

Fonte: Froment, Bischoff e De Wilde, 2011.

Legenda: $k$ simboliza a constante de velocidade da reação; $K_{i}$, as constantes de equilíbrio de adsorção da espécie $i ; E$, a energia de ativação; $Q_{i}$, as entalpias de adsorção da espécie $i$; e $T$, a temperatura absoluta de reação. 


\section{RESULTADOS E DISCUSSÃO}

Seguindo a metodologia descrita anteriormente, obtiveram-se os resultados apresentados neste capítulo.

\subsection{ENSAIOS EM REATOR BATELADA COM ÁGUA COMO SOLVENTE}

Os resultados dos ensaios preliminares realizados no reator batelada utilizando água como solvente foram obtidos pelo detector de UV-Vis para HMF e furfural e pelo detector de I.R. para glicose, frutose, ácido fórmico e ácido levulínico e são apresentados nos subitens seguintes a fim de analisar o desempenho dos catalisadores e reagentes selecionados.

\subsubsection{Efeito do tipo do catalisador}

A partir dos dados obtidos, foi analisado o efeito do tipo de catalisador utilizando as resinas de troca iônica de matriz: gelular (SGC650H) ou macroporosa (CT275). As concentrações molares, bem como os balanços materiais calculados pela Equação (9), página 55, estão apresentados nas Figuras 18 e 19.

Figura 18 - Concentrações normalizadas em função do tempo de reação para o ensaio a $110^{\circ} \mathrm{C}$ com alimentação de frutose, resina gelular SGC650H e água.

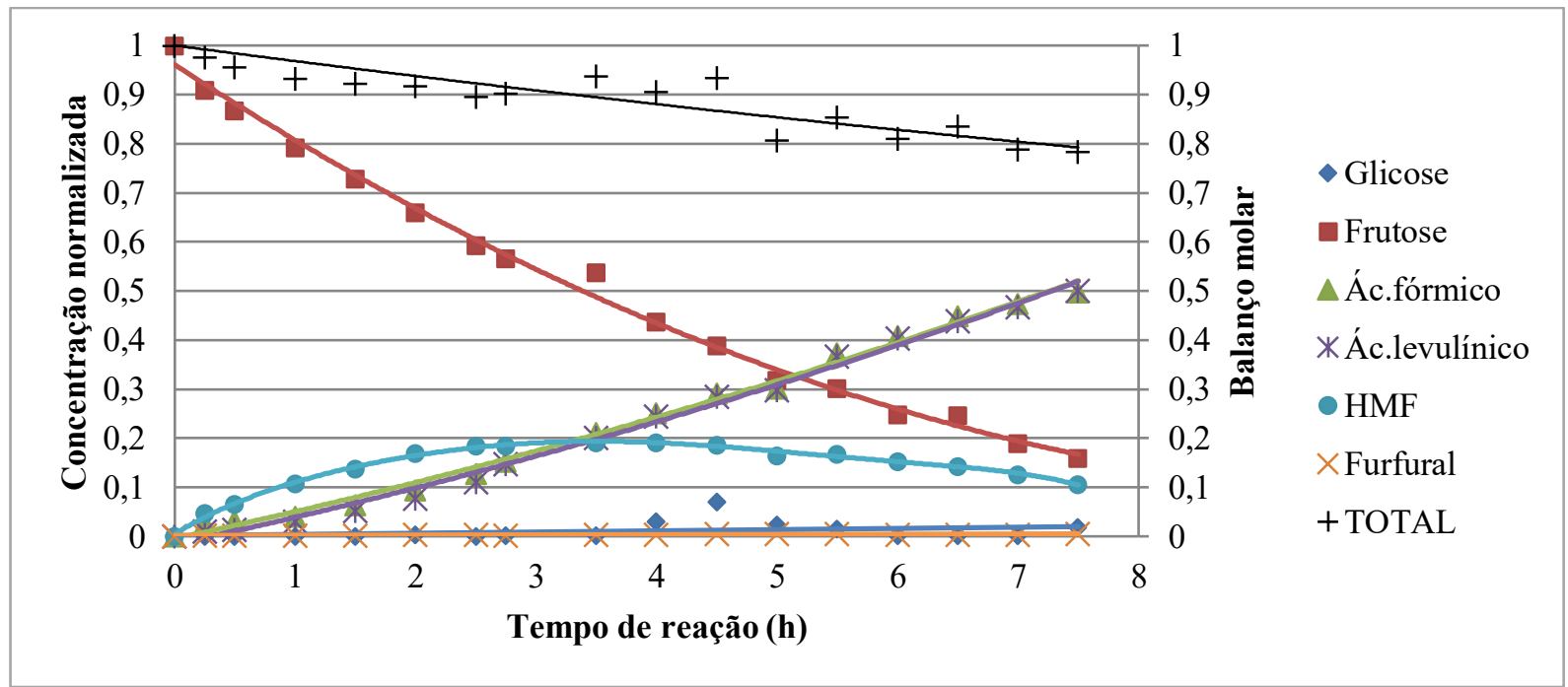

Fonte: Autora.

Nota: Concentrações normalizadas em relação à concentração de alimentação do reagente $\left(5,6 \cdot 10^{-2} \mathrm{M}\right.$ de frutose $)$ e balanço molar (série de dados "TOTAL") calculado pela concentração total das espécies analisadas. 
Figura 19 - Concentrações normalizadas em função do tempo de reação para o ensaio a $110^{\circ} \mathrm{C}$ com alimentação de frutose, resina macroporosa CT275 e água.

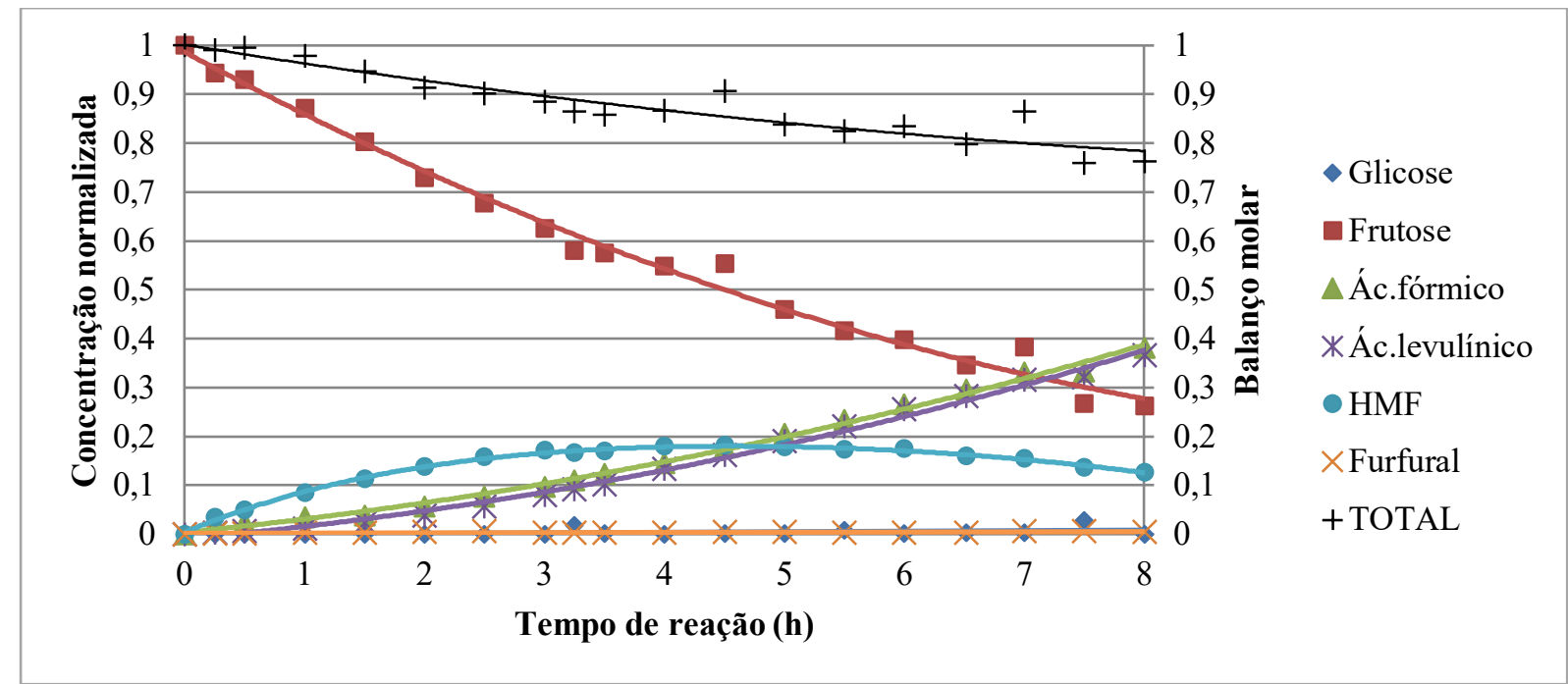

Fonte: Autora.

Nota: Concentrações normalizadas em relação à concentração de alimentação do reagente $\left(5,6 \cdot 10^{-2} \mathrm{M}\right.$ de frutose) e balanço molar (série de dados "TOTAL") calculado pela concentração total das espécies analisadas.

O comportamento decrescente dos balanços materiais representados pelas curvas pretas nas Figuras 18 e 19 indicou a formação de subprodutos não identificados pela cromatografia, tais como as huminas.

Os resultados obtidos (Tabela 9) mostraram que a resina SGC650H (Figura 18) apresentou um rendimento máximo de HMF após 3,5 h de reação, enquanto o rendimento máximo para a resina CT275 (Figura 19) só foi obtido após 4,5 h. Além disso, os valores máximos de conversão e rendimentos em HMF e ácido levulínico foram menores para a resina CT275, mostrando que sua matriz macroporosa não contribui positivamente para a reação.

Tabela 9 - Conversão e rendimentos máximos obtidos nos ensaios a $110^{\circ} \mathrm{C}$ com utilização de frutose como reagente e água como solvente.

\begin{tabular}{lcc}
\hline \hline Catalisador: & SGC650H & CT275 \\
\hline \hline Conversão máxima: & $84,0 \%(7,5 \mathrm{~h})$ & $73,9 \%(8,0 \mathrm{~h})$ \\
\hline Rendimento máximo de HMF: & $20,0 \%(3,5 \mathrm{~h})$ & $18,9 \%(4,5 \mathrm{~h})$ \\
\hline Rendimento máximo de Ácido levulínico: & $50,1 \%(7,5 \mathrm{~h})$ & $36,6 \%(8,0 \mathrm{~h})$ \\
\hline \hline
\end{tabular}

Fonte: Autora.

Comparando os resultados deste estudo após $3 \mathrm{~h}$ de reação a $110{ }^{\circ} \mathrm{C}$ com os de Poço et al. (2012) realizados a $120{ }^{\circ} \mathrm{C}$ a partir da frutose utilizando um reator Parr, obtiveram-se os valores apresentados na Tabela 10. Em ambos os estudos, a resina SGC650H, apesar de 
possuir menor número de centros ativos, apresentou maiores conversões e rendimentos em ácido levulínico que a resina CT275, enquanto o rendimento em HMF para a primeira resina foi maior apenas nos ensaios realizados a $110^{\circ} \mathrm{C}$ neste trabalho. Isso é um indicativo de que a reação de hidrólise do HMF para formação do ácido levulínico é mais favorecida pelo aumento da temperatura em detrimento da reação de formação do HMF.

Tabela 10 - Comparação entre os valores experimentais ${ }^{\mathrm{a}}$ e uma referência bibliográfica ${ }^{\mathrm{b}}$ com utilização de frutose como reagente e água como solvente.

\begin{tabular}{lcccc}
\hline \hline Temperatura: & \multicolumn{2}{c}{$\mathbf{1 1 0}^{\circ} \mathbf{C}^{\mathbf{a}}$} & \multicolumn{2}{c}{$\mathbf{1 2 0}^{\circ} \mathbf{C}^{\mathbf{b}}$} \\
\hline \hline Tempo de reação: & \multicolumn{2}{c}{$3 \mathrm{~h}$} & $\mathrm{~h}$ \\
\hline Resina/Catalisador: & $\mathrm{SGC} 650 \mathrm{H}$ & $\mathrm{CT} 275$ & $\mathrm{SGC} 650 \mathrm{H}$ & $\mathrm{CT} 275$ \\
\hline Conversão: & $43,4 \%$ & $37,4 \%$ & $90,4 \%^{\mathrm{c}}$ & $61,2 \%{ }^{\mathrm{c}}$ \\
\hline Rendimento de HMF: & $19,2 \%$ & $17,8 \%$ & $7,2 \%$ & $33,3 \%$ \\
\hline Rendimento de Ácido levulínico: & $14,8 \%$ & $7,9 \%$ & $43,9 \%$ & $35,6 \%$ \\
\hline \hline a este trabalho & & & & \\
b Poço et al. (2012) & & & & \\
\hline \hline Fonte: Autora.
\end{tabular}

\subsubsection{Efeito do tipo de açúcar}

As concentrações das substâncias analisadas ao longo do tempo de reação para os ensaios utilizando glicose como reagente e o balanço molar calculado pela Equação (9), página 55, são apresentadas nas Figuras 20 e 21 para as resinas SGC650H e CT275 como catalisador, respectivamente.

Figura 20 - Concentrações normalizadas em função do tempo de reação para o ensaio a $110{ }^{\circ} \mathrm{C}$ com alimentação de glicose, resina gel SGC650H e água.

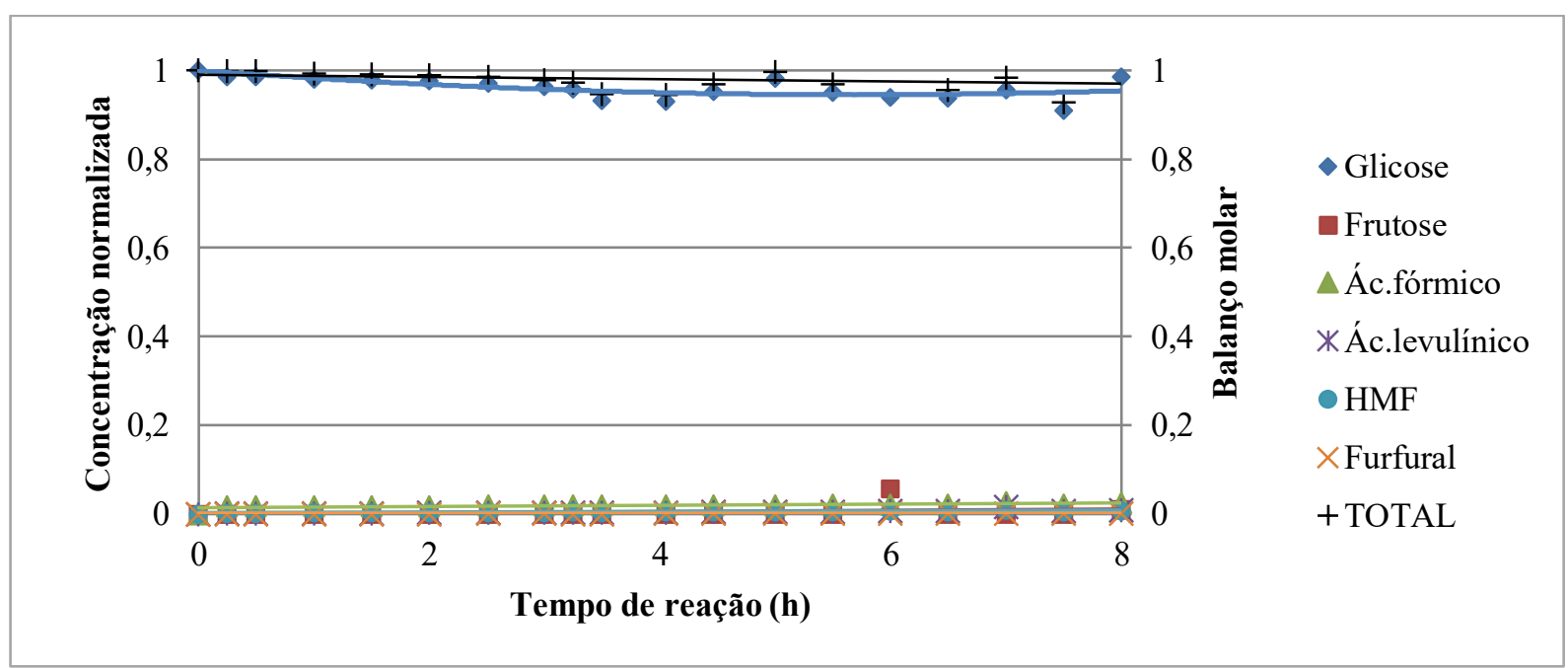

Fonte: Autora.

Nota: Concentrações normalizadas em relação à concentração de alimentação do reagente $\left(5,6 \cdot 10^{-2} \mathrm{M}\right.$ de glicose $)$ e balanço molar (série de dados "TOTAL”) calculado pela concentração total das espécies analisadas. 
Figura 21 - Concentrações normalizadas em função do tempo de reação para o ensaio a $110{ }^{\circ} \mathrm{C}$ com alimentação de glicose, resina macroporosa CT275 e água.

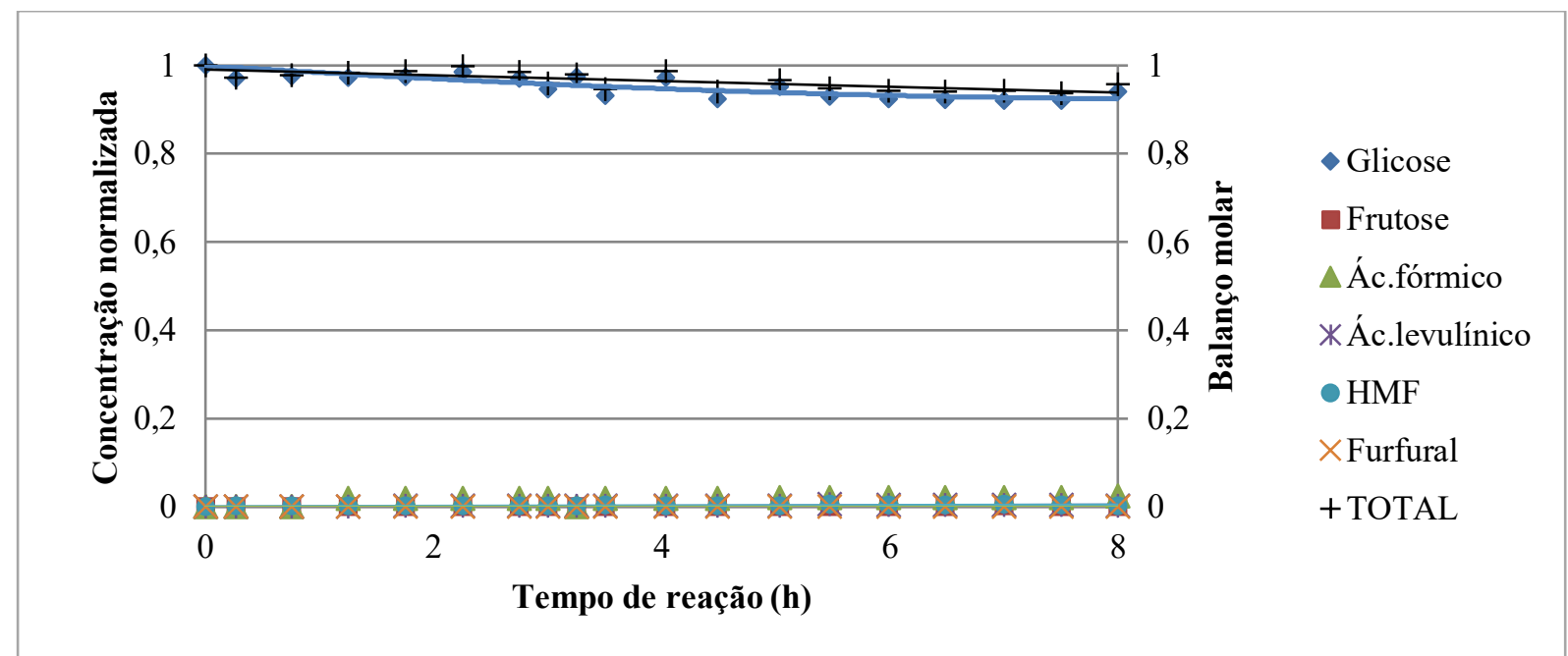

Fonte: Autora.

Nota: Concentrações normalizadas em relação à concentração de alimentação do reagente $\left(5,6 \cdot 10^{-2} \mathrm{M}\right.$ de glicose) e balanço molar (série de dados "TOTAL") calculado pela concentração total das espécies analisadas.

Os resultados dos ensaios que utilizaram glicose como reagente (Tabela 11) apresentaram baixa conversão (máximo de $9 \%$ ) e baixos rendimentos (menores que 1,5\% para ácido levulínico e HMF), confirmando a menor reatividade da glicose para a formação do HMF quando comparada à frutose. As concentrações analisadas foram tão baixas, que o ruído nos cromatogramas passou a ser mais significativo, causando a flutuação dos dados.

Tabela 11 - Conversão e rendimentos máximos obtidos nos ensaios com utilização de glicose como reagente e água como solvente.

\begin{tabular}{lcc}
\hline Resina/Catalisador: & SGC650H & CT275 \\
\hline Conversão máxima: & $9,1 \%$ & $7,9 \%$ \\
\hline Rendimento máximo de HMF: & $1,2 \%$ & $0,9 \%$ \\
\hline Rendimento máximo de Ácido levulínico: & $1,5 \%$ & $0,6 \%$ \\
\hline \hline
\end{tabular}

Fonte: Autora.

Assim, tendo em vista o melhor desempenho da resina SGC650H e maior reatividade da frutose, os ensaios que utilizaram DMSO como solvente foram realizados empregando-se tais substâncias como catalisador e substrato, respectivamente. 


\subsection{ENSAIOS EM REATOR BATELADA COM DMSO COMO SOLVENTE}

A utilização de DMSO como solvente limitou a análise por HPLC como mostrado no Apêndice A, de modo que apenas a concentração de HMF foi mensurada. Apesar dos cromatogramas indicarem outras substâncias, suas áreas percentuais em relação ao HMF (exemplificado na Figura 22) foram consideradas pequenas para a análise da concentração, visto que a área do HMF representa mais de $95 \%$ da área total dos picos no cromatograma.

Figura 22 - Área percentual em relação ao HMF dos picos em função do tempo de reação para o ensaio a $110^{\circ} \mathrm{C}$ com alimentação de $1,5 \%$ de frutose, DMSO e SGC650H.

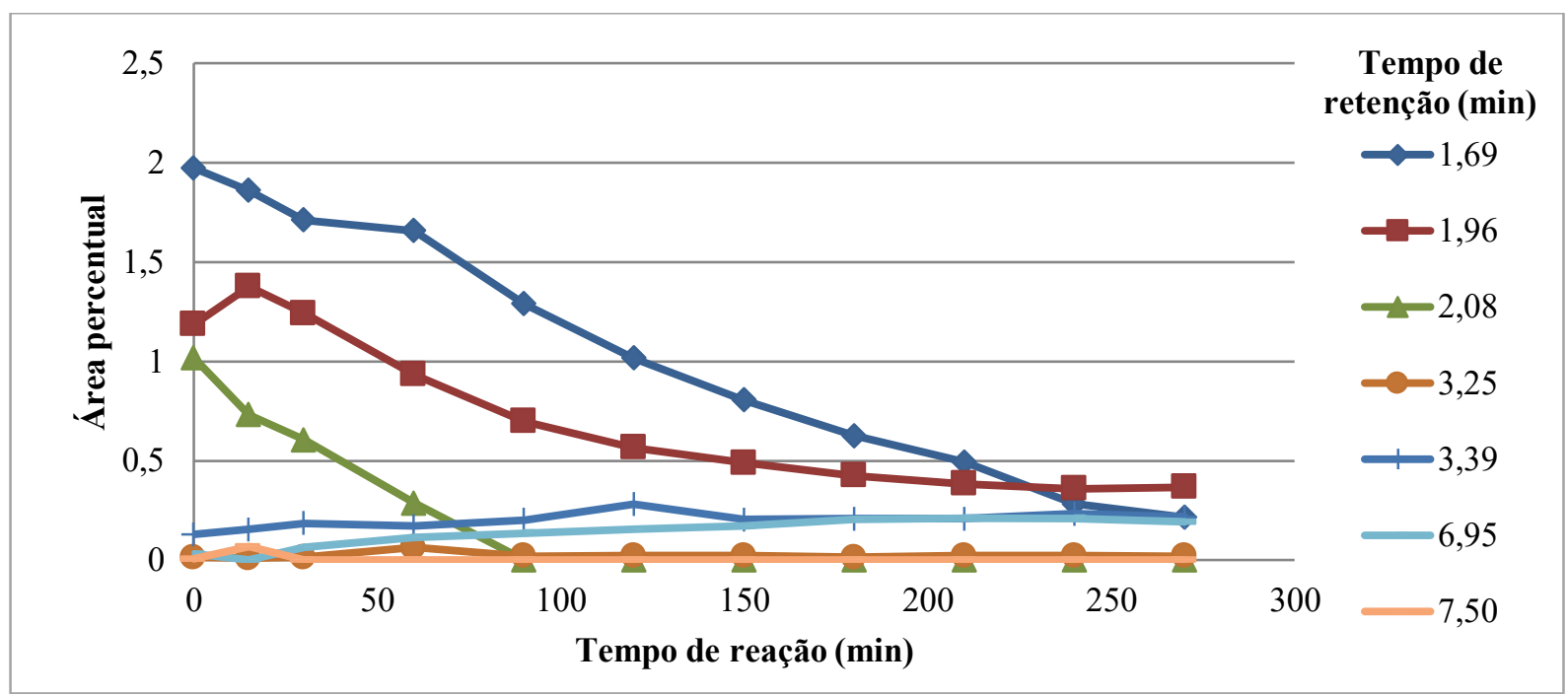

Fonte: Autora.

Nota: Coluna Shim-pack CLC-ODS $(\mathrm{M})^{\circledR}$ a $30^{\circ} \mathrm{C}$; eluente a $1,2 \mathrm{~mL} / \mathrm{min}$ de acetonitrila e ácido acético $1 \%(\mathrm{~m} / \mathrm{m})$ na proporção de 20:80; detector de UV-Vis a $266 \mathrm{~nm}$ operando a $40{ }^{\circ} \mathrm{C}$

Analisando os picos menores dos cromatogramas em área percentual como mostrado na Figura 22, três deles destacaram-se com 1,69 min, 1,96 min e 2,08 min de retenção, cujas áreas foram maiores no início da reação e diminuindo com o tempo, indicando que são consumidos durante a reação. Sugeriu-se então, que esses picos podem ser intermediários da reação, o que condiz com o mecanismo proposto por Amarasekara, Williams e Ebede (2008), Kimura, Nakahara e Matubayasi (2013) e Zhang J. et al. (2016) em DMSO que conseguiram identificar dois dos três intermediários.

\subsubsection{Ensaio sem catalisador (branco)}

As áreas dos picos referentes ao HMF obtidas nos ensaios em branco com alimentação de apenas frutose e DMSO, foram menores que as obtidas para as soluções padrões analisadas, 
como observado na curva de calibração apresentada na Figura 48 (página 108) do Apêndice B. As áreas foram tão pequenas, que o ruído nos cromatogramas e o sinal do DMSO (Figura 46, página 106) passaram a ser mais significativos. Portanto, foi considerado que não houve formação aparente de HMF catalisada pelo solvente nas condições experimentais utilizadas no presente trabalho.

\subsubsection{Comparação entre solvente aquoso e não aquoso}

Nos experimentos que utilizaram água como solvente foi possível analisar a conversão e o rendimento do HMF, enquanto para o DMSO como solvente, apenas o rendimento do HMF foi mensurado. Tais resultados são apresentados na Figura 23.

Figura 23 - Gráficos para comparação de resultados utilizando diferentes solventes: água e DMSO.

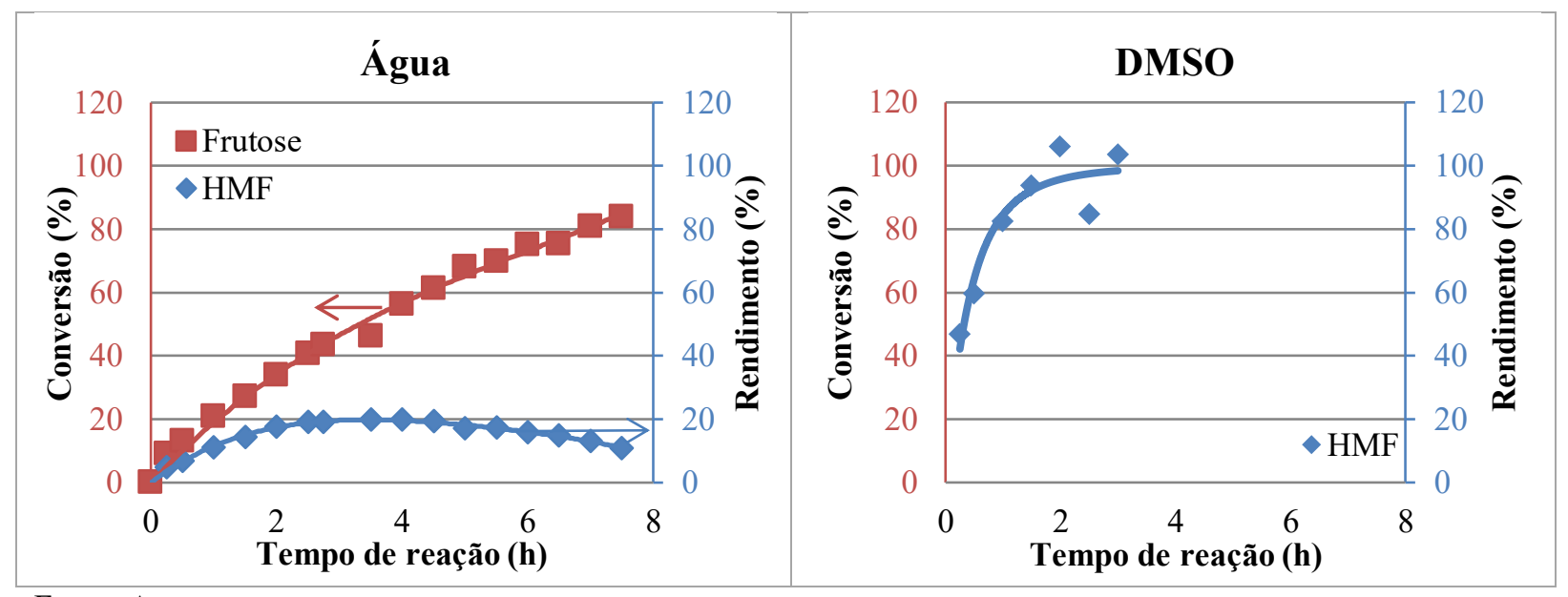

Fonte: Autora.

Nota: Ensaios realizados em batelada a $110^{\circ} \mathrm{C}$ com alimentação de resina gel SGC650H bruta e de $1 \%(\mathrm{~m} / \mathrm{m})$ de frutose no respectivo solvente.

Os resultados obtidos da reação de frutose em diferentes solventes apresentados na Figura 23 mostraram que o meio não aquoso, no caso o DMSO, propiciou maiores rendimento do HMF, atingindo aproximadamente $100 \%$ em 3 h de reação, enquanto o ensaio em meio aquoso atingiu um máximo de $20 \%$ em 3,5 h. Mesmo sem dados da conversão no ensaio com DMSO, sabe-se que todo HMF do meio reacional é formado a partir da frutose, então a conversão deve ser igual (se não houve reações paralelas) ou maior (quando houve formação de subprodutos) que o rendimento do HMF. Baseado nisso, foi possível concluir que a taxa de reação também foi maior em solvente não aquoso, então o DMSO como 
solvente mostra-se vantajoso comparado à água quando o objetivo é a otimização da formação de HMF.

Os resultados condizem com o que foi reportado na pesquisa bibliográfica como por Kuster (1990) e Carlini et al. (1999) de que a utilização de solventes anidros apresenta maiores rendimentos, uma vez que a menor concentração de água no meio reacional reduz a formação de produtos de hidrólise e huminas.

\subsubsection{Efeito da temperatura de reação}

Baseado no ajuste dos valores experimentais pelo método de otimização que se utilizou da energia de ativação e correção da concentração de catalisador pela Equação (15), os perfis de cada temperatura de reação são apresentados nas Figuras 24, 25, 26 e 27 para diferentes concentrações de alimentação. Nestas figuras foi possível notar as diferenças de concentração das alíquotas retiradas no tempo $0 \mathrm{~h}$ da reação, mais evidente para as curvas a $110^{\circ} \mathrm{C}$, mostrando que houve formação do produto HMF antes do tempo inicial, devido à impossibilidade de adição do catalisador após o sistema atingir a temperatura analisada. $\mathrm{O}$ instante de início da reação $(t=0 \mathrm{~h})$ só foi considerado quando o meio reacional atingiu a temperatura de reação em estudo.

Figura 24 - Concentração de HMF em função do tempo de reação para ensaios com alimentação de $1,5 \%$ (m/m) de frutose em DMSO a diferentes temperaturas.

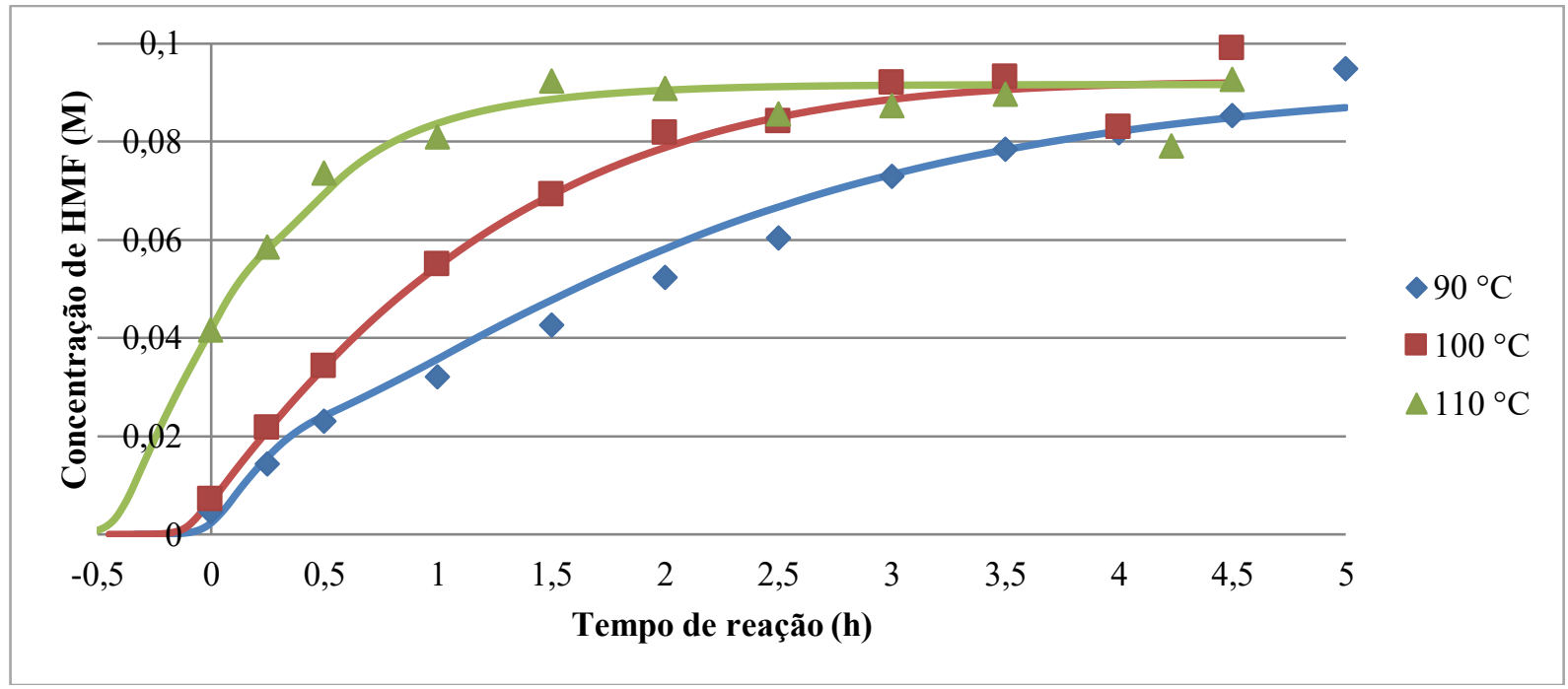

Fonte: Autora.

Nota: Ensaios realizados em batelada com resina gelular SGC650H bruta como catalisador e DMSO como solvente. 
Figura 25 - Concentração de HMF em função do tempo de reação para ensaios com alimentação de $3,0 \%(\mathrm{~m} / \mathrm{m})$ de frutose em DMSO a diferentes temperaturas.

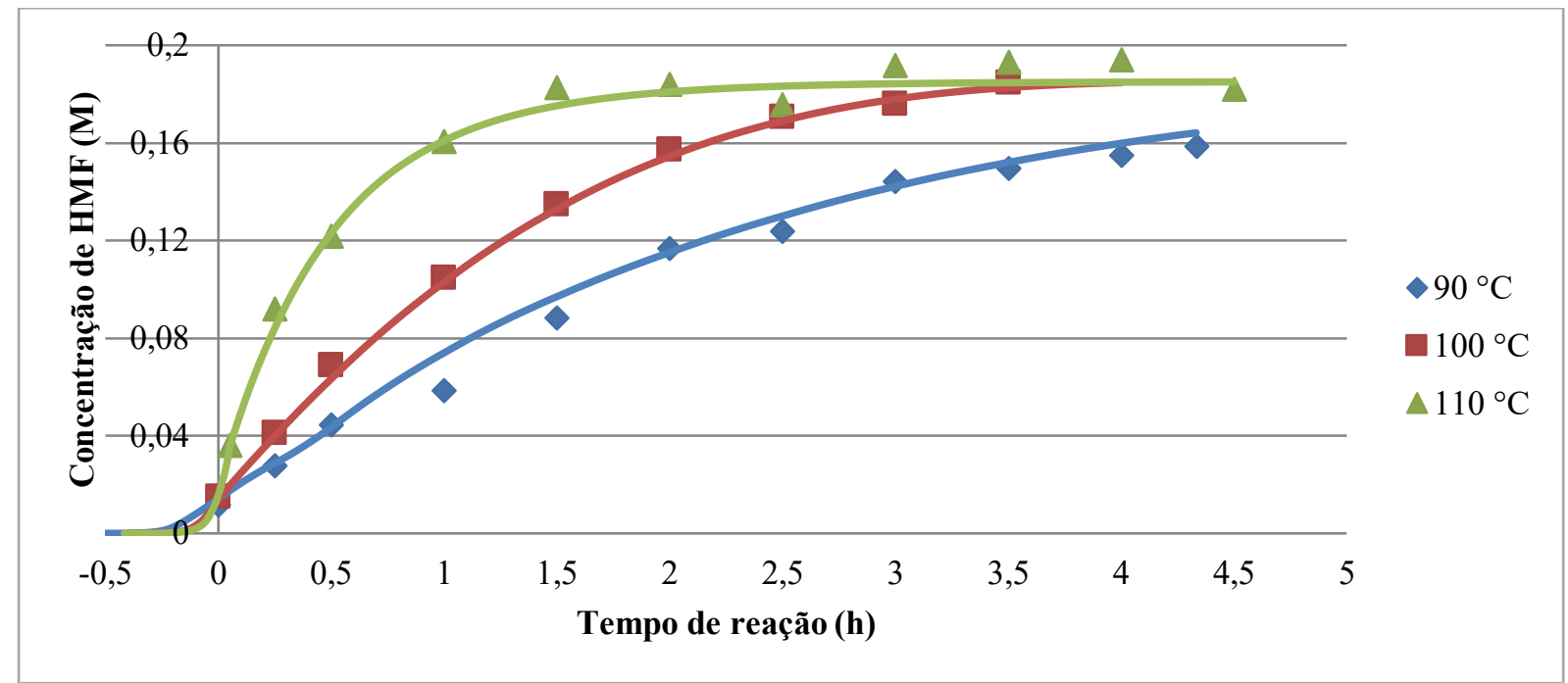

Fonte: Autora.

Nota: Ensaios realizados em batelada com resina gelular SGC650H bruta como catalisador e DMSO como solvente.

Figura 26 - Concentração de HMF em função do tempo de reação para ensaios com alimentação de 4,5 \% (m/m) de frutose em DMSO a diferentes temperaturas.

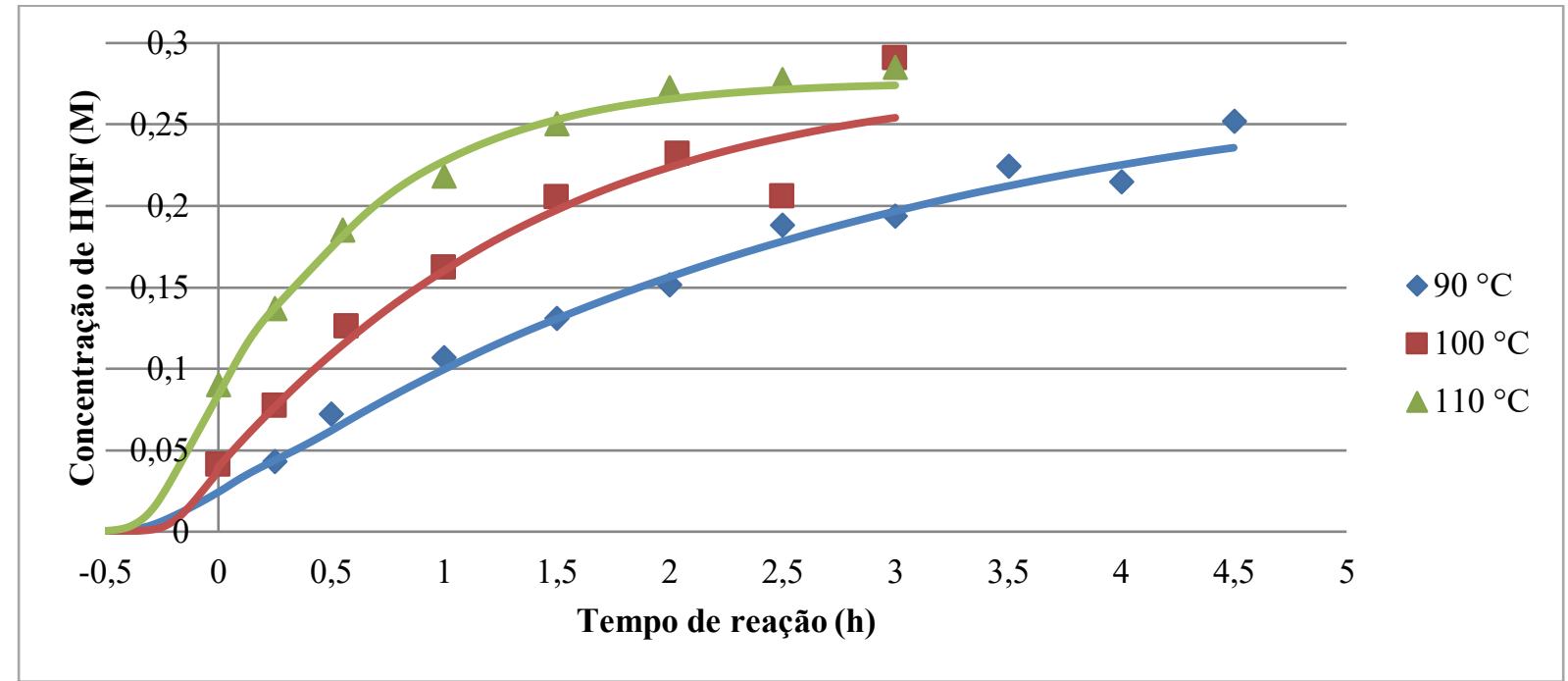

Fonte: Autora.

Nota: Ensaios realizados em batelada com resina gelular SGC650H bruta como catalisador e DMSO como solvente. 
Figura 27 - Concentração de HMF em função do tempo de reação para ensaios com alimentação de $13,5 \%(\mathrm{~m} / \mathrm{m})$ de frutose em DMSO a diferentes temperaturas.

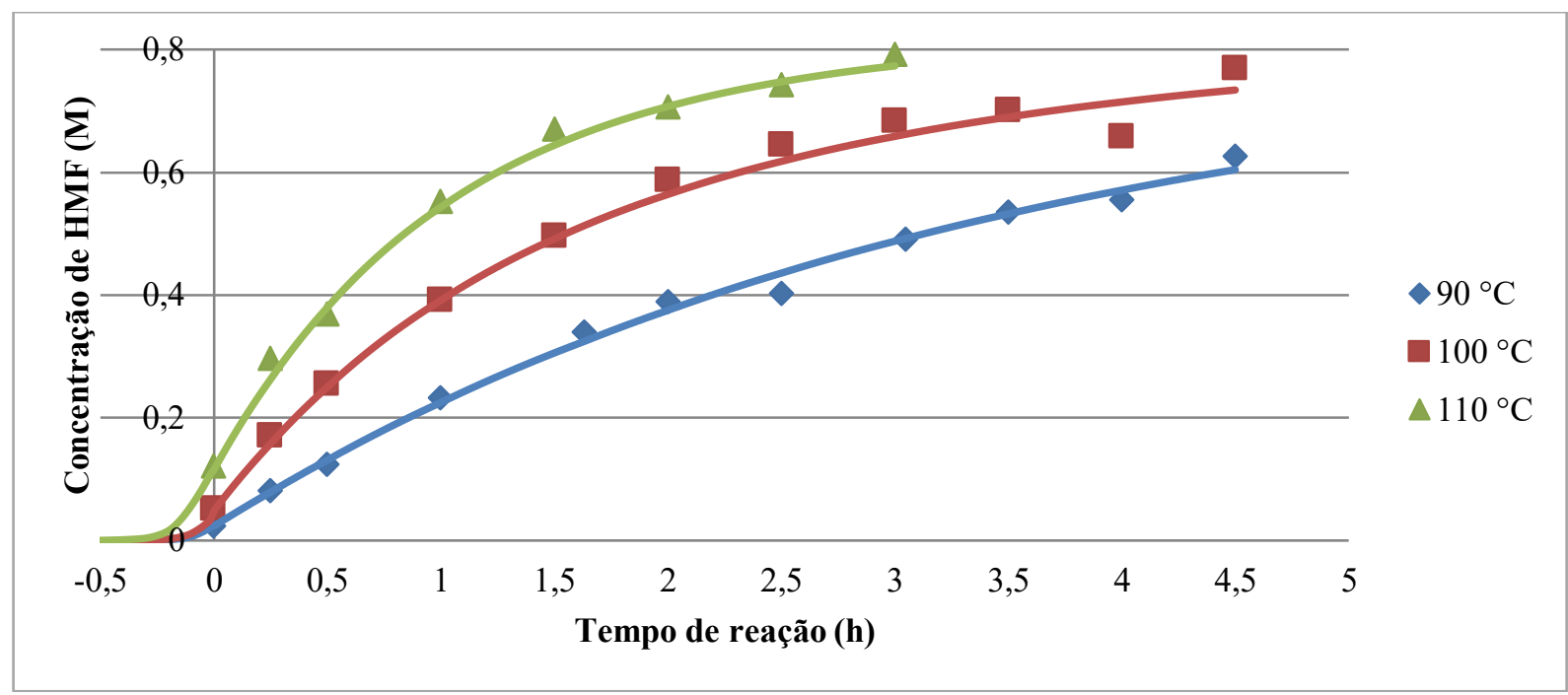

Fonte: Autora.

Nota: Ensaios realizados em batelada com resina gelular SGC650H bruta como catalisador e DMSO como solvente.

A análise das Figuras 24 a 27 indicou que a reação é favorecida em temperaturas maiores, uma vez que o aumento da concentração do produto HMF aponta para um consumo mais rápido do reagente, necessitando de um tempo de reação menor. Porém a aplicação de resinas de troca iônica limita o uso de maiores temperaturas de reação devido às suas baixas estabilidades térmicas, visto que há recomendações do fabricante quanto à temperatura máxima de operação (Tabela 2, página 44), neste caso, aproximadamente $130{ }^{\circ} \mathrm{C}$.

\subsubsection{Efeito da concentração de frutose alimentada}

Os comportamentos do rendimento em HMF ao longo da reação para cada valor de concentração alimentada são apresentados nas Figuras 28, 29 e 30 para diferentes temperaturas de reação. $\mathrm{O}$ fato das curvas começarem com rendimentos de HMF diferentes de zero indicou que houve consumo do reagente durante a etapa de aquecimento do reator. Nessas figuras, as curvas de regressão foram baseadas no ajuste dos valores experimentais pelo método de otimização que levaram em conta a energia de ativação e correção da concentração de catalisador pela Equação (15). 
Figura 28 - Rendimento de HMF em função do tempo de reação para ensaios a $90{ }^{\circ} \mathrm{C}$ com diferentes concentrações de alimentação do reagente.

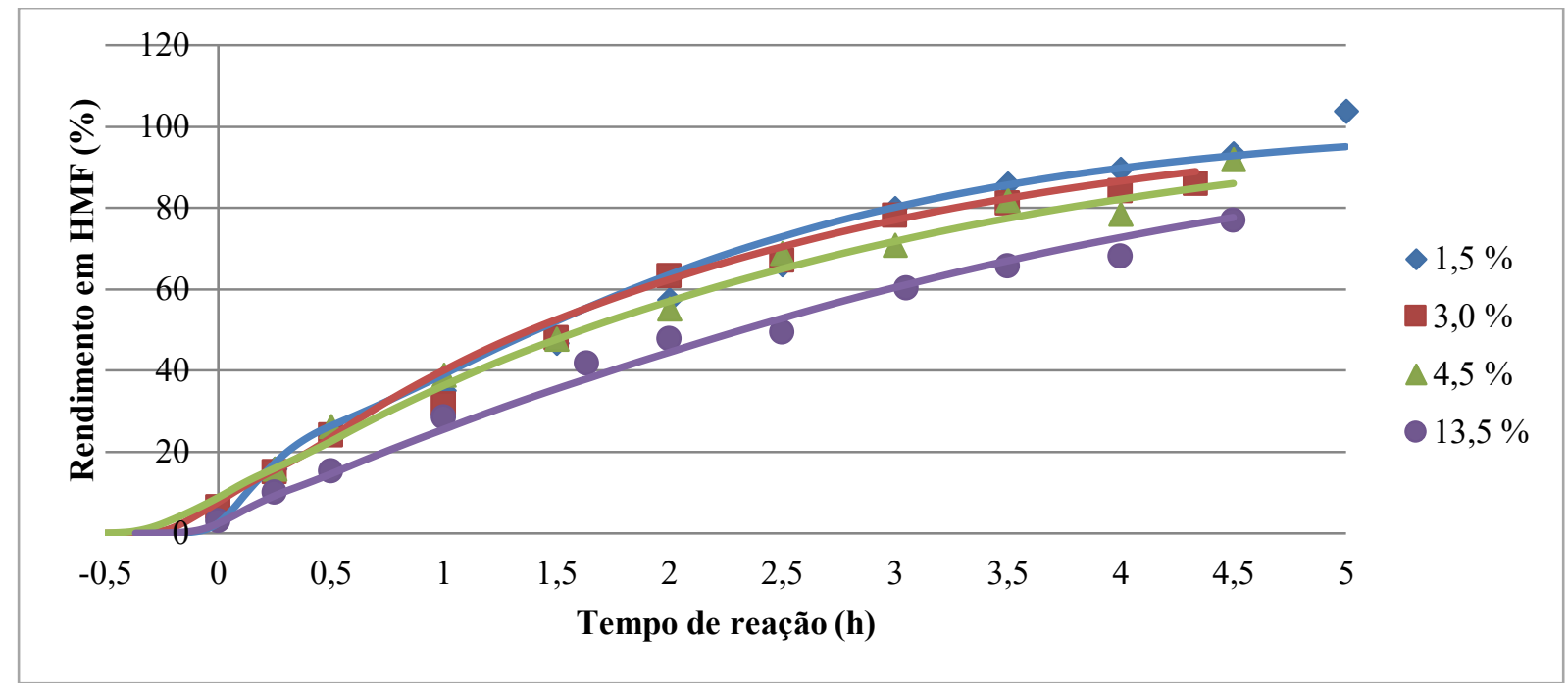

Fonte: Autora.

Nota: Ensaios realizados em batelada com resina gelular SGC650H bruta como catalisador e DMSO como solvente.

Figura 29 - Rendimento em HMF em função do tempo de reação para ensaios a $100{ }^{\circ} \mathrm{C}$ com diferentes concentrações de alimentação do reagente.

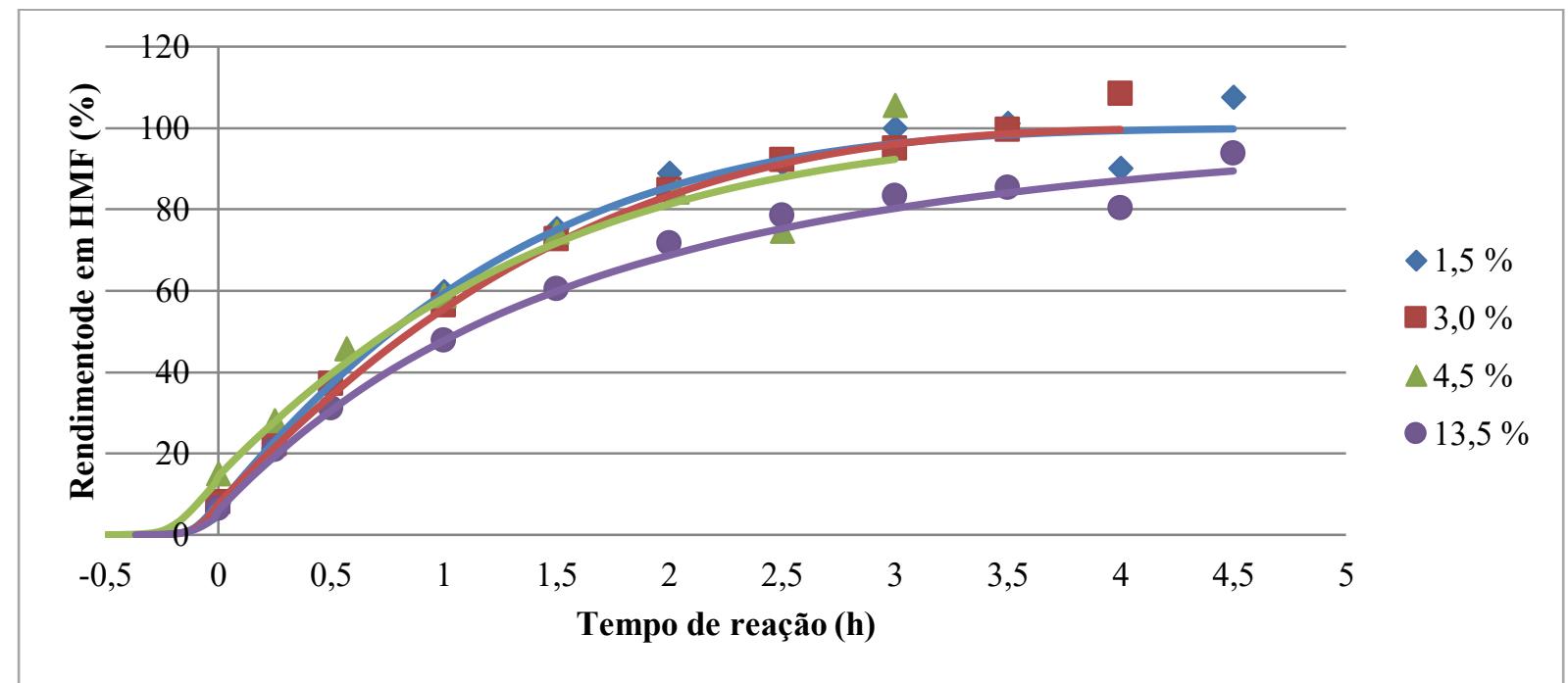

Fonte: Autora.

Nota: Ensaios realizados em batelada com resina gelular SGC650H bruta como catalisador e DMSO como solvente. 
Figura 30 - Rendimento em HMF em função do tempo de reação para a $110{ }^{\circ} \mathrm{C} \mathrm{com}$ diferentes concentrações de alimentação do reagente.

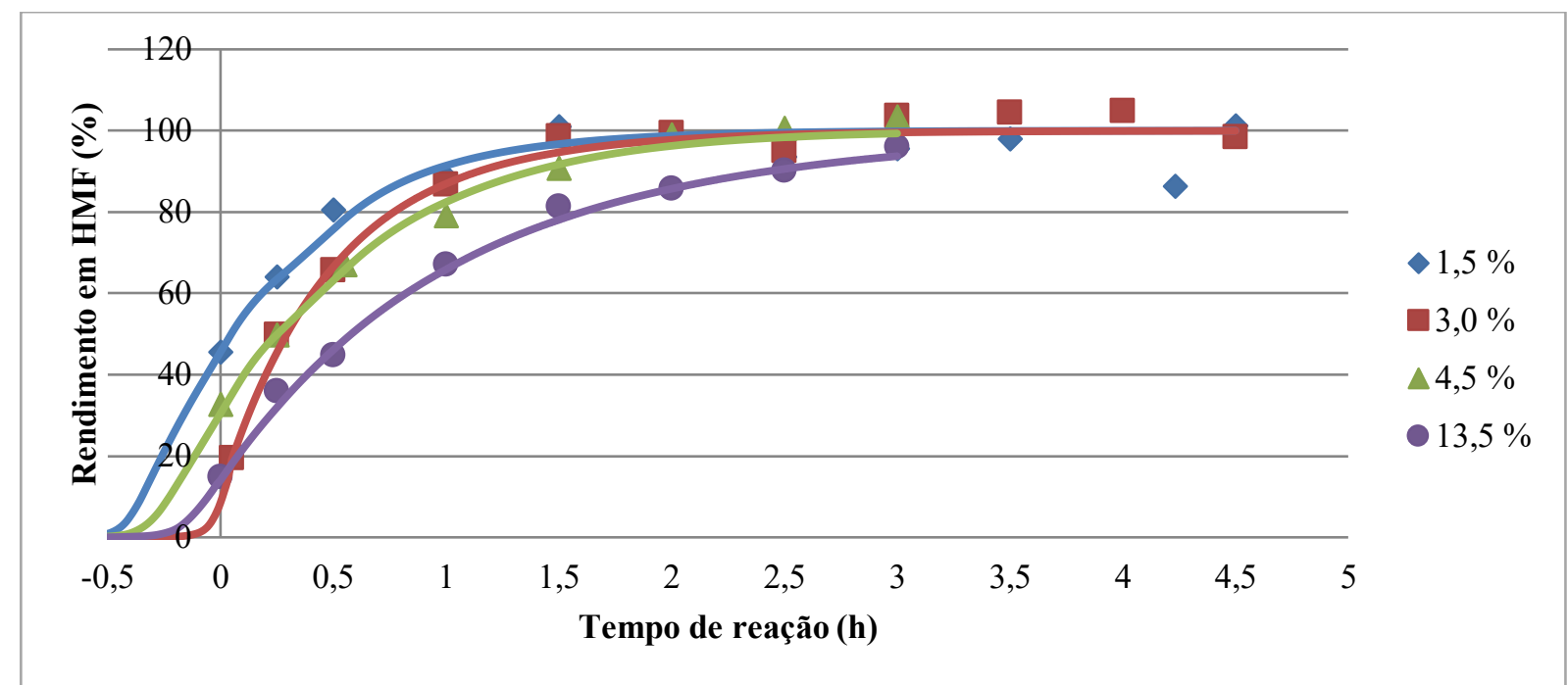

Fonte: Autora.

Nota: Ensaios realizados em batelada com resina gelular SGC650H bruta como catalisador e DMSO como solvente.

Os valores de rendimento a $110{ }^{\circ} \mathrm{C}$ (Figura 30) de quase $100 \%$ obtidos a partir de $3 \mathrm{~h}$ de reação indicam que as reações consecutivas e paralelas foram pouco pronunciadas e assim, a proposição de que o rendimento de HMF é equivalente à conversão enunciada pela Equação (8), página 55, é uma aproximação válida.

De modo geral, foi possível observar a tendência de reação mais rápida para os ensaios com menores concentrações alimentadas de substrato, de modo a demandar tempos menores de reação para atingir o mesmo rendimento.

Nas curvas obtidas com 13,5\% de alimentação de frutose, foram observados crescimentos mais lento em relação às outras curvas. Tal observação está possivelmente relacionada aos seguintes fatores:

a) ocorrência de uma limitação que poderia ser atribuída a fenômenos de transporte ou ao aumento da adsorção de reagentes, solvente ou produtos no catalisador;

b) maior probabilidade de ocorrência de polimerização e formação de huminas, assim diminuindo a seletividade do HMF. Segundo Kuster (1990), essas huminas apresentam coloração marrom a preta, que pôde ser verificada visualmente ao comparar as amostras (Figura 31). 
Figura 31 - Colorações das amostras com diferentes concentrações de frutose alimentada.

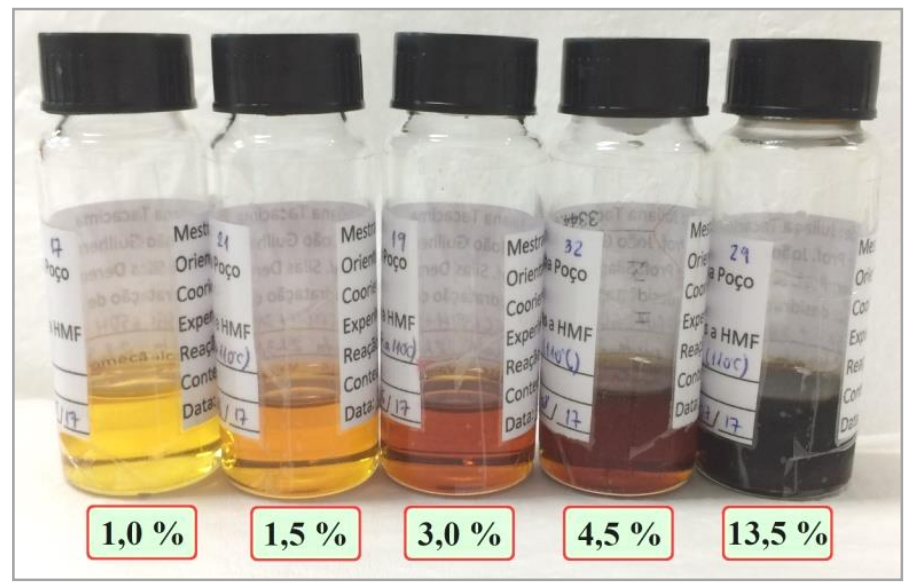

Fonte: Autora.

Nota: Amostras dos ensaios em batelada a $110^{\circ} \mathrm{C}$ após $2,5 \mathrm{~h}$ de reação utilizando resina SGC650H bruta e DMSO.

\subsubsection{Efeito do tamanho de partícula de catalisador}

As distribuições granulométricas realizadas por difração a laser estão apresentadas na Figura 32 e as características obtidas experimentalmente para a resina de troca iônica SGC650H utilizada nos experimentos, na Tabela 12.

Figura 32 - Distribuições granulométricas obtidas pelo analisador de tamanho de partículas Malvern Mastersizer 2000.

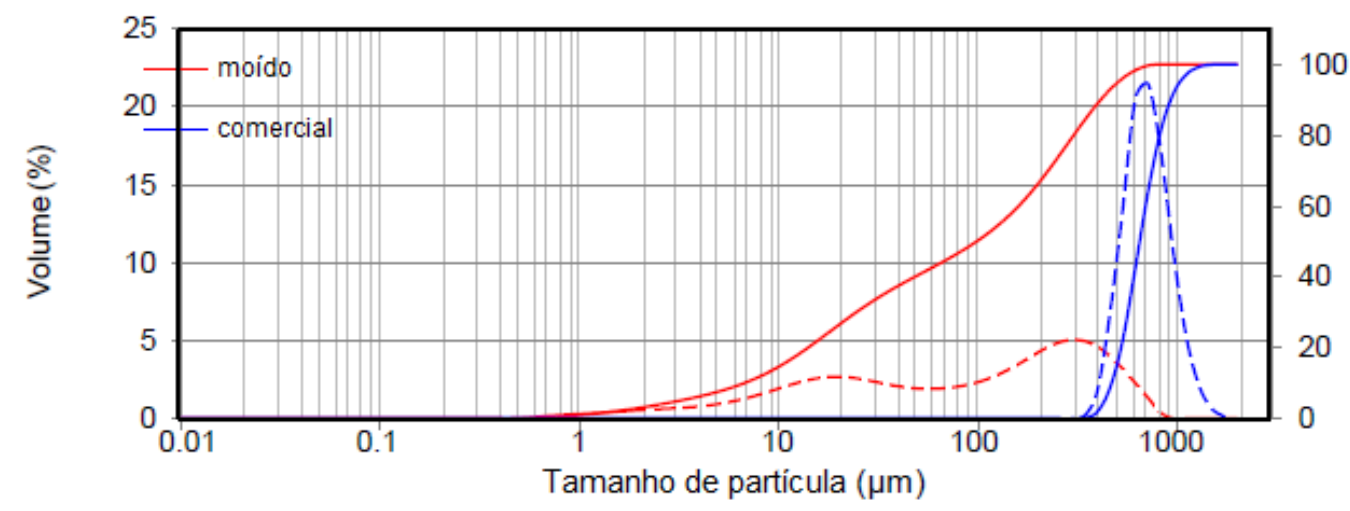

Fonte: IPT.

Nota: As linhas tracejadas indicam a distribuição granulométrica diferencial, já as linhas cheias, a distribuição granulométrica acumulada. 
Tabela 12 - Características da resina SGC650H em diferentes granulometrias.

\begin{tabular}{|c|c|c|c|c|}
\hline \multicolumn{2}{|c|}{ Característica } & $\begin{array}{l}\text { SGC650H } \\
\text { comercial }\end{array}$ & $\begin{array}{l}\text { SGC650H } \\
\text { moído }\end{array}$ & $\begin{array}{c}\text { Razão } \\
\text { moído:comercial }\end{array}$ \\
\hline \multicolumn{2}{|c|}{ Razão de massa (b.s./b.u.): } & 0,5457 & $\mathrm{a}^{\mathrm{a}}$ & \\
\hline \multirow{2}{*}{$\begin{array}{c}\text { Diâmetro médio } \\
(\mu \mathrm{m})^{\mathbf{b}}\end{array}$} & volumétrico: & 787,435 & 162,212 & \\
\hline & de Sauter: & 733,659 & 14,613 & \\
\hline \multirow{2}{*}{$\begin{array}{l}\text { Área específica } \\
\left(\mathrm{cm}^{2} / \mathrm{g}\right)\end{array}$} & pelo $D_{\text {volumétrico: }}$ & 62,97 & 305,69 & \\
\hline & pelo $D_{\text {Sauter }}:$ & 67,59 & 3393,33 & \\
\hline \multirow{2}{*}{$\begin{array}{c}\text { Área total no ensaio } \\
\left(\mathrm{cm}^{2}\right)\end{array}$} & pelo $D_{\text {volumétrico: }}$ : & 1034,03 & 8388,17 & 8,11 \\
\hline & pelo $D_{\text {Sauter: }}$ & 1109,83 & 93113,06 & 83,90 \\
\hline $\begin{array}{l}\text { Taxa de reação inicial } \\
\left(\mathrm{mol}^{-} \mathrm{L}^{-1} \cdot \mathrm{min}^{-1}\right)\end{array}$ & $\begin{array}{l}\text { Método integral } \\
(\mathrm{n}=1) \text { : }\end{array}$ & $-1,421 \cdot 10^{-3}$ & $-2,224 \cdot 10^{-2}$ & 15,64 \\
\hline $\begin{array}{l}\text { a sem informação de base ú } \\
\text { b valores obtidos por difraç }\end{array}$ & mida. & & & \\
\hline
\end{tabular}

A análise granulométrica do catalisador moído indicou diferença entre os valores dos diâmetros médios volumétrico e de Sauter (obtido pela relação volume/superfície), mostrando que o tamanho das partículas do catalisador não era uniforme. Por este motivo, dependendo da definição do diâmetro médio utilizado nos cálculos, a área superficial de catalisador durante os experimentos apresentou diferenças expressivas, com razões de 8,11 e 83,90 para o diâmetro volumétrico e de Sauter respectivamente.

O aumento da taxa de reação para menores tamanhos de partículas pode ser observado também nos perfis de concentração de HMF ao longo da reação apresentados na Figura 33, uma vez que a formação do produto é mais acelerada para o catalisador moído, concluindo-se apenas qualitativamente que a reação é favorecida quando os tamanhos de partícula de catalisador são menores. 
Figura 33 - Rendimento de HMF em função do tempo de reação para ensaios a $90{ }^{\circ} \mathrm{C}$ com diferentes granulometrias da SGC650H como catalisador.

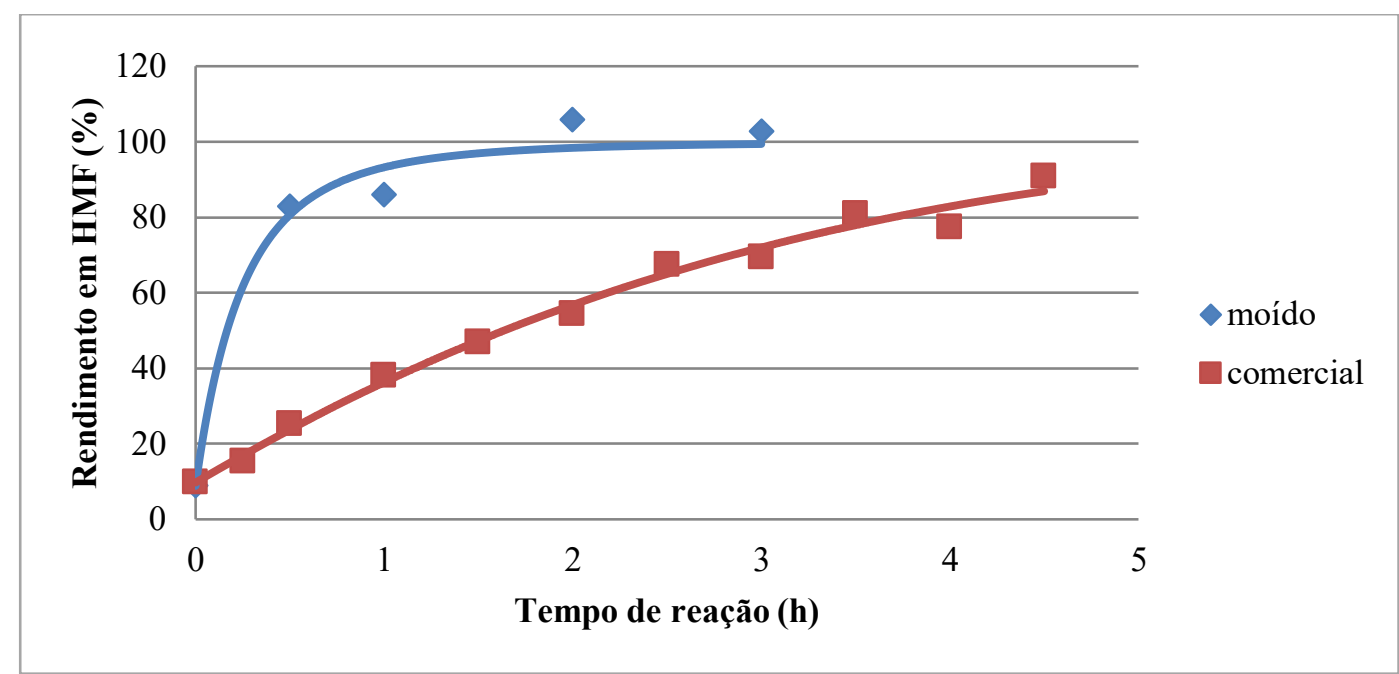

Fonte: Autora.

Nota: Ensaios realizados em batelada com alimentação de 4,5 \% (m/m) de frutose em DMSO. A resina moída foi alimentada seca, já a resina bruta (comercial), úmida.

Shimizu, Uozumi e Satsuma (2009) reportaram rendimento em HMF de $100 \%$ utilizando em seus experimentos: frutose, resina ácida Amberlyst-15 moída com diâmetros de partícula entre $0,150 \mathrm{~mm}$ e $0,053 \mathrm{~mm}$, DMSO com $2 \mathrm{~h}$ de reação a $120^{\circ} \mathrm{C}$, cujo valor é superior à temperatura utilizada neste estudo $\left(90^{\circ} \mathrm{C}\right)$. As conclusões para a utilização de menores tamanhos de partícula de catalisador foram: menor teor de água adsorvida no catalisador, já que o mesmo foi seco em estufa; maior facilidade nos processos de transferência de massa e dessorção de produtos, o que resulta em maiores conversões e menores formações de subprodutos.

\subsubsection{Análise cinética da reação pelo método integral}

A partir dos dados de concentração do reagente durante a reação, foi possível calcular os parâmetros cinéticos pelo método integral para uma reação de pseudo primeira ordem, com as curvas de $-\ln (1-X)$ em função do tempo de reação. A Figura 34 mostra três séries de dados como exemplo destas curvas. 
Figura 34 - Gráfico linearizado da conversão em função do tempo de reação em diferentes temperaturas.

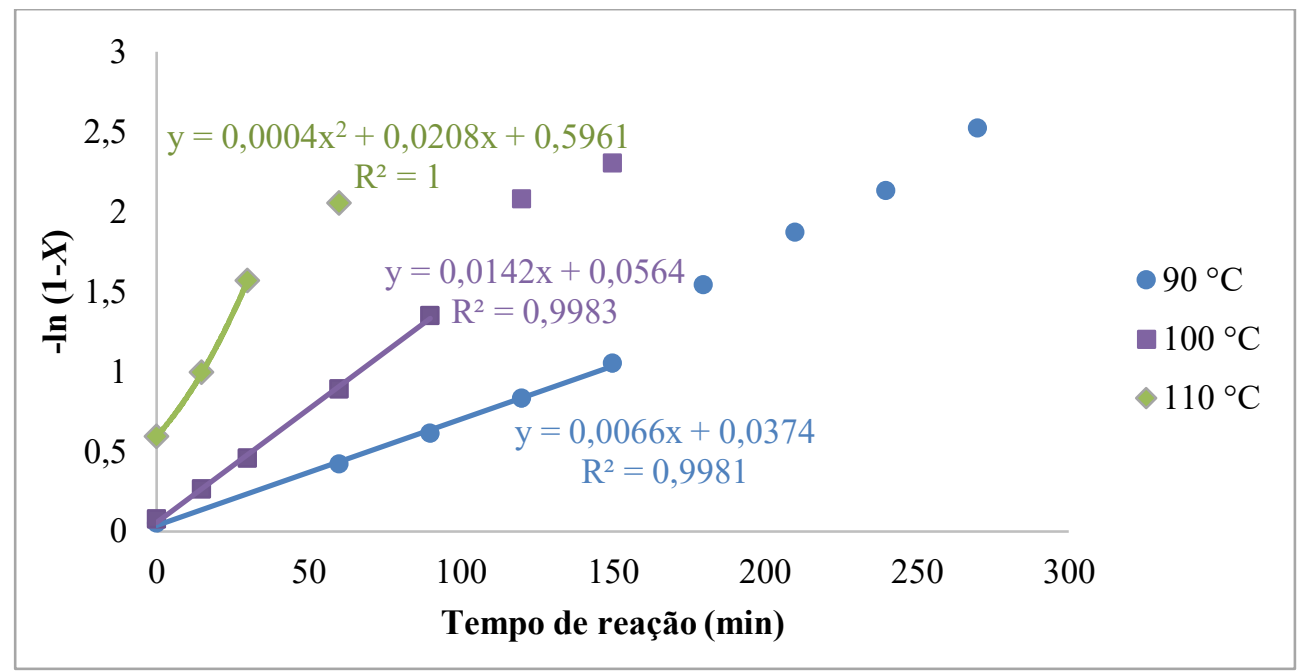

Fonte: Autora.

Nota: Ensaios realizados em batelada com alimentação de 1,5\% $\%(\mathrm{~m} / \mathrm{m})$ de frutose em DMSO e resina gelular SGC650H bruta como catalisador.

Na Figura 34, observa-se que houve dificuldade em ajustar os dados em uma regressão linear, assim foi dada preferência às regressões polinomiais, de acordo com a inclinação (derivada) em $t=0$ visualmente mais apropriada.

Com os valores das constantes cinéticas obtidas pela Equação (23), página 57, calcularam-se as constantes de taxa em termos da massa de catalisador pela Equação (20), página 57, cujos resultados são apresentados na Tabela 13.

Tabela 13 - Constantes de velocidade e parâmetros de Arrhenius da reação global de formação de HMF obtidos pelo método integral.

\begin{tabular}{|c|c|c|c|c|c|}
\hline \multirow{2}{*}{$\begin{array}{c}C_{F_{0}} \\
(\% \mathrm{~m} / \mathrm{m})\end{array}$} & \multicolumn{3}{|c|}{$k^{\prime} \cdot 10^{4}\left(\mathrm{~L}_{\mathrm{gcat}^{-1}}{ }^{-1} \cdot \mathrm{min}^{-1}\right)$} & \multirow{2}{*}{$E_{A}(\mathrm{~kJ} / \mathrm{mol})$} & \multirow{2}{*}{$\ln \left(k_{0}^{\prime}\right)$} \\
\hline & $90^{\circ} \mathrm{C}$ & $100{ }^{\circ} \mathrm{C}$ & $110^{\circ} \mathrm{C}$ & & \\
\hline 1,5 & 1,180 & 2,043 & 5,757 & 91,41 & 21,14 \\
\hline 3,0 & 1,069 & 1,969 & 5,095 & 90,14 & 20,65 \\
\hline 4,5 & 1,024 & 1,961 & 3,335 & 68,35 & 13,46 \\
\hline 13,5 & 0,917 & 1,632 & 2,543 & 59,07 & 10,28 \\
\hline $4,5^{*}$ & 8,670 & & & & \\
\hline
\end{tabular}

* Ensaio com catalisador moído

Fonte: Autora.

Os valores para as constantes de velocidade da reação em relação à massa de catalisador apresentados na Tabela 13 correspondem às análises qualitativas gráficas obtidas das Figuras 24 a 33 (páginas 69 a 76): constantes de taxa de reação maiores para temperaturas 
maiores de reação e para maior área superficial de catalisador, porém constantes menores para a alimentação de reagente em maiores concentrações.

Os parâmetros de Arrhenius apresentados na Tabela 13 foram obtidos a partir das constantes de velocidade da reação em termos de massa de catalisador, por meio dos gráficos de Arrhenius linearizados ilustrados na Figura 35.

Figura 35 - Regressão linear da equação de Arrhenius para os ensaios com diferentes concentrações de alimentação de frutose.

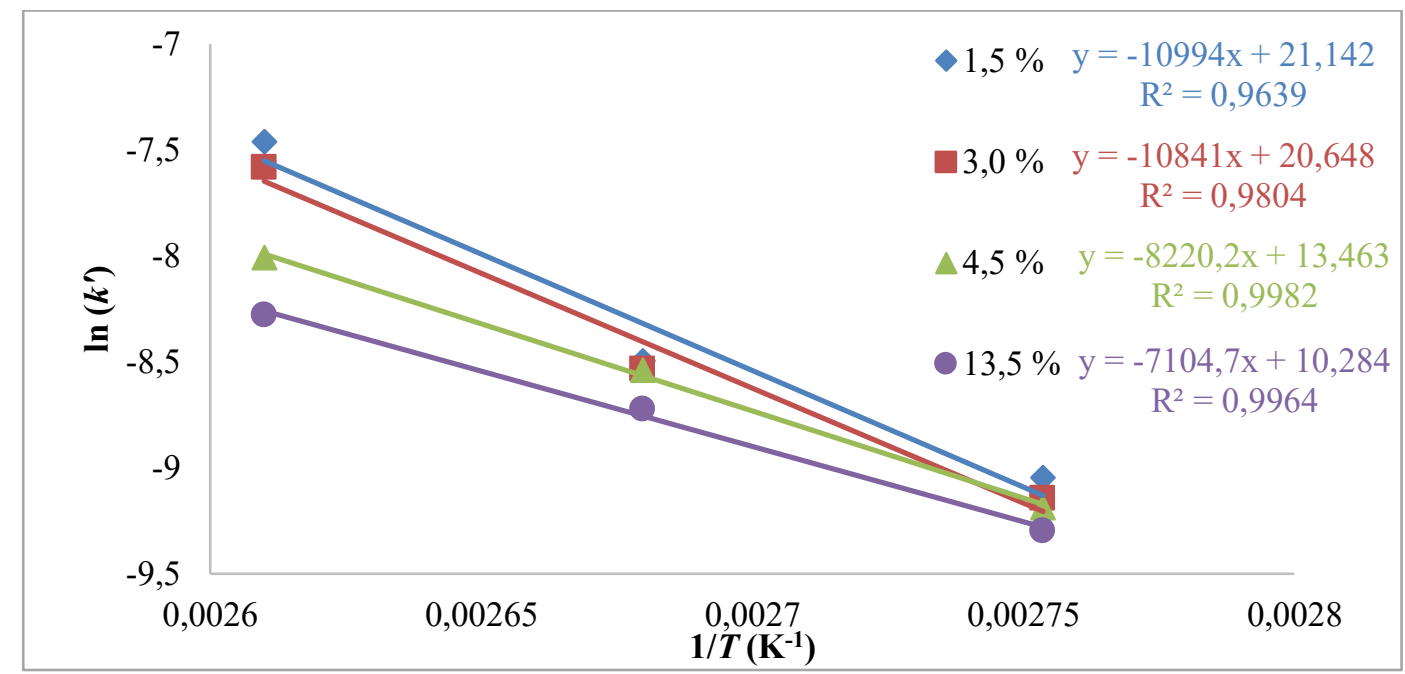

Fonte: Autora.

Nota: Ensaios realizados em batelada com resina gelular SGC650H bruta como catalisador e DMSO como solvente.

Observa-se que três das curvas apresentadas na Figura 35 têm uma tendência de haver uma intersecção em uma temperatura específica. Essa tendência é conhecida como fenômeno isocinético de compensação é confirmado pelo Diagrama de Cremer-Constable (Figura 36) que mostra uma tendência linear entre os valores obtidos de $\ln \left(k_{0}^{\prime}\right)$ e $E_{A}$. A variação dos valores de energia de ativação observada ocorre frequentemente em catálise heterogênea ao modificar variáveis controladas, neste caso, a concentração de reagente. Se essa variação for linear ao termo pré-exponencial $\ln \left(k_{0}^{\prime}\right)$, este comportamento é chamado de efeito de compensação, como pode ser verificado no gráfico de Cremer-Constable. Se a reação apresenta o efeito de compensação, as curvas do diagrama de Arrhenius para diferentes séries de dados (Figura 35) se cruzam em um mesmo ponto chamado de temperatura isocinética (BOND et al., 2000). 
Figura 36 - Diagrama de Cremer-Constable mostrando o efeito de compensação dos resultados para o reator em batelada.

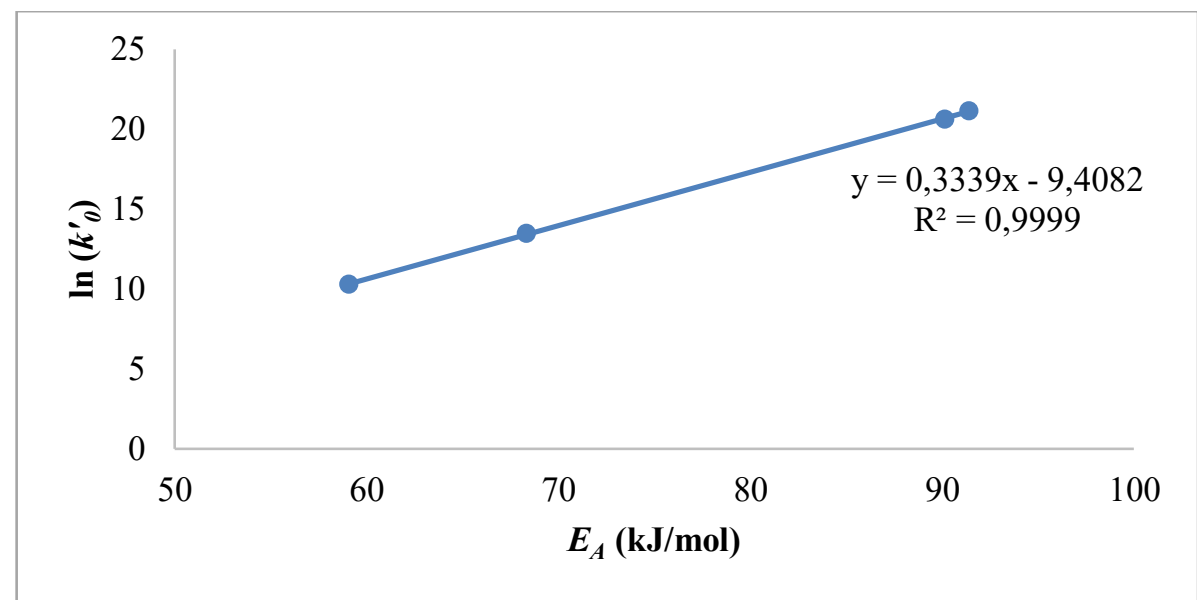

Fonte: Autora.

Nota: Ensaios realizados com alimentação de frutose, DMSO e resina gelular SGC650H bruta como catalisador.

Dentre as muitas possíveis causas para o efeito de compensação, podem-se citar as taxas das reações na superfície variando de modo diferente, visto que o mecanismo envolve a formação de intermediários; variação da concentração inicial de reagente, que não é a mesma de alimentação; reações paralelas de modo que a mesma reação ocorre em sítios diferentes do catalisador, ou entre sítios diferentes numa mesma molécula (FERREIRA; POÇO, 2014; POÇO; FURLAN; GIUDICI, 2002; GALWEY, 1997).

\subsubsection{Análise cinética da reação considerando o aquecimento}

Utilizando o método por otimização para simular a concentração do reagente, cujos gráficos são apresentados no Apêndice C, foi possível calcular os parâmetros de Arrhenius para a reação de pseudo primeira ordem, cujos valores são apresentados na Tabela 14 juntamente com os valores obtidos pelo método integral.

Tabela 14 - Comparação entre os parâmetros de Arrhenius para a reação de pseudo primeira ordem obtidas pelo método de Euler e pelo método integral.

\begin{tabular}{|c|c|c|c|c|c|c|}
\hline \multirow{2}{*}{$\begin{array}{c}C_{F_{0}} \\
(\% \mathrm{~m} / \mathrm{m})\end{array}$} & \multicolumn{3}{|c|}{ Energia de ativação (kJ/mol) } & \multicolumn{3}{|c|}{$\ln \left(k_{0}^{\prime}\right)$} \\
\hline & Otimização & Integral & Erro (\%) & Otimização & Integral & Erro (\%) \\
\hline 1,5 & 91,09 & 91,41 & 0,35 & 21,14 & 21,14 & 0,0000 \\
\hline 3,0 & 89,66 & 90,14 & 0,53 & 20,65 & 20,65 & 0,0000 \\
\hline 4,5 & 67,80 & 68,35 & 0,81 & 13,46 & 13,46 & 0,0000 \\
\hline 13,5 & 58,84 & 59,07 & 0,39 & 10,28 & 12,54 & 0,0081 \\
\hline
\end{tabular}

Fonte: Autora. 
Novamente, observou-se uma variação dos valores de energia de ativação linear para concentrações de alimentação diferentes, de modo que ocorre um efeito de compensação do termo pré-exponencial $\ln \left(k_{0}\right)$, conforme apresentado no gráfico de Cremer-Constable (Figura $37)$.

Figura 37 - Efeito de compensação dos resultados obtidos para o reator batelada.

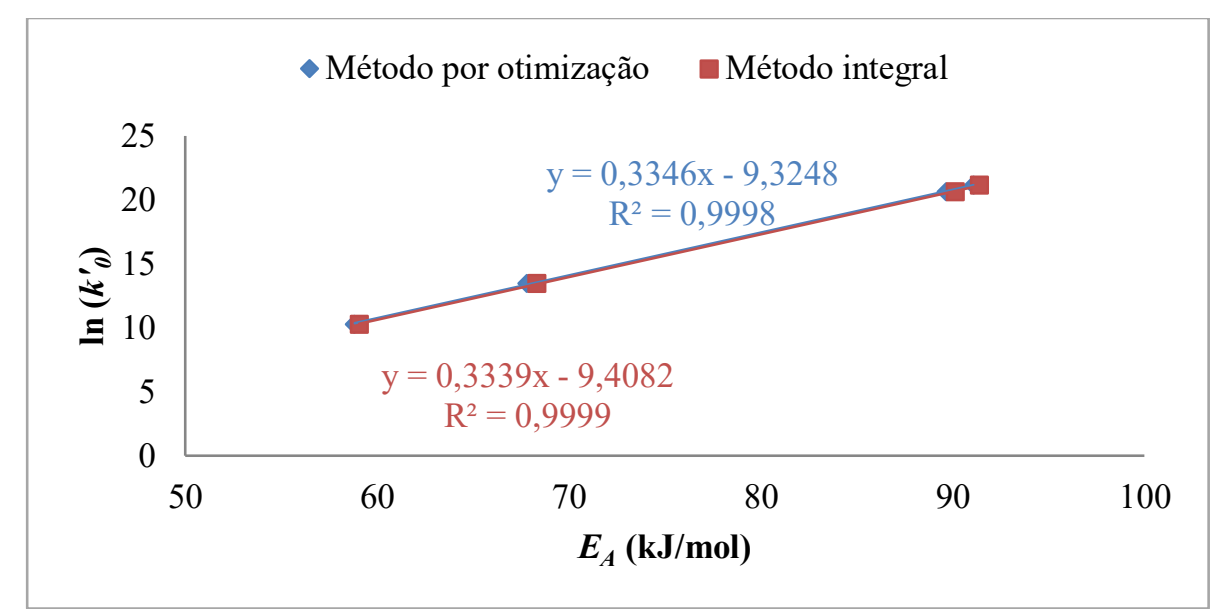

Fonte: Autora.

Nota: O método por otimização foi utilizado nos cálculos com variação de temperatura, enquanto o método integral, no instante inicial em que desconsiderava essa variação.

Os resultados de energia de ativação obtidos foram menores que o obtido por Moreau et al. (1996) de $141 \mathrm{~kJ} / \mathrm{mol}$ para a reação a $165^{\circ} \mathrm{C}$ catalisada por zeólitas, ou seja, as resinas precisam de uma quantidade menor de energia para ocorrência da reação, o que justifica o fato delas necessitarem de uma temperatura de reação menor para atingir altos valores de conversão quando comparadas às zeólitas.

\subsubsection{Mecanismo pelo método de reação da etapa limitante}

Ainda considerando o intervalo de reação isotérmica. O gráfico da taxa de reação inicial em função da concentração inicial do reagente é mostrado na Figura 38. Comparando-o à Figura 16 (página 60), é possível concluir que a dessorção do produto não é a etapa limitante, pois não apresentou perfis independentes de $C_{F_{0}}$. Porém os dados experimentais não permitiram inferir se a adsorção ou a reação na superfície é a limitante, de modo que as duas hipóteses foram testadas. 
Figura 38 - Gráfico da taxa inicial de reação em função da concentração inicial de frutose.

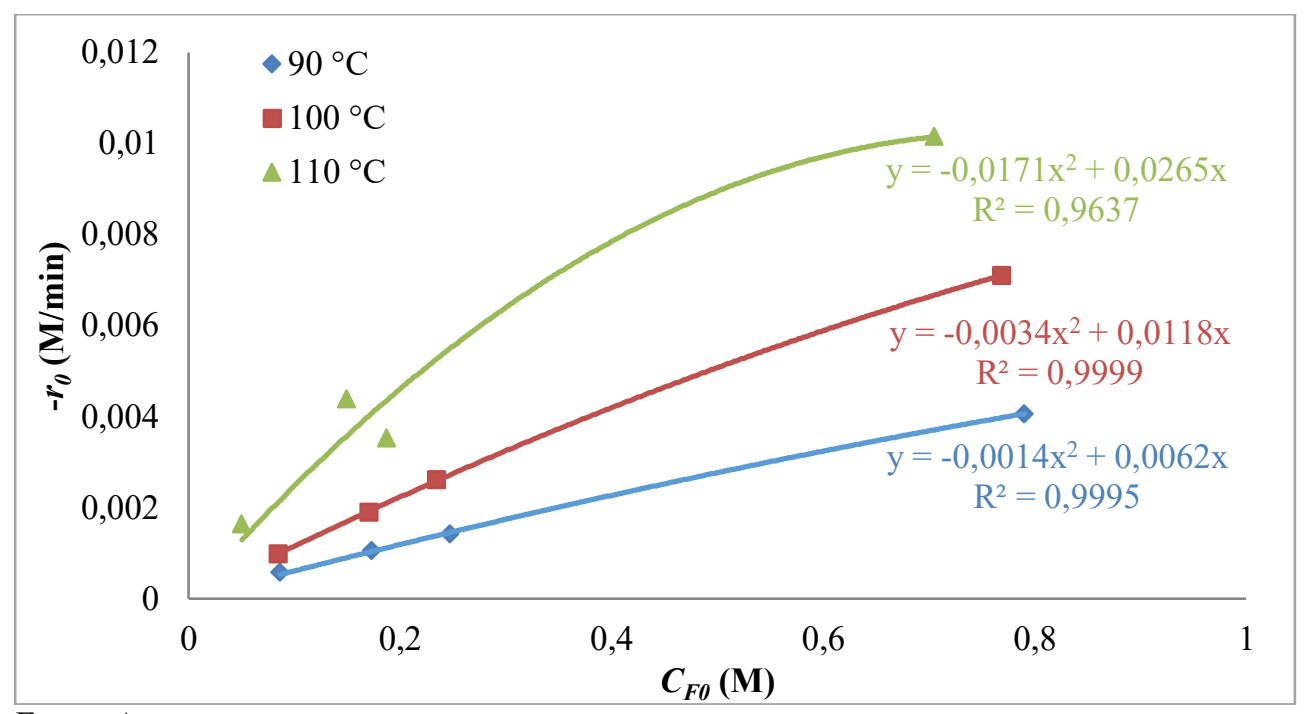

Fonte: Autora.

Nota: Ensaios realizados em batelada com alimentação de frutose, DMSO e resina gelular SGC650H bruta como catalisador.

Os possíveis modelos para as leis de velocidade na forma da Equação (35), página 61, são apresentados na Tabela 15, considerando que a reação global é irreversível.

Tabela 15 - Equações para as leis de velocidade baseados no modelo LHHW.

\begin{tabular}{lll}
\hline $\begin{array}{c}\text { ETAPA } \\
\text { LIMITANTE }\end{array}$ & MODELO \\
\hline \hline Adsorção & $-r_{F}=r_{a d s . F}=\frac{k_{a d s . F} \cdot C_{F}}{1+\frac{K_{a d s . F}}{K_{r . s .}} \cdot C_{H} \cdot C_{W}^{3}+K_{a d s . H} \cdot C_{H}+K_{a d s . W} \cdot C_{W}+K_{a d s . I} \cdot C_{I}}$ & $(37)$ \\
\hline Adsorção & $-r_{\text {ads.F }} \cdot C_{F}$ \\
\hline Adsorção & $-r_{a d s . F}=\frac{\left(1+\sqrt{\frac{K_{a d s . F}}{K_{r . s .}} \cdot C_{H} \cdot C_{W}^{3}}+K_{a d s . H} \cdot C_{H}+K_{a d s . W} \cdot C_{W}+K_{a d s . I} \cdot C_{I}\right)^{2}}{k_{a d s . F} \cdot C_{F}}$
\end{tabular}

Fonte: Autora “adaptado de” Froment, Bischoff e De Wilde, 2011.

Utilizando a ferramenta de Análise de Dados do Excel $^{\circledR}$ para fazer a regressão dos dados com $\frac{C_{F}}{-r_{F}^{\prime}}$ ou $\sqrt{\frac{C_{F}}{-r_{F}^{\prime}}}$ como variável dependente e $C_{F}, \sqrt{C_{F}}, C_{H}$ e $C_{I}$ como variáveis 
independentes, analisaram-se as correlações estatisticamente. Os modelos que consideraram a adsorção como etapa limitante não apresentaram variáveis estatisticamente significativas. Já os modelos para a reação na superfície como etapa limitante apresentaram significância apenas para a variável referente à concentração da frutose.

Pelo modelo da Equação (40), página 81, para reação na superfície limitante e sem a dissociação do reagente em dois sítios, obtiveram-se as constantes cinéticas apresentadas na Tabela 16.

Tabela 16 - Constantes cinéticas calculadas pelo modelo para reação na superfície limitante, sem adsorção da água e reação global irreversível.

\begin{tabular}{cccc}
\hline \hline $\boldsymbol{T}\left({ }^{\circ} \mathbf{C}\right)$ & 90 & 100 & 110 \\
\hline \hline $\boldsymbol{k}_{\text {r.s. }}\left[\mathbf{m o l}^{-1} \cdot \mathbf{m i n}^{-1}\right]$ & 0,0392 & 0,0675 & 0,0448 \\
\hline $\boldsymbol{K}_{\text {ads.F }}\left[\mathbf{L} \cdot \mathbf{m o l}^{-1}\right]$ & 0,1660 & 0,1768 & 0,6934 \\
\hline \hline
\end{tabular}

Fonte: Autora

Com os resultados da Tabela 16, foi possível montar os gráficos de Arrhenius e de Van’t Hoff apresentados na Figura 39.

Figura 39 - Gráficos de Arrhenius e de Van’t Hoff para reação na superfície limitante, sem dissociação do reagente.

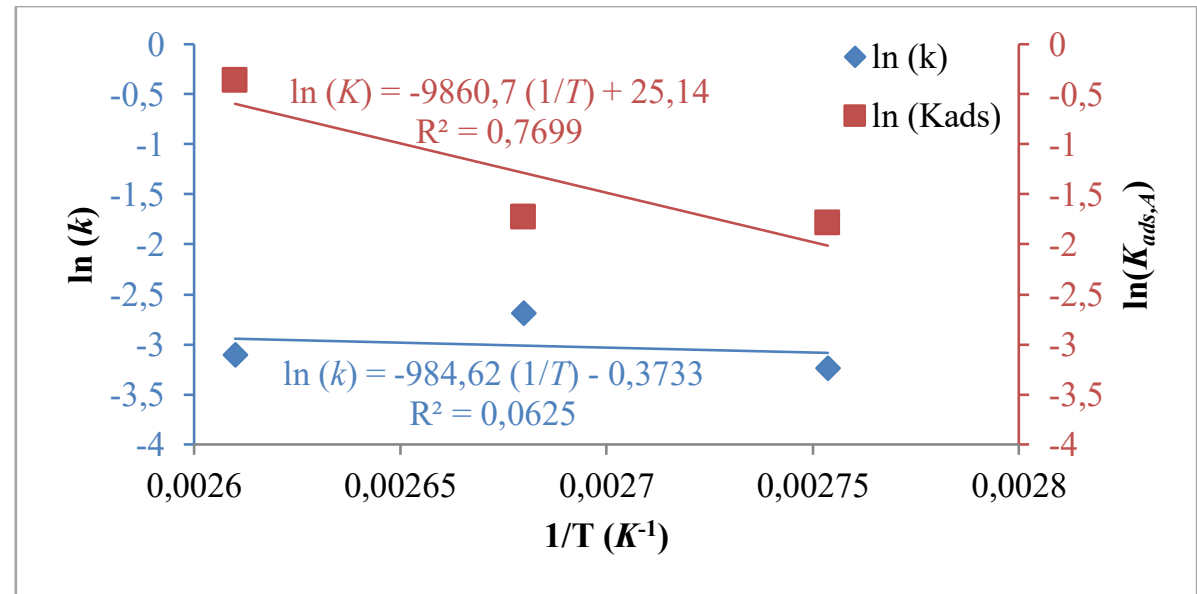

Fonte: Autora.

Nota: Ensaios realizados em batelada com alimentação de frutose, DMSO e resina gelular SGC650H bruta como catalisador.

Comparando a Figura 39 à Figura 17 (página 62), notou-se que o gráfico de Van’t Hoff obtido foi incoerente por apresentar coeficiente angular negativo, permitindo concluir que o modelo utilizado não é o correto. Tal comportamento foi observado também nos outros 
modelos estudados. Por este motivo, concluiu-se que o mecanismo da reação de desidratação da frutose é mais complexo, devendo-se realizar um estudo mais aprofundado para obter uma lei de velocidade que se aplique a qualquer condição de temperatura e concentração de substrato.

Visto que não houve ajuste dos dados experimentais aos modelos que consideram uma etapa limitante e a presença do efeito de compensação podem indicar uma reação superficial mais complexa com várias etapas. Os mecanismos propostos por Amarasekara, Williams e Ebede (2008), Kimura, Nakahara e Matubayasi (2013) e Zhang J. et al. (2016) mostram que a reação ocorre com formação de intermediários, de modo que a lei da velocidade talvez possa ser obtida utilizando a hipótese do estado pseudoestacionário (HEPE).

\subsection{ENSAIOS EM REATOR CONTÍNUO COM DMSO COMO SOLVENTE}

A utilização do reator contínuo mostrou-se vantajosa em relação ao reator em batelada, pois se garantiu que a concentração alimentada no reator já se encontrava na temperatura de reação. Isto foi possível devido ao arranjo experimental permitir a estabilização da temperatura de reação antes do contato entre reagente e catalisador, o que não foi possível no reator batelada.

\subsubsection{Efeitos da temperatura de reação e concentração de alimentação}

As conversões calculadas pela Equação (8), página 55, em função do tempo de residência no reator dos ensaios em reator contínuo com as condições indicadas na Tabela 7 (página 53) são apresentadas nas Figuras 40 e 41. 
Figura 40 - Conversão da frutose em função do tempo médio de residência em reator contínuo a diferentes temperaturas.

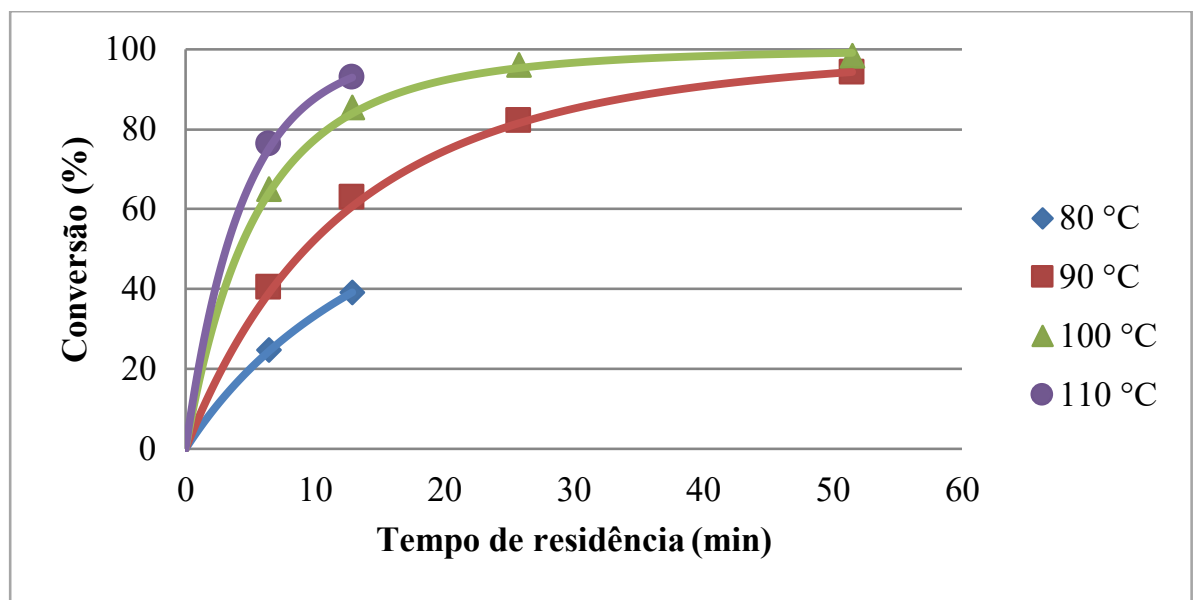

Fonte: Autora.

Nota: Ensaios realizados em reator contínuo com recheio de resina SGC650H bruta como catalisador e alimentação de $4,5 \%(\mathrm{~m} / \mathrm{m})$ de frutose em DMSO.

As curvas de conversão apresentadas mostram que a temperatura favorece a reação, ao contrário da concentração de alimentação da frutose, confirmando as conclusões obtidas pelos resultados do reator em batelada, nos quais as maiores conversões foram atingidas em um determinado tempo de residência no reator ao aumentar-se a temperatura. Por outro lado, o aumento da concentração alimentada reduziu a conversão em um mesmo tempo de residência, indicando uma possível saturação do catalisador ou o aumento da viscosidade da solução de alimentação que dificulta a transferência de massa.

Na Figura 41, é observado uma tendência menor de atingir-se $100 \%$ de conversão ao alimentar quantidades maiores de frutose, o que pode significar uma saturação do leito ou aumentar a formação de subprodutos, que além de ainda a menor seletividade a HMF, poderiam dificultar ou obstruir o acesso dos reagentes aos centros ativos. 
Figura 41 - Conversão da frutose em função do tempo médio de residência em reator contínuo para ensaios com diferentes alimentações de frutose e DMSO.

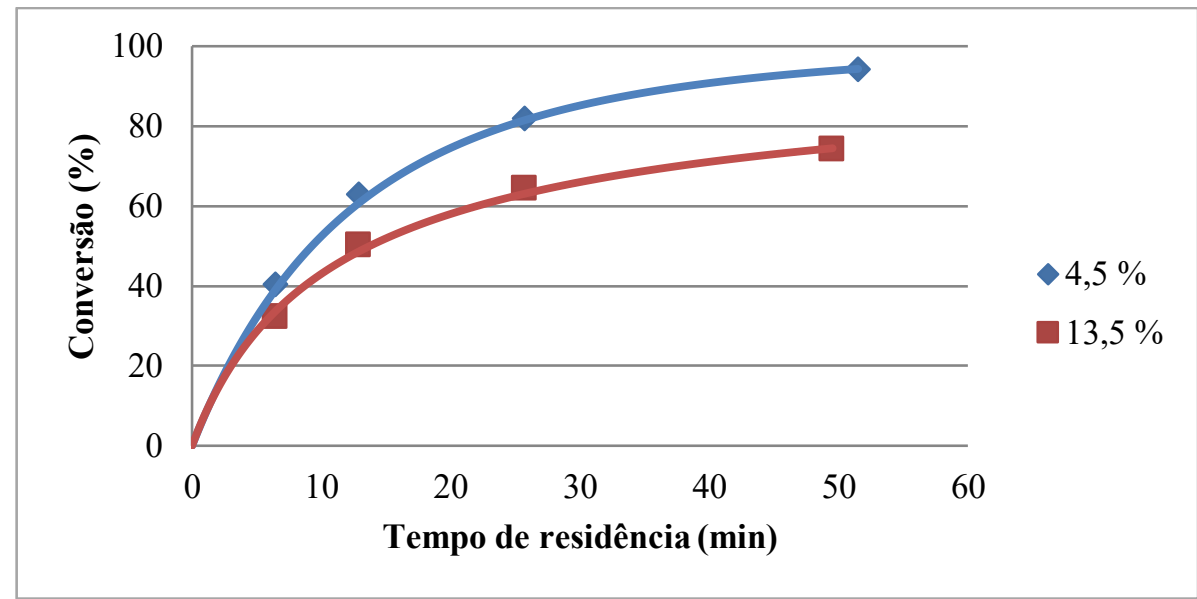

Fonte: Autora.

Nota: Ensaios realizados em reator contínuo com recheio de resina SGC650H bruta como catalisador e a $90^{\circ} \mathrm{C}$.

\subsubsection{Análise cinética da reação}

Pelo método integral, construíram-se os gráficos de $-\ln (1-X)$ versus $\tau$ exemplificados na Figura 42 pelas séries de dados com alimentação de 4,5 \% de frutose.

Figura 42 - Gráfico linearizado da conversão em função do tempo de permanência em reator contínuo a diferentes temperaturas.

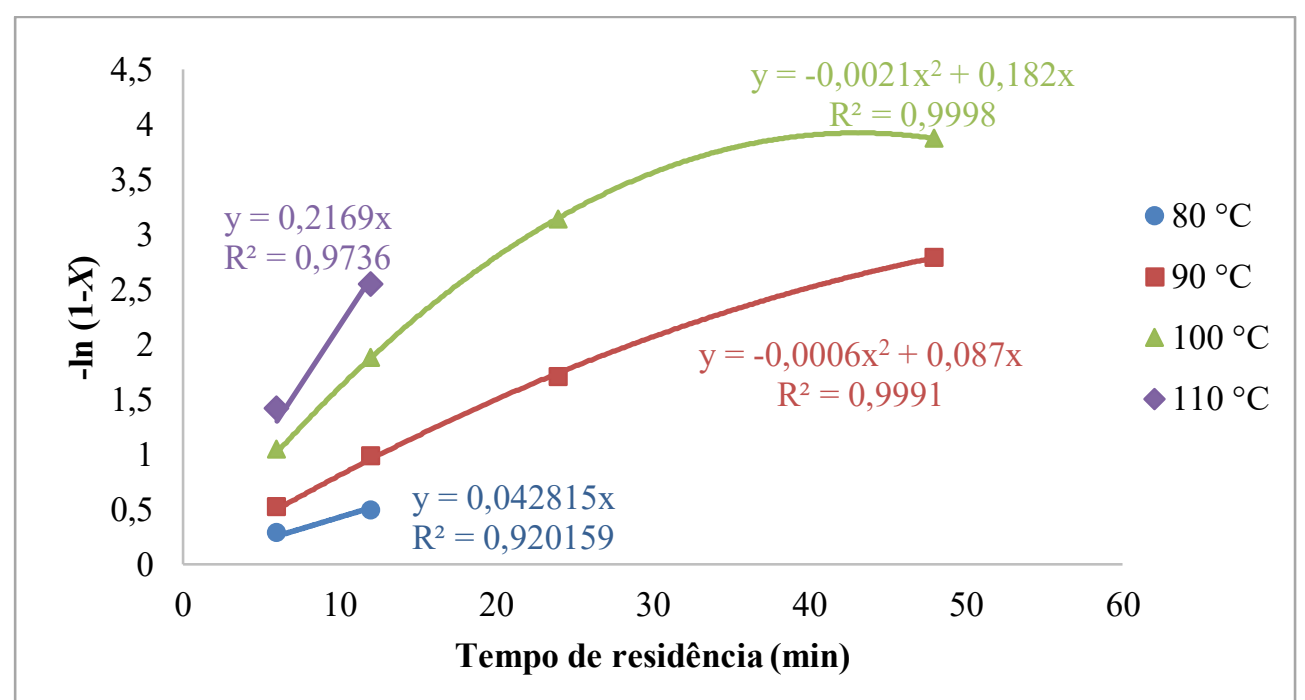

Fonte: Autora.

Nota: Ensaios realizados em reator contínuo com recheio de resina gelular SGC650H bruta como catalisador e alimentação de $4,5 \%(\mathrm{~m} / \mathrm{m})$ de frutose em DMSO. 
Os dados da Figura 42 mostram uma tendência à diminuição do valor da tangente com o aumento do tempo de residência. Comparando com os dados obtidos para o reator BTR, mostrados na Figura 34 (página 77), percebe-se que as curvas para o BTR possuem tangentes com tendência a aumentar ao longo do tempo de reação, de forma diferente à curva do PFR. Esta diferença mostrada pelo reator BTR está possivelmente relacionada com as características dos experimentos.

Os valores de $k$, constantes de taxa iniciais em termos da massa de catalisador, foram calculados a partir das tangentes das curvas da Figura 42 e são mostrados na Tabela 17 juntamente com os respectivos parâmetros de Arrhenius.

Tabela 17 - Constantes de velocidade e parâmetros de Arrhenius para a reação global de formação de HMF obtidos pelo método integral no reator contínuo.

\begin{tabular}{c|cccc|c|c}
\hline \hline \multirow{2}{*}{$\begin{array}{c}\boldsymbol{C}_{\boldsymbol{F}_{\mathbf{0}}} \\
(\mathbf{\%} \mathbf{m} / \mathbf{m})\end{array}$} & $80^{\circ} \mathrm{C}$ & $90{ }^{\circ} \mathrm{C}$ & $100{ }^{\circ} \mathrm{C}$ & $110^{\circ} \mathrm{C}$ & \multirow{2}{*}{$\begin{array}{c}\boldsymbol{E}_{\boldsymbol{A}} \\
(\mathbf{k J} / \mathbf{m o l})\end{array}$} & \multirow{2}{*}{$\ln \left(\boldsymbol{k}_{\mathbf{0}}^{\prime}\right)$} \\
\hline \hline $\mathbf{4 , 5}$ & 1,167 & 1,800 & 3,767 & 5,391 & 59,96 & 11,33 \\
\hline \hline $\mathbf{1 3 , 5}$ & 1,575 & & \\
\hline \hline
\end{tabular}

Fonte: Autora.

Comparando os dados das Tabelas 13 (página 77) e 17 (página 86), percebe-se que os valores das constantes cinéticas obtidas são menores para o reator batelada. Uma possível explicação para isso seria que elas foram calculadas no ponto inicial da reação, o qual foi melhor definido no reator contínuo, uma vez que não havia uma conversão de reagente durante o aquecimento do reator, logo os parâmetros obtidos para o reator contínuo foram considerados mais confiáveis.

Os valores dos parâmetros de Arrhenius obtidos no reator contínuo foram menores do que aqueles obtidos no reator batelada, no entanto esses dados ajustam no diagrama de Cremer-Constable contendo os dados do reator batelada, porém com uma possível tendência do valor parâmetro isocinético ser mais elevado (Figura 43). 
Figura 43 - Efeito de compensação dos resultados obtidos para os reatores batelada e contínuo.

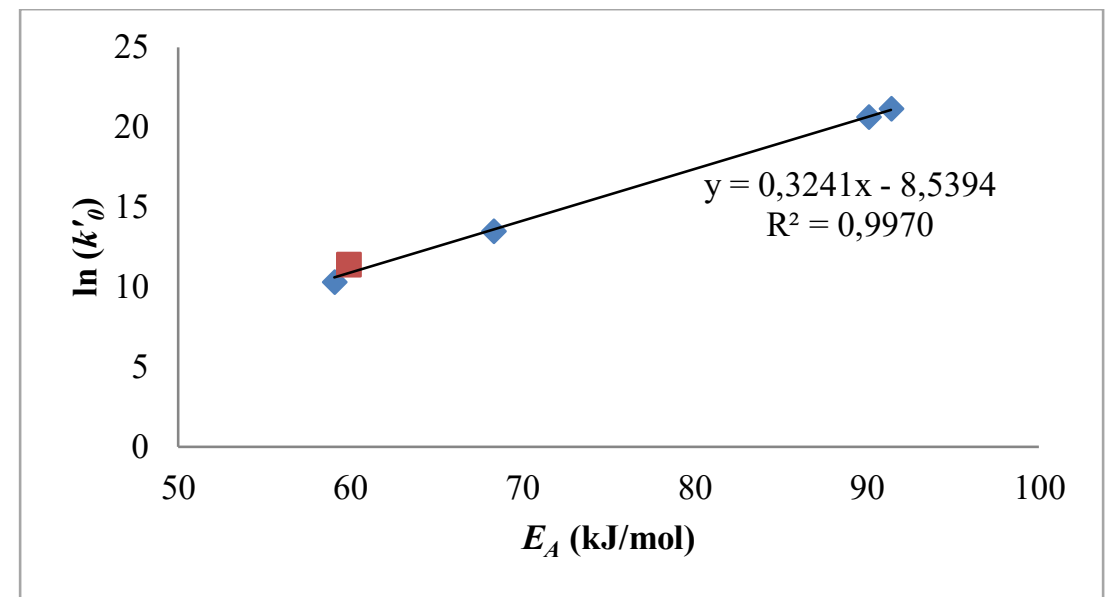

Fonte: Autora.

Nota: Os pontos azuis representam valores para o ensaio em batelada e o ponto vermelho, ensaio contínuo.

Os diagramas de Cremer-Constable permitiram o cálculo da temperatura isocinética através da relação utilizada por Poço, Furlan e Giudici (2002), de modo que se obteve um valor médio de $(90,5 \pm 6,5){ }^{\circ} \mathrm{C}$.

\subsubsection{Comparação entre reator batelada e contínuo}

Experimentos utilizando DMSO como solvente foram realizados nos dois tipos de reatores (batelada e contínuo), cujos resultados foram comparados como pode ser visualizado pela Figura 44.

Figura 44 - Gráficos para comparação de resultados para diferentes tipos de reator.

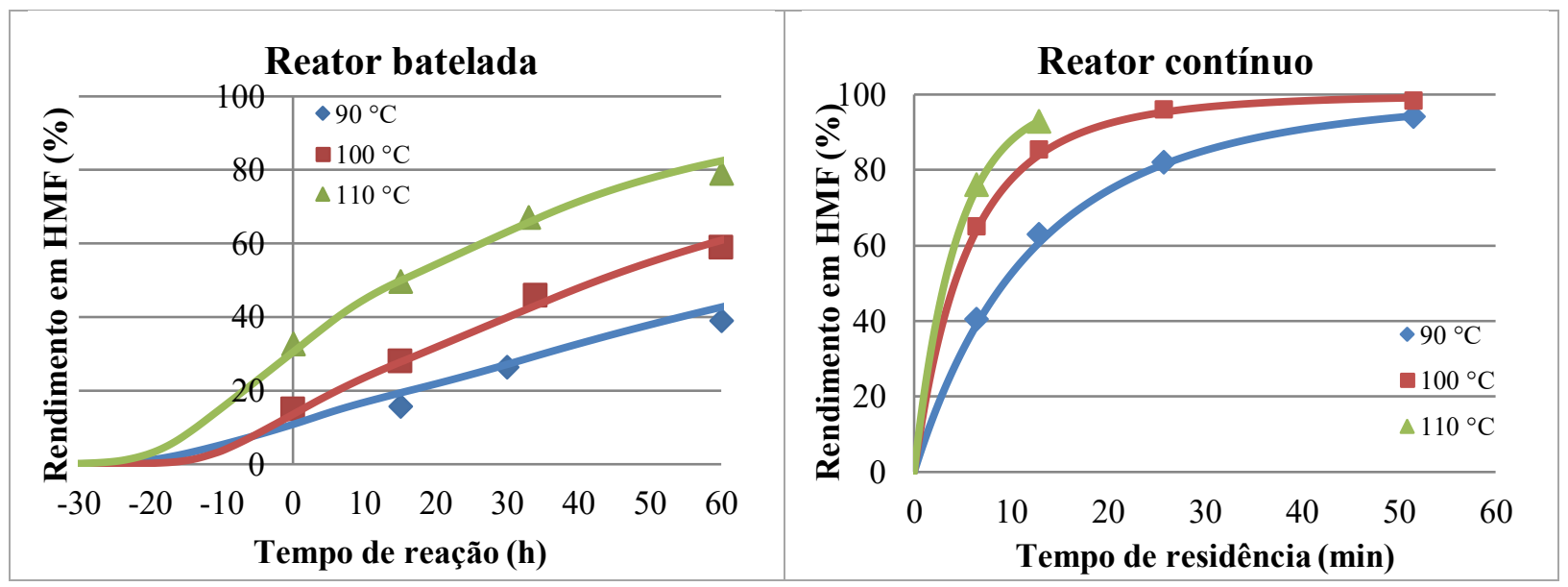

Fonte: Autora.

Nota: Ensaios realizados com alimentação de 4,5 \% (m/m) de frutose em DMSO e resina gel SGC650H bruta como catalisador. 
Comparando os resultados de cada reator, o reator contínuo apresentou a vantagem de estabilização da temperatura durante a reação. Além disso, pela Figura 44 foi possível perceber que suas taxas de reação foram maiores que no reator batelada, uma vez que o seu tempo necessário para atingir altos valores de rendimento foi maior, com valores acima de $74 \%$ em 20 min, em contraste aos valores abaixo de $55 \%$ em tempo equivalente para o reator batelada.

Comparando as equações de taxa e do ajuste pelo método integral de cada reator, resumidas na Tabela 18, sendo que a relação PBR:BTR foi obtida nos pontos de mesma conversão e concentração da frutose nos dois reatores, ou seja $X^{B T R}=X^{P B R}$ e $C_{F}^{B T R}=C_{F}^{P B R}$.

Tabela 18 - Equações para comparação entre reatores batelada e contínuo.

\begin{tabular}{ccc}
\hline \hline Reator batelada & Reator contínuo & Razão PBR:BTR \\
\hline \hline$r_{F}^{B T R}=-k^{\prime} \cdot C_{c a t}^{B T R} \cdot C_{F}^{B T R}{ }^{n}$ & $r_{F}^{P B R}=-k^{\prime} \cdot C_{c a t}^{P B R} \cdot C_{F}^{P B R^{n}}$ & $\frac{C_{c a t}^{P B R}}{C_{c a t}^{B T R}}=\frac{r_{F}^{P B R}}{r_{F}^{B T R}}$ \\
\hline$-\ln \left(1-X^{B T R}\right)=k^{\prime} \cdot C_{c a t}^{B T R} \cdot t^{B T R}$ & $-\ln \left(1-X^{P B R}\right)=k^{\prime} \cdot C_{c a t}^{P B R} \cdot \tau^{P B R}$ & $\frac{C_{c a t}^{P B R}}{C_{c a t}^{B T R}}=\frac{t^{B T R}}{\tau^{P B R}}$ \\
\hline \hline
\end{tabular}

Fonte: Autora.

Nota: Sobrescritos referentes às variáveis no respectivo reator, $B T R$ para o reator batelada e $P B R$ para o reator contínuo

A concentração de catalisador em base seca foi de $450,0 \mathrm{~g} / \mathrm{L}$ no reator contínuo e de aproximadamente $56,5 \mathrm{~g} / \mathrm{L}$ no batelada, portanto $C_{\text {cat }}^{P B R} / C_{\text {cat }}^{B T R}=8,0$, o que significa que, sob as mesmas condições de temperatura e concentração de alimentação, o tempo médio de residência necessário para atingir a mesma conversão é 8,0 vezes maior no reator batelada, enquanto a taxa de reação é 8,0 vezes maior no reator contínuo. Experimentalmente, confirmaram-se esses comportamentos, porém não esse valor, possivelmente devido à variação de temperatura no reator batelada.

Além disso, o fato da concentração de catalisador ser maior no reator contínuo diminui a probabilidade de ocorrência de reações homogêneas (na fase líquida), uma vez que seu volume é menor que no reator batelada e, como o tempo de contato necessário com o catalisador é menor para atingir mesmos valores de conversão, diminui também a probabilidade de ocorrência das reações consecutivas, principalmente da formação de huminas. 


\section{CONCLUSÕES}

O objetivo do presente projeto foi a obtenção de HMF com elevados rendimentos devido ao seu potencial como plataforma química. A seleção das condições de reação foi baseada na literatura, dando-se preferência à utilização de catalisadores heterogêneos.

A utilização de resinas de troca iônica com dois tipos de matrizes (gel e macroporosa) mostrou que a resina gel SGC650H apresentou resultados (conversão de frutose de $84 \%$, rendimento máximo de $20 \%$ para HMF e $50 \%$ para ácido levulínico) ligeiramente superiores quando comparados resina macroporosa CT275 (conversão de $74 \%$, rendimento máximo de $19 \%$ para HMF e $37 \%$ para ácido levulínico) em meio aquoso a $110{ }^{\circ} \mathrm{C}$.

Acompanhando a evolução das concentrações das substâncias durante a reação da frutose como substrato em meio aquoso, foi possível observar que o HMF é intermediário da reação de formação do ácido levulínico. Por este motivo, não foi possível obter altos rendimento e seletividade do HMF nessas condições, visto que sua hidrólise também é catalisada pelo mesmo tipo de catalisador formando os ácidos fórmico e levulínico.

A utilização da glicose como substrato apresentou conversão máxima de $9 \%$ e rendimentos menores que $1,5 \%$ para ácido levulínico e HMF durante $8 \mathrm{~h}$ de reação com quaisquer dos catalisadores em meio aquoso a $110^{\circ} \mathrm{C}$. Isso comprova que a reação de formação do HMF parte da frutose, e que a sua síntese a partir da glicose não é direta, demandando uma etapa de isomerização anterior.

Utilizando a frutose como reagente, SGC650H como catalisador e DMSO como solvente permitiram obter elevados rendimentos a HMF que virtualmente chegaram a $100 \%$ após $3 \mathrm{~h}$ de reação a $110^{\circ} \mathrm{C}$.

Notou-se que o comportamento da reação é favorecido ao aumentar a taxa de reação quando há o aumento da temperatura, a redução do tamanho da partícula do catalisador ou a utilização de reator tubular contínuo (PBR) ao invés de batelada (BTR), porém a taxa diminui para maiores concentrações de substrato (frutose).

As constantes de velocidade da reação obtidas pelo método integral para o PBR foram maiores que para o BTR, o que pode ser explicado pelo método de cálculo empregado que determina a constante de taxa no ponto inicial da reação. Este ponto inicial no reator batelada já apresenta consumo do reagente, de modo que a reação já se encontrava em um estágio mais avançado, onde a taxa de reação já é menor. Apesar de ter sido possível conseguir conclusões importantes a partir dos resultados do reator batelada, a análise cinética necessita de um estudo dos comportamentos variáveis de temperatura e concentração de catalisador melhor 
definidos. Tendo em vista a maior facilidade de determinação de dados cinéticos usando o reator de fluxo contínuo, a continuação desses ensaios com diferentes temperaturas e concentrações de alimentação facilitaria o desenvolvimento de uma lei de velocidade.

Os parâmetros de Arrhenius calculados para cada concentração de alimentação de frutose apresentaram uma variação característica conhecida como efeito de compensação. Essa variação dos parâmetros obtidos indicou que os valores calculados são aparentes e que o modelo adotado de cinética de pseudo primeira ordem é insuficiente para descrever a reação, pois deve haver outros fatores relevantes para a reação e devem ser considerados na lei de velocidade.

Aplicando o método de reação da etapa limitante (RLS) considerando a abordagem de Langmuir-Hinshelwood (LHHW) com os dados experimentais obtidos no BTR foi possível concluir que a dessorção do HMF não é a etapa limitante, porém não foi possível definir uma etapa limitante com os dados disponíveis e assim não se obteve modelo cinético com valores significativos para a reação heterogênea através da metodologia empregada. Como não se encontrou um mecanismo para a reação catalítica heterogênea, outro método poderia ser utilizado partindo da hipótese de estado pseudoestacionário (HEPE) para obter a lei de velocidade ao considerar reações em série e em paralelo. Para isto, sugere-se a utilização de um reator com reciclo em que as concentrações seriam analisadas em regime permanente. 


\section{REFERÊNCIAS}

AMARASEKARA, A. S.; WILliAMS, L. D.; EBEDE, C. C. Mechanism of the dehydration of D-fructose to 5-hydroxymethylfurfural in dimethyl sulfoxide at $150{ }^{\circ} \mathrm{C}$ : an NMR study. Carbohydrate Research, v. 343, p. 3021-3024, 2008.

ANEEL - Agência Nacional de Energia Elétrica. Atlas de energia elétrica do Brasil. 3. ed. Brasília, 2008.

ANTAL, M. J.; MOK Jr., W. S. L.; RICHARDS, G. Mechanism of formation of 5(hydroxymethyl)-2-furaldehyde from D-fructose and sucrose. Carbohydrate Research, $\mathrm{n}$. 199, p. 91-109, 1990.

ARMAROLI, T. et al. Acid sites characterization of niobium phosphate catalysts and their activity in fructose dehydration to 5-hydroxymethyl-2-furaldehyde. Journal of Molecular Catalysis A: Chemical, n. 151, p. 233-243, 2000.

ASGHARI, F. S.; YOSHIDA, H. Dehydration of fructose to 5-hydroxymethylfurfural in subcritical water over heterogeneous zirconium phosphate catalysts. Carbohydrate Research, v. 341, p. 2379-2387, 2006.

BIO-RAD LABORATORIES, INC. Guidelines for use and care of Aminex ${ }^{\circledR}$ resin-based columns: instruction manual. 2015.

BOND, G. C. et al. Compensation phenomena in heterogeneous catalysis: General principles and a possible explanation. Catalysis Reviews: Science and Engineering, v. 42, n. 3, p. 323$383,2000$.

CARLINI, C. et al. Selective saccharides dehydration to 5-hydroxymethyl-2-furaldehyde by heterogeneous niobium catalysts. Applied Catalysis A: General, v. 183, p. 295-302, 1999.

CARNITI, P. et al. Niobic acid and niobium phosphate as highly acidic viable catalysts in aqueous medium: Fructose dehydration reaction. Catalysis Today, v. 118, p. 373-378, 2006.

et al. Absence of expected side-reactions in the dehydration reaction of fructose to HMF in water over niobic acid catalyst. Catalysis Communications, v. 12, p. 1122-1126, 2011.

CHINNAPPAN, A. et al. Ionic liquid with metal complexes: An efficient catalyst for selective dehydration of fructose to 5-hydroxymethylfurfural. Chemical Engineering Journal, v. 237, p. 95-100, 2014.

CONSTANTINIDES, A.; MOSTOUFI, N. Numerical methods for chemical engineers with MATLAB applications. New Jersey: Prentice-Hall, 1999.

CRISCI, A. J. et al. Bifunctional Solid Catalysts for the Selective Conversion of Fructose to 5-Hydroxymethylfurfural. Topics in Catalysis, n. 53, p. 1185-1192, 2010. 
DAL SANTO, V. et al. Design and Use of Nanostructured Single-Site Heterogeneous Catalysts for the Selective Transformation of Fine Chemicals. Molecules, v. 15, p. 38293856, 2010.

EPA - Agência de Proteção Ambiental dos Estados Unidos. Green Chemistry. 2016. Disponível em: <https://www.epa.gov/greenchemistry>. Acesso em: 20 abr. 2016.

ERTL, G.; KNÖZINGER, H.; SCHÜTH, F.; WEITKAMP, Jens (Ed.). Handbook of heterogeneous catalysis. 2. ed. rev. and enl. Weinheim: Wiley-VCH, 2008.

FAN, C. et al. Conversion of fructose and glucose into 5-hydroxymethylfurfural catalyzed by a solid heteropolyacid salt. Biomass and Bioenergy, v. 35, p. 2659-2665, 2011.

FANG, Z. et al. Efficient conversion of carbohydrates into 5-hydroxymethylfurfural catalyzed by the chromium-exchanged montmorillonite K-10 clay. Biomass and Bioenergy, v. 60, p. 171-177, 2014.

FERREIRA, P.E.; POÇO, J. G. R. Efeito cinético de compensação observado na reação de cura de resina epóxi (DGEBA) com dicianodiamida. In: CONGRESSO BRASILEIRO DE ENGENHARIA QUÍMICA, 20., 2014, Florianópolis. Anais... Florianópolis: [s.n.], 2014.

FERREIRA, V. F.; ROCHA, D. R.; SILVA, F. C. Potencialidades e oportunidades na química da sacarose e outros açúcares. Química Nova, v. 32, n. 3, p. 623-638, 2009.

FOGLER, H. S. Cálculo de reatores: o essencial da engenharia das reações químicas. $1 .^{\circ} \mathrm{ed}$. Rio de Janeiro: LTC, 2014.

FROMENT, G. F.; BISCHOFF, K. B.; DE WILDE, J. Chemical reactor analysis and design. 3. ed. New Jersey: Chichester: John Wiley, 2011.

GALLO, J. M. R. et al. Production and upgrading of 5-hydroxymethylfurfuralusing heterogeneous catalysts and biomass-derived solvents. Green Chemistry, v. 15, p. 85-90, 2013.

GALWEY, A. K. Compensation behaviour recognized in literature reports of selected heterogeneous catalytic reactions: aspects of the comparative analyses and significance of published kinetic data. Thermochimica Acta, v. 294, p. 205-219, 1997.

GATES, B. C. Catalytic Chemistry. New York: Wiley, 1992.

GOMIDE, R. Operações unitárias: operações com sistemas sólidos granulares. São Paulo: Edição do autor, 1980. V. 1.

GUCBILMEZA, Y.; DOGUA, T.; BALCI, S. Vanadium incorporated high surface area MCM-41 catalysts. Catalysis Today, v. 100, p. 473-477, 2005.

HELFFERICH, F. G. Ion Exchange. New York: McGraw-Hill, 1989. 
HUO, Q.; MARGOLESE, D.; STUCKY, G. D. Surfactant Control of Phases in the Synthesis of Mesoporous Silica-Based Materials. Chemistry of Materials, v. 8, n. 5, p. 1147-1160, 1996.

IEA - Agência Internacional de Energia. World Energy Outlook 2016 sees broad transformations in the global energy landscape. 2016. Disponível em:

$<$ https://www.iea.org/newsroom/news/2016/november/world-energy-outlook-2016.html $>$. Acesso em: 05 fev. 2017.

IPCC - Painel Intergovenamental sobre Mudanças Climáticas. Climate Change 2014:

Mitigation of Climate Change. 2014. Disponível em: <https://www.ipcc.ch/report/ar5/wg3/>. Acesso em: 05 fev. 2017.

JAIN, A. et al. Conversion of fructose, glucose and sucrose to5-hydroxymethyl-2-furfural over mesoporous zirconium phosphate catalyst. Applied Catalysis A: General, v. 489, p. 72$76,2015$.

JIAN-WEN, D. et al. Pilot synthesis and commercial application in FCC catalyst of MCM-41 zeolite. Journal of Porous Materials, v. 15, p. 189-197, 2008.

JIANG, N. et al. Effect of formic acid on conversion of fructose to 5-hydroxymethylfurfural in aqueous/butanol media. Bioenergy Research, v. 5, p.380-386, 2012.

JIMÉNEZ-MORALES, I. et al. Production of 5-hydroxymethylfurfural from glucose using aluminium doped MCM-41 silica as acid catalyst. Applied Catalysis B: Environmental, v. 164, p. 70-76, 2015.

KIMURA, H.; NAKAHARA, M.; MATUBAYASI, N. Solvent Effect on Pathways and Mechanisms for D-Fructose Conversion to 5-Hydroxymethyl-2-furaldehyde: In Situ ${ }^{13} \mathrm{C}$ NMR Study. The Journal of Physical Chemistry A, v. 117, p. 2102-2113, 2013.

KIMURA, V.T. et al.Obtenção de ácido levulínico e 5-HMF de açúcares oriundos de biomassa renovável com catalisadores heterogêneos.In: CONGRESSO BRASILEIRO DE ENGENHARIA QUÍMICA INICIAÇÃO CIENTÍFICA (COBEQ-IC), 10., 2013, Vassouras. Anais...Vassouras, RJ: [s.n.], 2013.

KIMURA, V.T. et al. Estudo da obtenção de ácido levulínico a partir de matérias-primas renováveis utilizando catalisadores ácidos heterogêneos - Mecanismo. In: ENCONTRO REGIONAL DE CATÁLISE (ERCAT), 21., 2014, Campinas. Anais...Campinas: [s.n.], 2014a.

KIMURA, V.T. et al.Obtenção de ácido levulínico e outros produtos a partir de açúcares usando catalisadores heterogêneos. In: CONGRESSO BRASILEIRO DE ENGENHARIA QUÍMICA (COBEQ), 20., 2014, Florianópolis. Anais...Florianópolis: [s.n.], 2014b.

KIRK, R. E.; OTHMER, D. F. Encyclopedia of chemical technology. 2. ed. rev. New York; London: John Wiley, 1963. 
KRUGER, J. S.; NIKOLAKIS, V.; VLACHOS, D. G. Aqueous-phase fructose dehydration using Brønsted acid zeolites: Catalytic activity of dissolved aluminosilicate species. Applied Catalysis A: General, v. 469, p. 116-123, 2014.

KUSTER, B. F. M. 5-Hydroxymethylfurfural (HMF): a review focusing on its manufacture. Starch/Stärke, n. 42, p. 314-321, 1990.

Kung Fu Panda 3. Direção de Jennifer Yuh Nelson e Alessandro Carloni. Produção de Melissa Cobb. Glendale: DreamWorks Animation, 2016. DVD.

KUNZ, M. Hydroxymethylfurfural, a possible basic chemical for industrial intermediates. Studies in Plant Science, v. 3, p. 149-160, 1993.

LANSALOT-MATRAS, C.; MOREAU, C. Dehydration of fructose into 5hydroxymethylfurfural in the presence of ionic liquids. Catalysis Communications, v. 4, p. 517-520, 2003.

LABSYNTH. Ficha de informações de segurança de produtos químico: dimetilsulfóxido. 2014. Disponível em: <http://downloads.labsynth.com.br/FISPQ/rv2012/FISPQ\%20Dimetilsulfoxido.pdf>. Acesso em: 06 set. 2016.

LEVENSPIEL, Octave. Engenharia das reações químicas. 3. ed. São Paulo: Edgard Blücher, 2000.

LIU, B. et al. Effective conversion of carbohydrates into biofuel precursor 5hydroxymethylfurfural (HMF) over Cr-incorporated mesoporous zirconium phosphate. Industrial Crops and Products, v. 76, p. 781-786, 2015.

LUCAS, N. et al. Dehydration of fructose to 5-hydroxymethyl furfural over ordered AlSBA15 catalysts. Microporous and Mesoporous Materials, v. 181, p. 38-46, 2013.

MENDES, L. V. P. Produção de 5-hidroximetilfurfural por desidratação da frutose através da catálise heterogênea e homogênea. Dissertação (Mestrado em Tecnologia de Processos Químicos e Bioquímicos) - Universidade Federal do Rio de Janeiro, Escola de Química, Rio de Janeiro, 2012.

MILCENT, P. F.; CORRÊA, J. B. C. Produção do açúcar invertido por catálise heterogênea em leito de resina trocadora de íons. Boletim do Centro de Pesquisa e Processamento de alimentos - B.CEPPA, v. 9, n. 2, p. 79-105, 1991.

MOREAU, C. et al. Dehydration of fructose to 5-hydroxymethylfurfural over H-mordenites. Applied Catalysis A: General, n. 145, p. 211-224, 1996.

et al. Isomerization of glucose into fructose in the presence of cation-exchanged zeolites and hydrotalcites. Applied Catalysis A: General, n, 193, p. 257-264, 2000.

; FINIELS, A., VANOYE, L. Dehydration of fructose and sucrose into 5hydroxymethylfurfural in the presence of 1-H-3-methyl imidazolium chloride acting both as solvent and catalyst. Journal of Molecular Catalysis A: Chemical, n. 253, p. 165-169, 2006. 
MUSAU, R. M.; MUNAVU, R. M. The preparation of 5-hydroxymethyl-2-furaldehyde (HMF) from D-fructose in the presence of DMSO. Biomass, n. 13, p. 67-74, 1987.

NCBI - National Center for Biotechnology Information. PubChem Compound Database: 5hydroxymethylfurfural. Disponível em:

$<$ https://pubchem.ncbi.nlm.nih.gov/compound/237332>. Acesso em: 17 out. 2016.

OHARA, M. et al. Syntheses of 5-hydroxymethylfurfural and levoglucosan by selective dehydration of glucose using solid acid and base catalysts. Applied Catalysis A: General, n. 383, p. 149-155, 2010.

O'NEILL, R. et al. Kinetics of Aqueous Phase Dehydration of Xylose into Furfural Catalyzed by ZSM-5 Zeolite. Industrial \& Engineering Chemistry Research, v. 48, p. 4300-4306, 2009.

ORDOMSKY, V. V. et al. The effect of solvent addition on fructose dehydration to 5hydroxymethylfurfural in biphasic system over zeolites. Journal of Catalysis, n. 287, p. 68$75,2012$.

PATIL, S. K. R.; LUND, C. R. F. Formation and growth of humins via aldol addition and condensation during acid-catalyzed conversion of 5-hydroxymethylfurfural. Energy Fuels, n. 25, p. 4745-4755, 2011.

PAG N-TORRES, Y. J. et al. Production of 5-hydroxymethylfurfural from glucose using a combination of Lewis and Brønsted acid catalysts in water in a biphasic reactor with an alkylphenol solvent. ACS Catalysis, n. 2, p. 930-934, 2012.

POÇO, J. G. R.; FURLAN, H.; GIUDICI, R. A discussion on kinetic compensation effect and anisotropy. The Journal of Physical Chemistry B, v. 106, n. 18, p. 4873-4877, 2002.

et al. Avaliação de rotas de produção de ácido levulínico (“building block”) a partir de fontes renováveis. Relatório Técnico do Instituto de Pesquisas Tecnológicas do Estado de São Paulo (IPT). n. 140 697-205. Diretoria de Operações e Negócios - DON. 2014

PUROLITE. Purolite CT275: macroporous strong acid resin catalyst. 2016a. Disponível em: $<$ http://www.purolite.com/relid/619234/isvars/default/strong_acid_cation_gel.htm $>$. Acesso em: 03 mar. 2016.

. Supergel ${ }^{\text {TM }}$ SGC650H: gel strong acid cation resin - hydrogen form, uniform particle size. 2016b. Disponível em: <http://www.purolite.com/default.aspx?RelID=619149>. Acesso em: 03 mar. 2016.

RACKEMANN, D. W.; DOHERTY, W. O. S. The conversion of lignocellulosics to levulinic acid. Biofuels, Bioprod. Bioref, n. 5, p. 198-214, 2011.

RANOUX, A. et al. 5-Hydroxymethylfurfural synthesis from hexoses is autocatalytic. ACS Catalysis, n. 3, p. 760-763, 2013.

RASRENDRA, C. B. et al. The catalytic conversion of D-glucose to 5-hydroxymethylfurfural in DMSO using metal salts. Topics in Catalysis, n. 55, p. 543-549, 2012. 
SHIMADZU DO BRASIL. Prominence HPLC. 2016. Disponível em:

$<$ http://www.shimadzu.com.br/analitica/produtos/hplc/prominence_hplc/prominence_hplc.sht $\mathrm{ml}>$. Acesso em: 03 set. 2016.

. Shimadzu HPLC Colmuns. Disponível em:

<http://partoz.com/pdf/Chromatographs/HPLC\%20Columns.pdf>. Acesso em: 03 set. 2016.

SHIMIZU, K.; UOZUMI, R.; SATSUMA, A. Enhanced production of hydroxymethylfurfural from fructose with solid acid catalysts by simple water removal methods. Catalysis

Communications, v. 10, p. 1849-1853, 2009.

SIGMA-ALDRICH Co. LCC. Ficha de informações de segurança de produtos químico: 5(hidroximetil) furfural 99\%. 2015. Disponível em:

$<$ http://www.sigmaaldrich.com/catalog/product/aldrich/h40807?lang=pt\&region=BR $>$.

Acesso em: 06 set. 2016.

SIMEONOV, S. P.; AFONSO, C. A. M. Batch and flow synthesis of

5-hydroxymethylfurfural (HMF) from fructose as a bioplatform intermediate: An experiment for the organic or analytical laboratory. Journal of Chemical Education, v. 90, p. 1373$1375,2013$.

STARK, A. et al. Biomass-derived platform chemicals: thermodynamic studies on the extraction of 5-hydroxymethylfurfural from ionic liquids. Journal of Chemical and Engineering Data, n. 57, p. 2985-2991, 2012.

SWIFT, T. D. et al. Tandem Lewis acid/Brønsted acid-catalyzed conversion of carbohydrates to 5-hydroxymethylfurfural using zeolite beta. Journal of Catalysis, n. 333, p. 149-161, 2016.

TAKAGAKI, A.; NISHIMURA, S.; EBITANI, K. Catalytic transformations of biomassderived materials into value-added chemicals. CatalSurv Asia, v. 16, p.164-182, 2012.

TEIMOURI, A. et al. Catalytic conversion of glucose to 5-hydroxymethylfurfural (HMF) using nano-POM/nano- $-\mathrm{ZrO}_{2} /$ nano- $\gamma-\mathrm{Al}_{2} \mathrm{O}_{3}$. Journal of the Taiwan Institute of Chemical Engineers, v. 49, p. 40-50, 2015.

TONG, X.; MA, Y.; LI, Y. Biomass into chemicals: Conversion of sugars to furan derivatives by catalytic processes. Applied Catalysis A: General, v. 385, p. 1-13, 2010.

ULLMANN'S Encyclopedia of Industrial Chemistry. 7th Ed. completely rev. Weinheim: $\mathrm{VCH}, \mathrm{c} 2011.40 \mathrm{v}$.

UNIVERSIDADE FEDERAL DO ESPÍRITO SANTO. Coluna analítica Shim-pack CLCODS (M) ${ }^{\circledR}$ C18 Shimadzu. 2013. Disponível em: $<$ labiom.ufes.br/coluna-anal\%C3\%ADticashim-pack-clc-odsm®-c18-shimadzu>. Acesso em: 03 set. 2016.

VAN PUTTEN, R. et al. Hydroxymethylfurfural, a versatile platform chemical made from renewable resources. Chemical Reviews, v. 113, p. 1499-1597, 2013. 
WERPY, T. A.; PETERSEN, G. Top value added chemicals from biomass. Technical Report of U.S. Department of Energy (DOE), Golden, CO. v. 1, 2004. Disponível em: $<$ http://www.osti.gov/bridge >. Acesso em: 22 out. 2015.

$\mathrm{XU}, \mathrm{H}$. et al. Dehydration of fructose into 5-hydroxymethylfurfural by high stable ordered mesoporous zirconium phosphate. Fuel, n. 145, p. 234-240, 2015.

YUAN, Z. et al. Catalytic conversion of glucose to 5-hydroxymethyl furfural using inexpensive co-catalysts and solvents. Carbohydrate Research, n. 346, p. 2019-2023, 2011.

ZAKRZEWSKA, M. E.; BOGEL-ŁUKASIK, E.; BOGEL-ŁUKASIK, R. Ionic liquidmediated formation of 5-hydroxymethylfurfural - A promising biomass-derived building block. Chemical Reviews, v. 111, n. 2, p. 397-417, 2011.

ZHANG, J. et al. A combined experimental and computational study of the mechanism of fructose dehydration to 5-hydroxymethylfurfural in dimethylsulfoxide using Amberlyst 70, $\mathrm{PO}_{4}{ }^{3-} /$ niobic acid, or sulfuric acid catalysts. Applied Catalysis B: Environmental, n. 181, p. 874-887, 2016.

ZHANG, Y. et al. Direct conversion of biomass-derived carbohydrates to 5hydroxymethylfurural over water-tolerant niobium-based catalysts. Fuel, n. 139, p. 301-307, 2015.

ZHAO, Q. et al. High selective production of 5-hydroymethylfurfural from fructose by a solid heteropolyacid catalyst. Fuel, n. 90, p. 2289-2293, 2011. 
APÊNDICE A - RESUMO DAS PROPRIEDADES DO 5-HIDROXIMETIL-2FURFURAL (HMF) 


\section{Propriedades do HMF}

Algumas propriedades do HMF são apresentadas na Tabela 19.

Tabela 19 - Propriedades do HMF.

\begin{tabular}{lc}
\hline \multicolumn{2}{c}{ Propriedades } \\
\hline \hline Aparência: & Líquido ou pó amarelo escuro \\
\hline Fórmula molecular: & $\mathrm{C}_{6} \mathrm{H}_{6} \mathrm{O}_{3}$ \\
\hline Massa molar: & $126,11 \mathrm{~g} / \mathrm{mol}$ \\
\hline Ponto de fusão: & $28-34^{\circ} \mathrm{C}$ \\
\hline Ponto de ebulição: & $114-118^{\circ} \mathrm{C}$ \\
\hline Ponto de flash: & $79{ }^{\circ} \mathrm{C}$ \\
\hline Densidade: & $1,2430 \mathrm{~g} / \mathrm{cm}^{3}$ \\
\hline Pressão de vapor: & $5,28.10^{-3} \mathrm{~mm} \mathrm{Hg} \mathrm{a} 25^{\circ} \mathrm{C}$ \\
\hline Calor de combustão: & $665 \mathrm{kcal} / \mathrm{mol}^{\circ}$ \\
\hline Índice de refração: & 1,5627 a $18{ }^{\circ} \mathrm{C}$ \\
\hline \hline Fonte: Autora “adaptado de” Sigma-Aldrich Co., 2015 e NCBI, 2016.
\end{tabular}


APÊNDICE B - CURVAS DE CALIBRAÇÃO PARA A ANÁLISE POR HPLC 


\section{Caracterização das substâncias por cromatografia líquida de alta eficiência (HPLC)}

As curvas de calibração de cada substância foram obtidas por regressão linear da área do pico em relação à concentração, segundo a Equação (42).

$$
A=a \cdot C_{i}+b
$$

em que $A$ representa a área do pico integrada pelo próprio programa LCsolution; $C_{i}$, a concentração em mol/L da solução padrão da substância $i$ analisada; $a$ e $b$, são os respectivos coeficientes angular e linear obtidos por regressão linear.

As substâncias descritas na Tabela 3 (página 44) foram analisadas por HPLC nos ensaios preliminares com água como solvente utilizando a coluna Aminex HPX- $87 \mathrm{H}^{\circledR}$ e dois tipos de detectores dispostos em série: índice de refração (I.R.) e ultravioleta na faixa visível (UV-Vis). Entretanto, a utilização de DMSO como solvente nos experimentos apresentou um sinal largo com interferência no sinal do HMF nos cromatogramas obtidos para a coluna Aminex HPX-87H ${ }^{\circledR}$, como visto na Figura 45. A utilização da coluna Shim-pack CLC-ODS $(\mathrm{M})^{\circledR}$ de fase reversa e detector UV-Vis a $266 \mathrm{~nm}$ permitiu diminuir o sinal do DMSO para a análise do HMF, como mostrado em seu cromatograma da Figura 46.

Figura 45 - Cromatogramas de uma amostra de DMSO puro analisado pela coluna Aminex HPX-87H ${ }^{\circledR}$

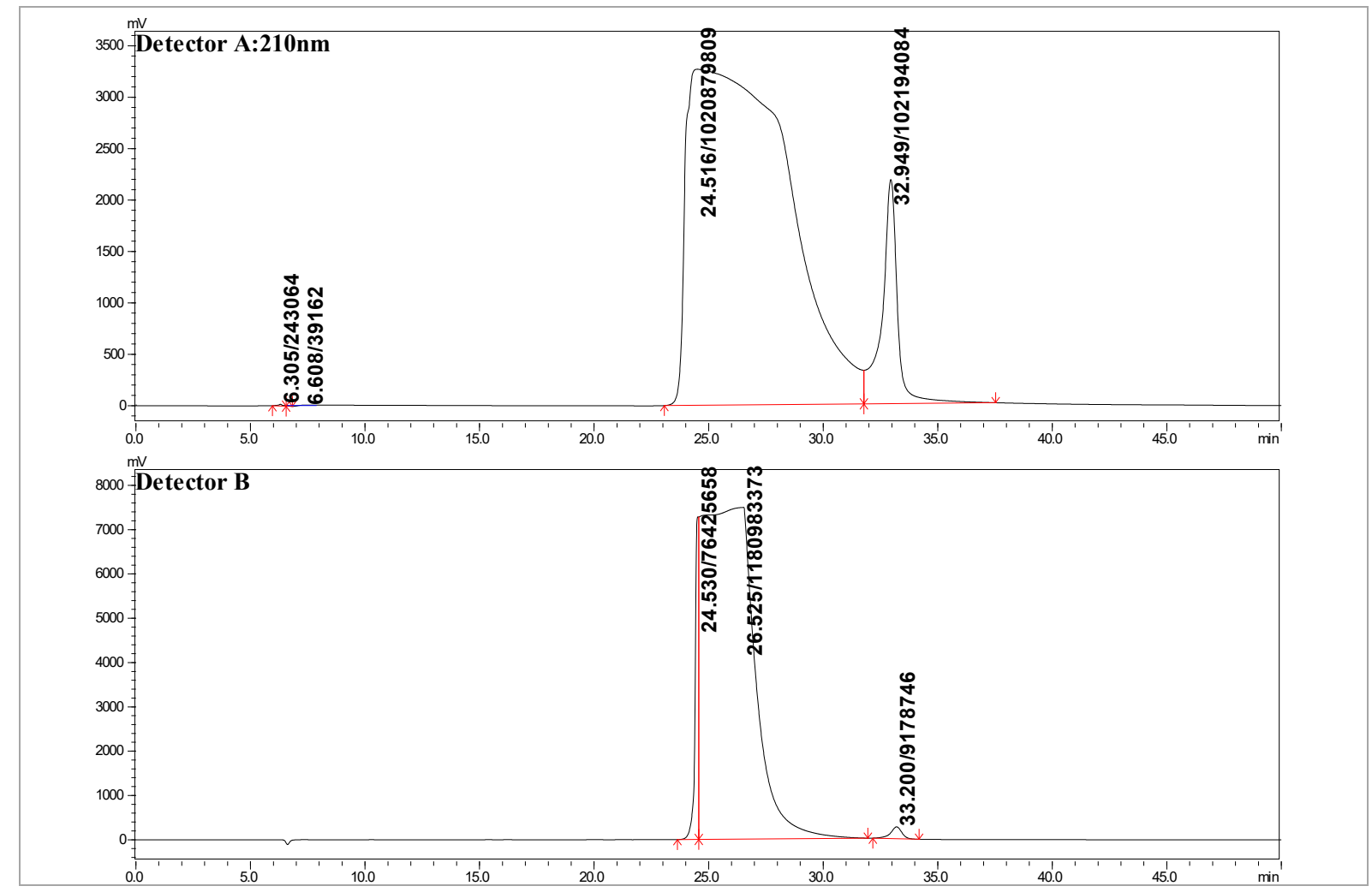

Fonte: Autora.

Legenda: Detector A (UV-Vis); Detector B (I.R.). 
Figura 46 - Cromatograma de uma amostra de DMSO puro analisado pela coluna Shim-pack CLC-ODS (M) ${ }^{\circledR}$ com o detector UV-Vis a $266 \mathrm{~nm}$.

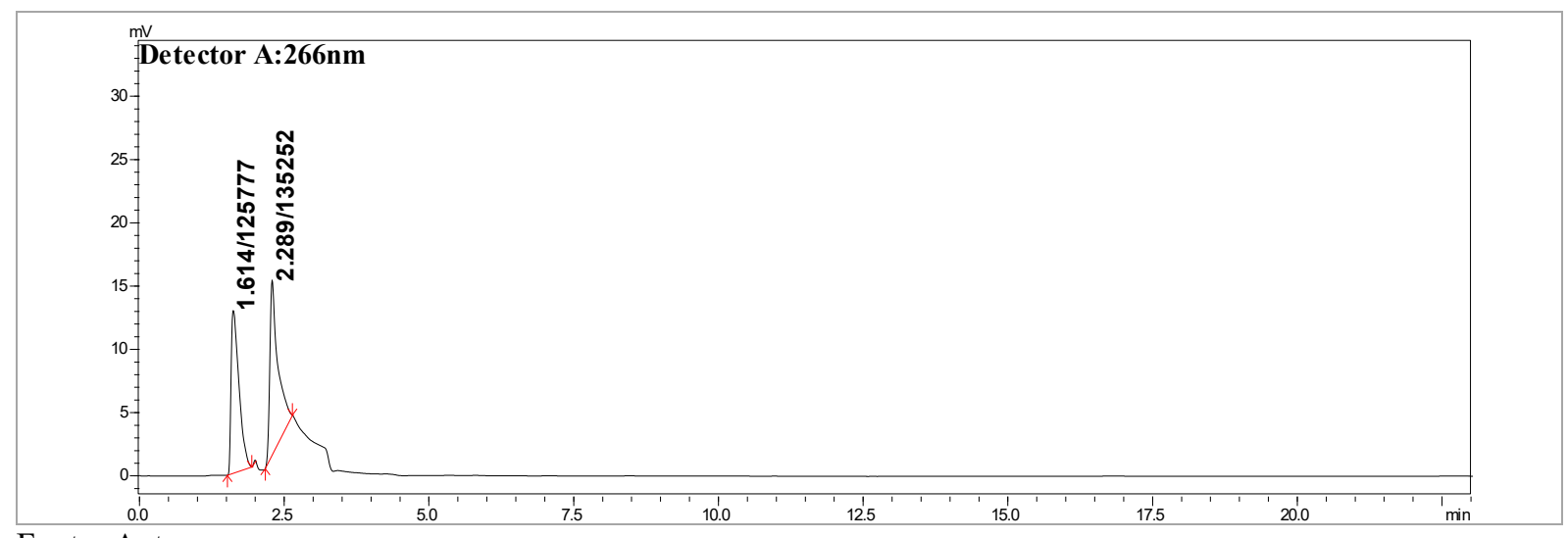

Fonte: Autora.

Os tempos de retenção apresentados por cada substância padrão descrita na Tabela 3 (página 44) analisadas por HPLC são mostrados na Tabela 20.

Tabela 20 - Tempos de retenção das soluções padrões analisadas.

\begin{tabular}{|c|c|c|c|}
\hline \multirow{3}{*}{ Substância } & \multicolumn{3}{|c|}{ Tempos de retenção $(\min )$} \\
\hline & \multicolumn{2}{|c|}{ Aminex HPX-87H ${ }^{\circledR}$} & \multirow{2}{*}{$\begin{array}{l}\text { ão (min) } \\
\text { Shim-pack CLC-ODS (M) } \\
\text { UV-Vis }(266 \mathrm{~nm})\end{array}$} \\
\hline & UV-Vis $(210 \mathrm{~nm})$ & I.R. & \\
\hline D-Glicose & 9,33 & 9,55 & 2,32 \\
\hline D-Frutose & 10,02 & 10,28 & 1,51 \\
\hline Ácido Fórmico & 13,90 & 14,15 & 2,11 \\
\hline Ácido Levulínico & 15,59 & 15,84 & 2,11 \\
\hline HMF & 29,13 & 29,38 & 2,28 \\
\hline Furfural & 43,13 & 43,41 & 3,42 \\
\hline
\end{tabular}

Fonte: Autora.

Os coeficientes das curvas de calibração para a coluna Aminex $\mathrm{HPX}-87 \mathrm{H}^{\circledR}$ são apresentados na Tabela 21 e as curvas para o HMF, na Figura 47.

Tabela 21 - Coeficientes das curvas de calibração para a coluna Aminex HPX-87H ${ }^{\circledR}$ utilizada nos ensaios preliminares.

\begin{tabular}{cc|ccc|ccc}
\hline \hline \multirow{2}{*}{ Substância } & $\begin{array}{c}\text { Massa molar } \\
(\mathbf{g} / \mathbf{m o l})\end{array}$ & \multicolumn{3}{|c|}{ UV-Vis (210 nm) } & \multicolumn{3}{c}{ I.R. } \\
\cline { 3 - 8 } & 180,16 & $\mathbf{a}$ & $\mathbf{b}$ & $\mathbf{R}^{\mathbf{2}}$ & $\mathbf{a}$ & $\mathbf{b}$ & $\mathbf{R}^{\mathbf{2}}$ \\
\hline \hline D-Glicose & 195856 & 2266 & 0,6707 & 513.484 .569 & -13.867 & 0,9999 \\
\hline D-Frutose & 180,16 & 16863294 & -1619 & 0,9943 & 505.130 .474 & 22.218 & 0,9999 \\
\hline Ácido Fórmico & 46,03 & 88433346 & -75520 & 0,9959 & 46.129 .984 & -47.874 & 0,9946 \\
\hline Ácido Levulínico & 116,12 & 72036043 & -36074 & 0,9948 & 240.193 .508 & -24.794 & 0,9999 \\
\hline Furfural & 96,08 & 1875560198 & -26392 & 0,9996 & 133.239 .975 & 23.840 & 0,9898 \\
\hline \hline
\end{tabular}

Fonte: Autora.

Nota: Coluna a $60{ }^{\circ} \mathrm{C}$; eluente a $0,6 \mathrm{~mL} / \mathrm{min}$ de ácido sulfúrico $5 \mathrm{mM}$; detectores de I.R. e UV-Vis a $210 \mathrm{~nm}$ operando a $40{ }^{\circ} \mathrm{C}$. 
Figura 47 - Curvas de calibração do HMF para a coluna Aminex HPX87H ${ }^{\circledR}$ e detectores I.R. e UV-Vis a $210 \mathrm{~nm}$ utilizados nos ensaios com água.

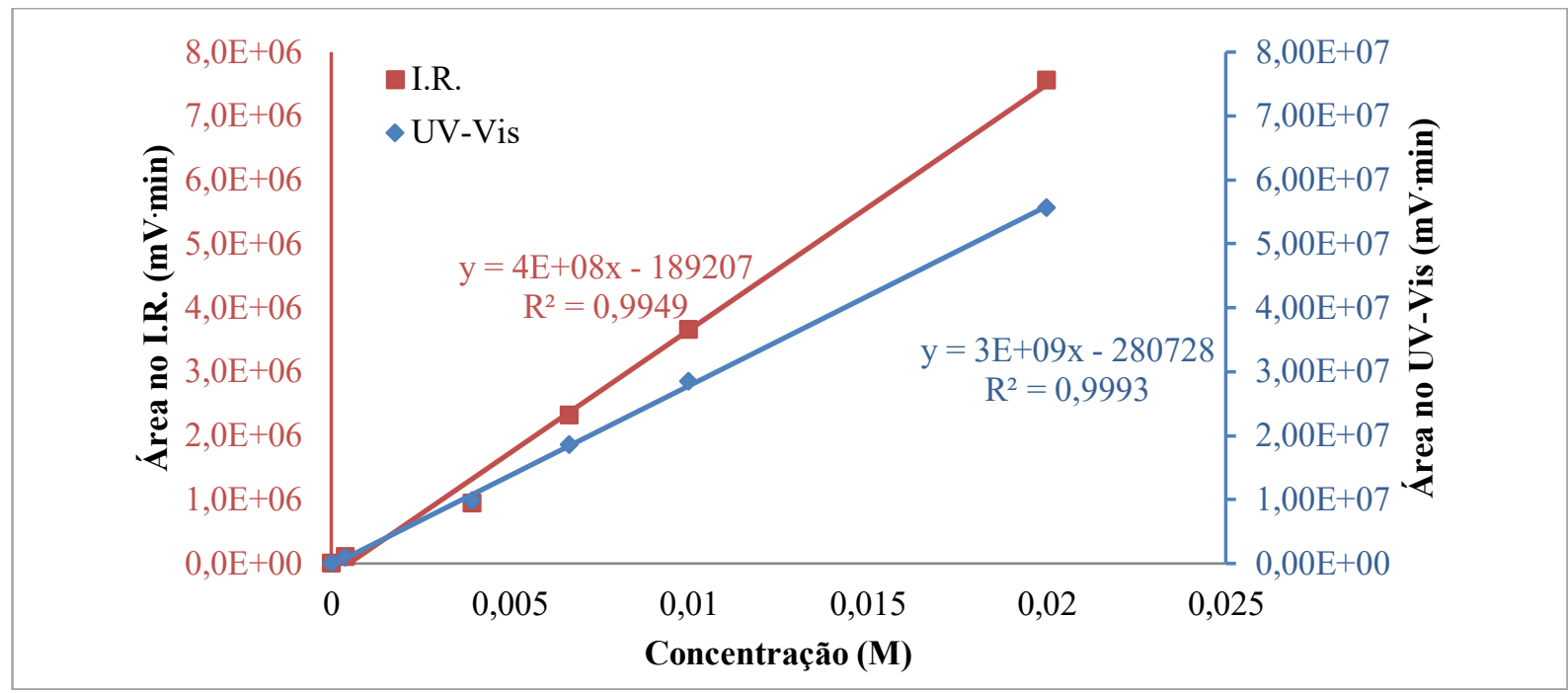

Fonte: Autora.

Nota: Coluna a $60{ }^{\circ} \mathrm{C}$; eluente a $0,6 \mathrm{~mL} / \mathrm{min}$ de ácido sulfúrico $5 \mathrm{mM}$; detectores de I.R. e UV-Vis a $210 \mathrm{~nm}$ operando a $40{ }^{\circ} \mathrm{C}$

As soluções padrões apresentaram picos cujas áreas são apresentadas na Tabela 22 para a coluna Shim-pack CLC-ODS (M)® utilizada nos ensaios com DMSO.

Tabela 22 - Área do pico referente à respectiva concentração analisada e área relativa para a coluna Shim-pack CLC-ODS (M) ${ }^{\circledR}$ utilizada nos ensaios com DMSO.

\begin{tabular}{ccccc}
\hline \hline Substância & Concentração $(\mathbf{g} / \mathbf{L})$ & Concentração $\mathbf{( M )}$ & Área & Área relativa (\%) \\
\hline \hline D-Glicose & 9,00 & 0,0500 & 27656 & 0,93 \\
\hline D-Frutose & 8,00 & 0,0444 & 21665 & 0,73 \\
\hline Ácido Fórmico & 2,50 & 0,0543 & 92494 & 3,10 \\
\hline Ácido Levulínico & 2,50 & 0,0215 & 457683 & 15,4 \\
\hline HMF & 0,05 & 0,0004 & 2981081 & 100 \\
\hline Furfural & 0,05 & 0,0005 & 6279047 & 211 \\
\hline \hline
\end{tabular}

Fonte: Autora.

Nota: Área relativa calculada utilizando o pico do HMF como base.

A partir da Tabela 22 foi possível verificar que a glicose, frutose, ácido fórmico e ácido levulínico, apesar de suas concentrações maiores, apresentaram sinal desprezível em relação ao HMF e ao furfural nos cromatogramas. A diferenciação desses dois últimos foi feita por seus tempos de retenção apresentados na Tabela 20 de 2,28 min e 3,42 min, respectivamente.

A curva de calibração do HMF para os ensaios com DMSO como solvente é apresentada na Figura 48. 
Figura 48 - Curva de calibração do HMF para a coluna Shim-pack CLCODS (M) ${ }^{\circledR}$ utilizada nos ensaios com DMSO.

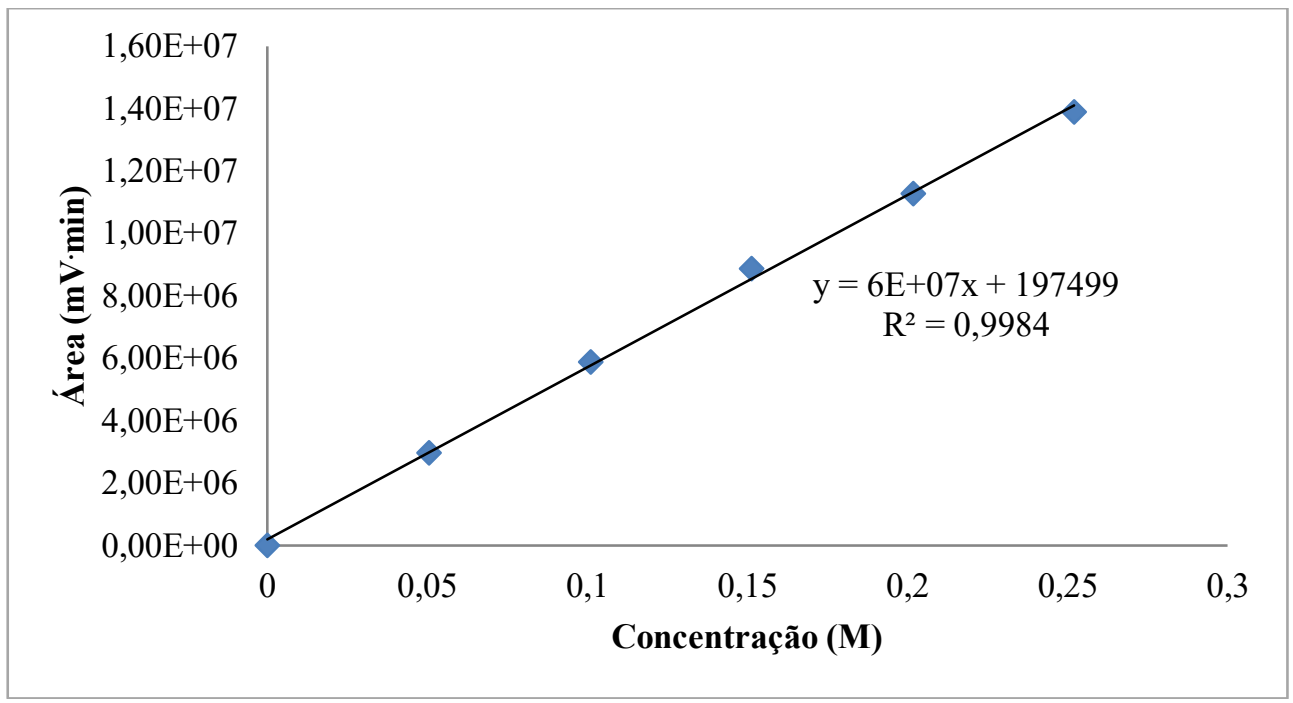

Fonte: Autora.

Nota: Coluna a $30{ }^{\circ} \mathrm{C}$; eluente a $1,2 \mathrm{~mL} / \mathrm{min}$ de acetonitrila:ácido acético $1 \%(\mathrm{~m} / \mathrm{m})$ na proporção 20:80; detector de UV-Vis a $266 \mathrm{~nm}$ operando a $40^{\circ} \mathrm{C}$ 
APÊNDICE C - GRÁFICOS DOS DADOS SIMULADOS POR OTIMIZAÇÃO 


\section{Simulação da concentração de HMF por otimização}

Os ensaios com utilização de frutose, DMSO e resina SGC650H bruta como catalisador em reator batelada necessitaram de ajuste considerando o efeito da temperatura, cujos valores calculados por esse ajuste são comparados aos experimentais nas Figuras 52 a 62.

Figura 49 - Comparação entre dados experimentais e valores calculados para a concentração de HMF no ensaio a $90{ }^{\circ} \mathrm{C}$ com alimentação de $1,5 \%(\mathrm{~m} / \mathrm{m})$ de frutose.

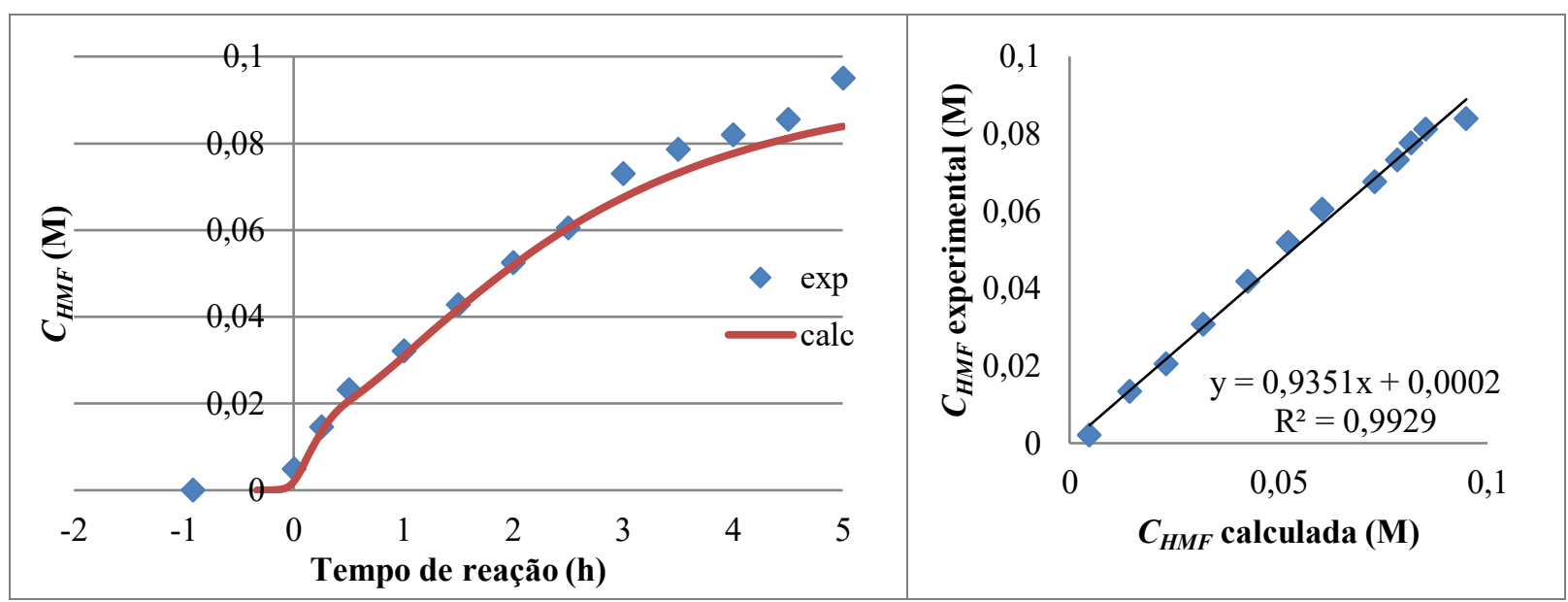

Fonte: Autora.

Nota: Ensaios realizados em batelada com resina gelular SGC650H bruta como catalisador e DMSO como solvente.

Figura 50 - Comparação entre dados experimentais e valores calculados para a concentração de HMF no ensaio a $100{ }^{\circ} \mathrm{C}$ com alimentação de $1,5 \%(\mathrm{~m} / \mathrm{m})$ de frutose.

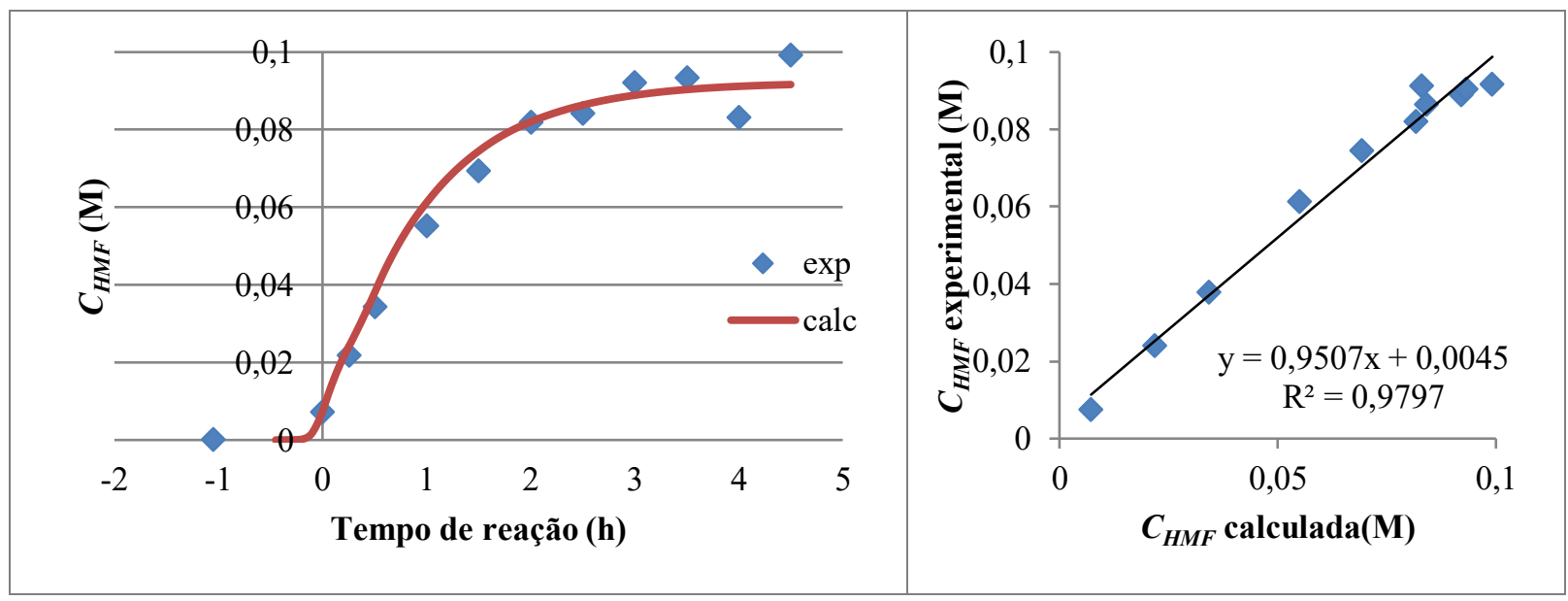

Fonte: Autora.

Nota: Ensaios realizados em batelada com resina gelular SGC650H bruta como catalisador e DMSO como solvente. 
Figura 51 - Comparação entre dados experimentais e valores calculados para a concentração de HMF no ensaio a $110^{\circ} \mathrm{C}$ com alimentação de $1,5 \%(\mathrm{~m} / \mathrm{m})$ de frutose.

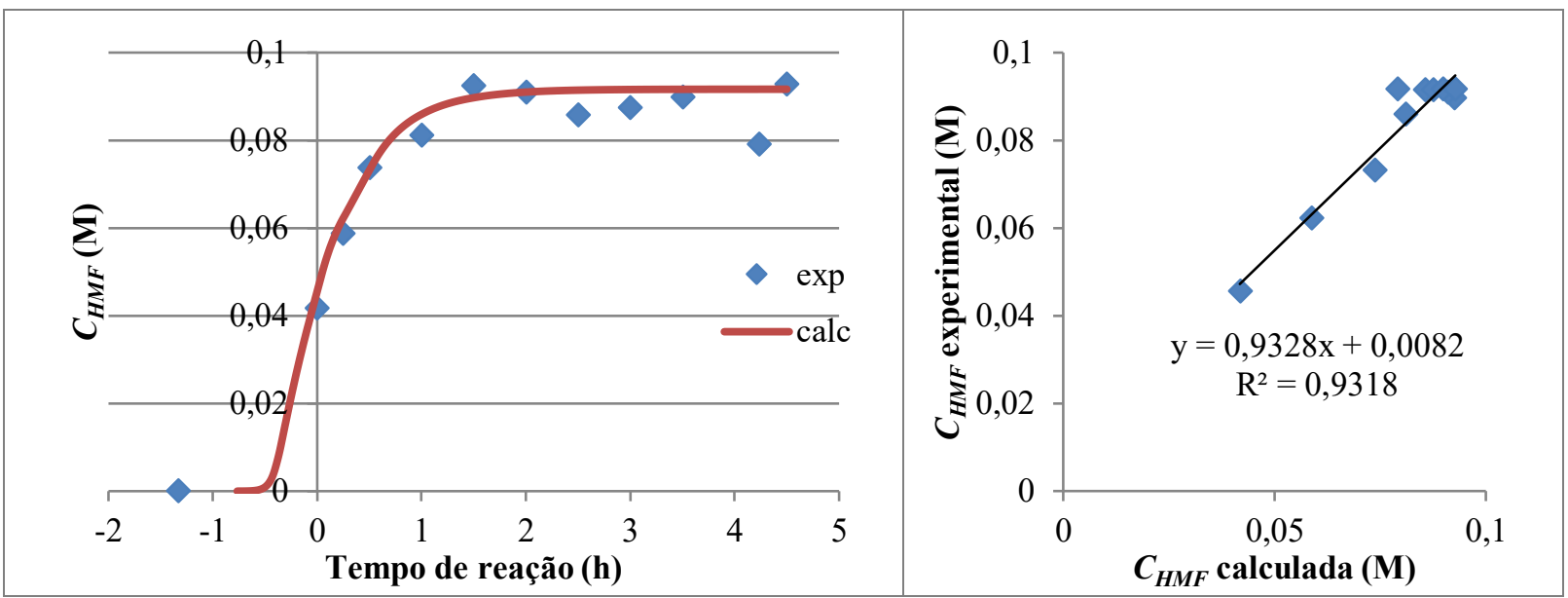

Fonte: Autora.

Nota: Ensaios realizados em batelada com resina gelular SGC650H bruta como catalisador e DMSO como solvente.

Figura 52 - Comparação entre dados experimentais e valores calculados para a concentração de $\mathrm{HMF}$ no ensaio a $90{ }^{\circ} \mathrm{C}$ com alimentação de $3,0 \%(\mathrm{~m} / \mathrm{m})$ de frutose.
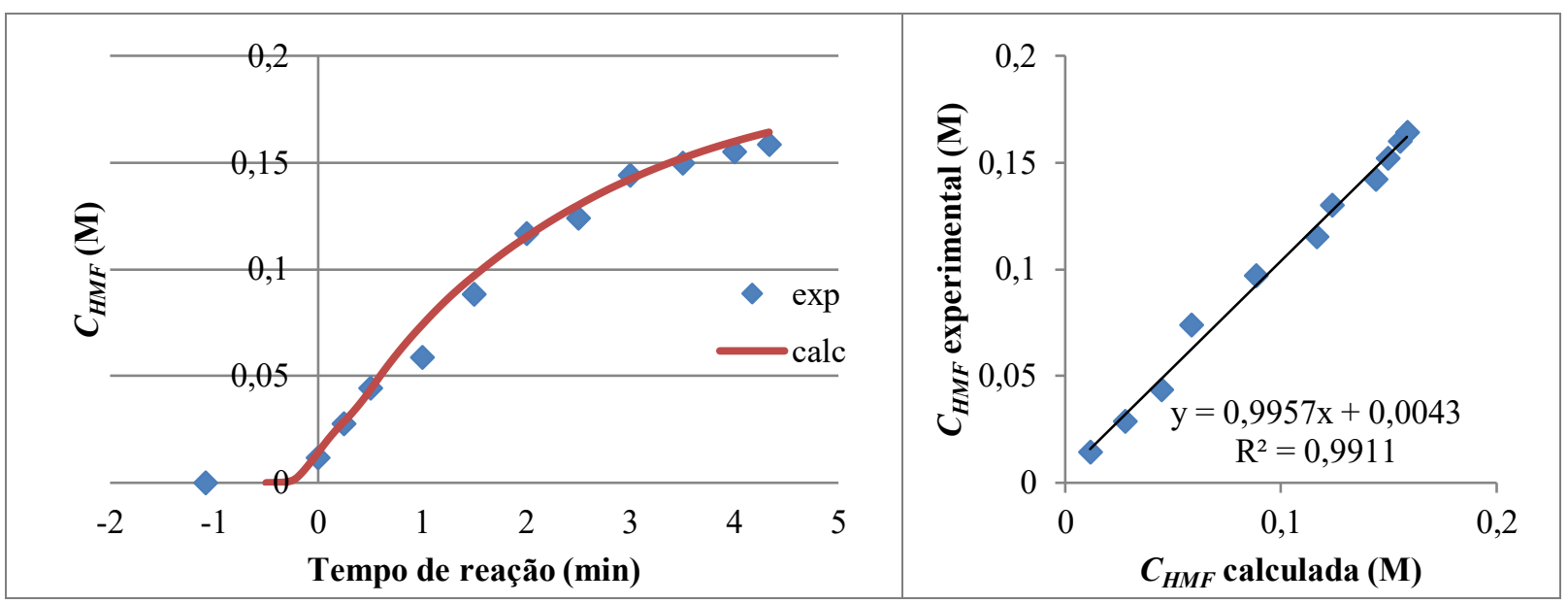

Fonte: Autora.

Nota: Ensaios realizados em batelada com resina gelular SGC650H bruta como catalisador e DMSO como solvente. 
Figura 53 - Comparação entre dados experimentais e valores calculados para a concentração de HMF no ensaio a $100{ }^{\circ} \mathrm{C}$ com alimentação de $3,0 \%(\mathrm{~m} / \mathrm{m})$ de frutose.

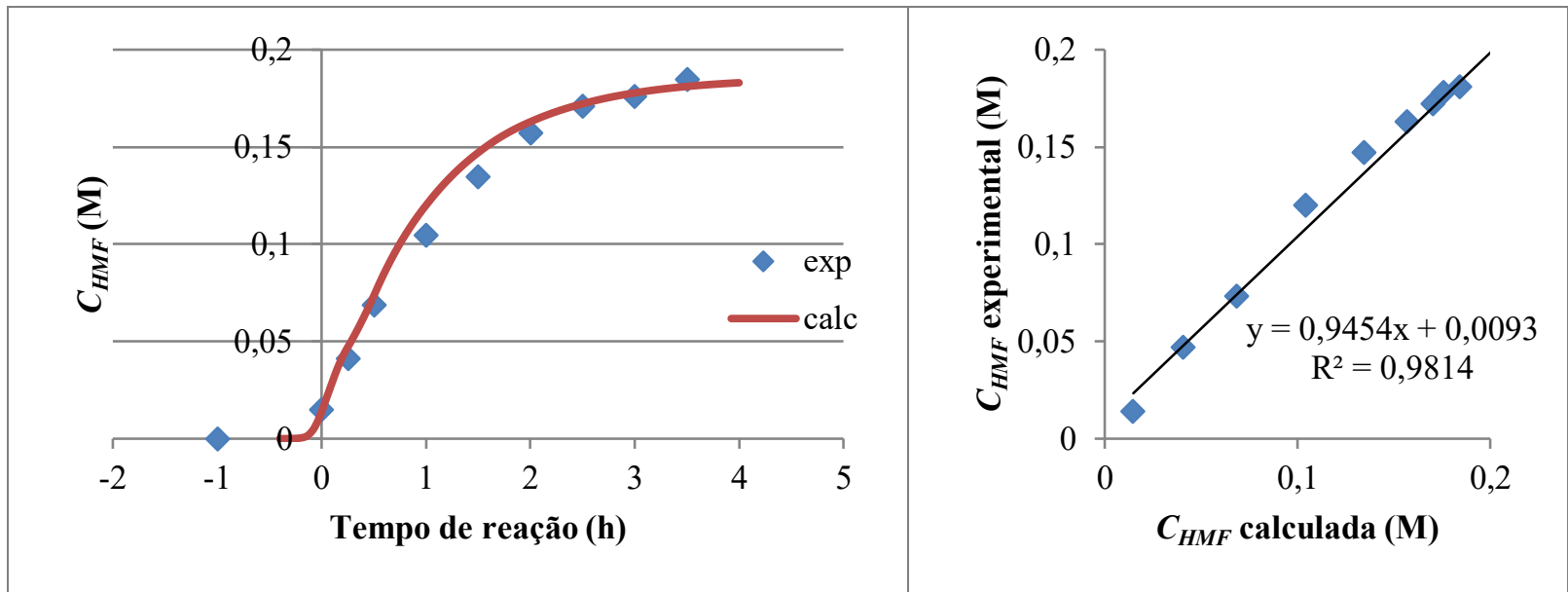

Fonte: Autora.

Nota: Ensaios realizados em batelada com resina gelular SGC650H bruta como catalisador e DMSO como solvente.

Figura 54 - Comparação entre dados experimentais e valores calculados para a concentração de HMF no ensaio a $110{ }^{\circ} \mathrm{C}$ com alimentação de $3,0 \%(\mathrm{~m} / \mathrm{m})$ de frutose.

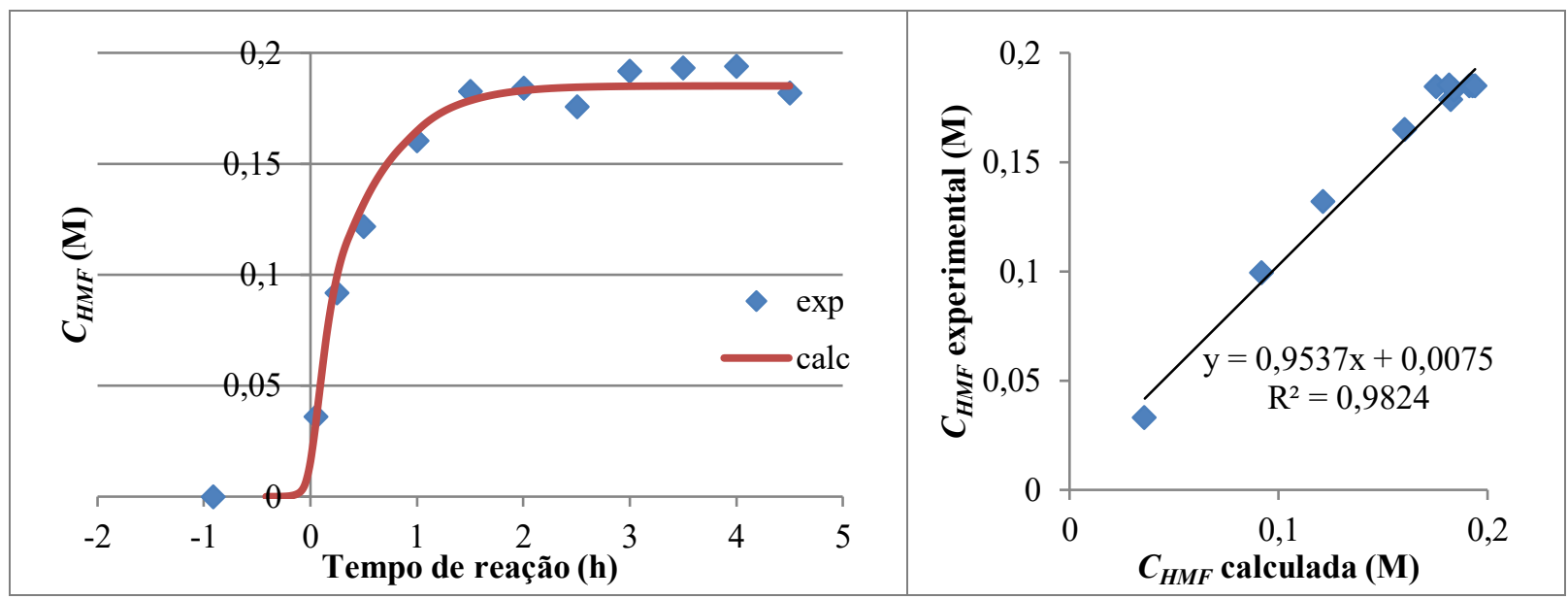

Fonte: Autora.

Nota: Ensaios realizados em batelada com resina gelular SGC650H bruta como catalisador e DMSO como solvente. 
Figura 55 - Comparação entre dados experimentais e valores calculados para a concentração de HMF no ensaio a $90{ }^{\circ} \mathrm{C}$ com alimentação de $4,5 \%(\mathrm{~m} / \mathrm{m})$ de frutose.

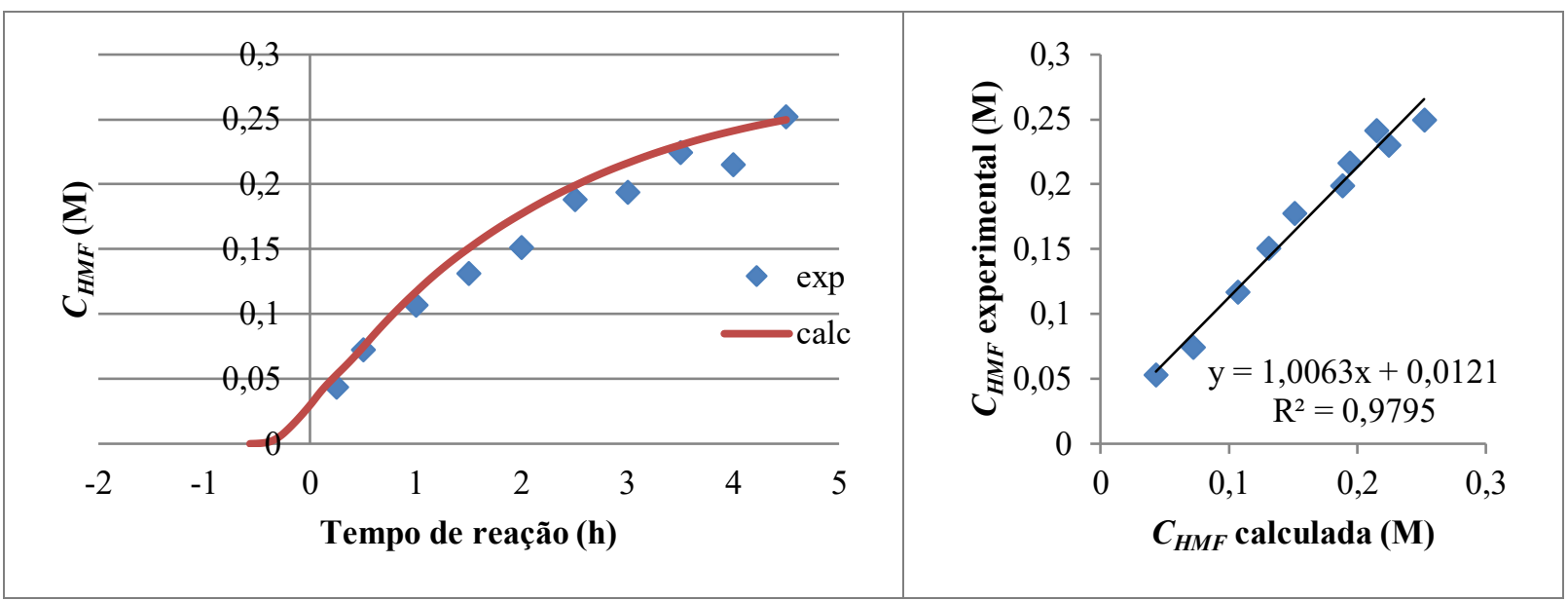

Fonte: Autora.

Nota: Ensaios realizados em batelada com resina gelular SGC650H bruta como catalisador e DMSO como solvente.

Figura 56 - Comparação entre dados experimentais e valores calculados para a concentração de HMF no ensaio a $100{ }^{\circ} \mathrm{C}$ com alimentação de $4,5 \%(\mathrm{~m} / \mathrm{m})$ de frutose.

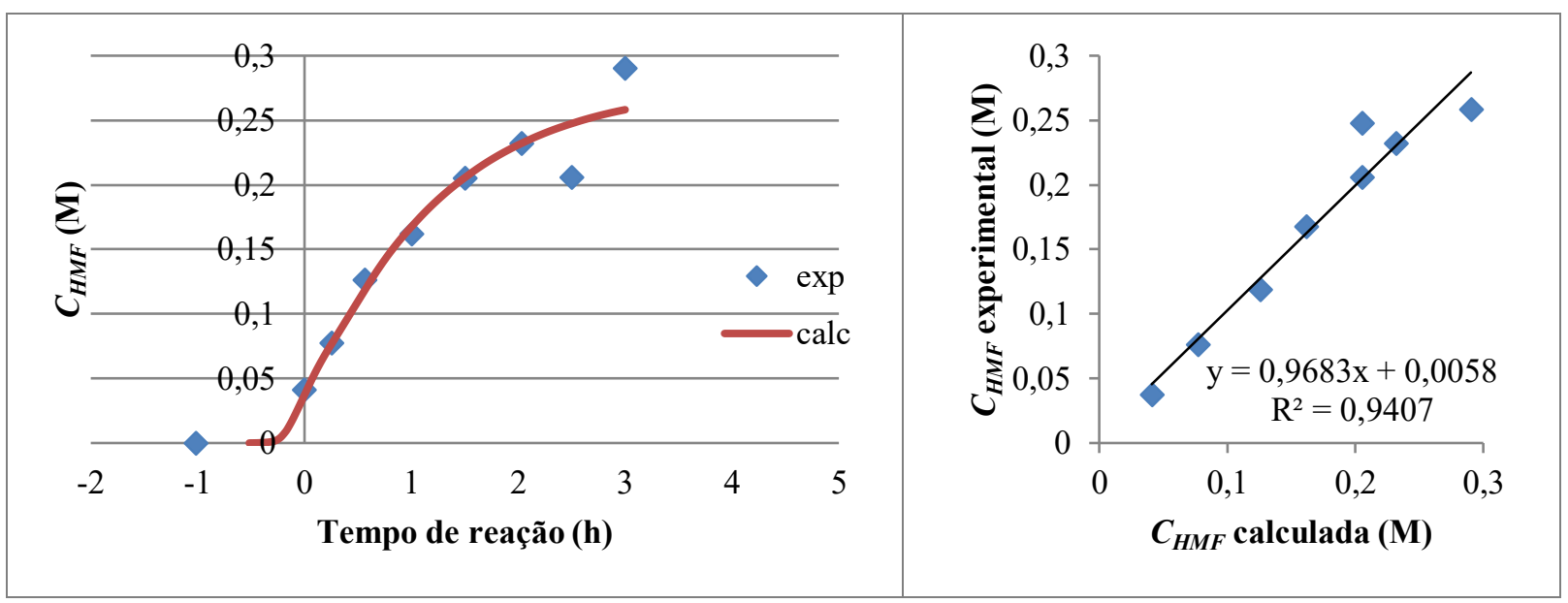

Fonte: Autora.

Nota: Ensaios realizados em batelada com resina gelular SGC650H bruta como catalisador e DMSO como solvente. 
Figura 57 - Comparação entre dados experimentais e valores calculados para a concentração de HMF no ensaio a $110{ }^{\circ} \mathrm{C}$ com alimentação de $4,5 \%(\mathrm{~m} / \mathrm{m})$ de frutose.

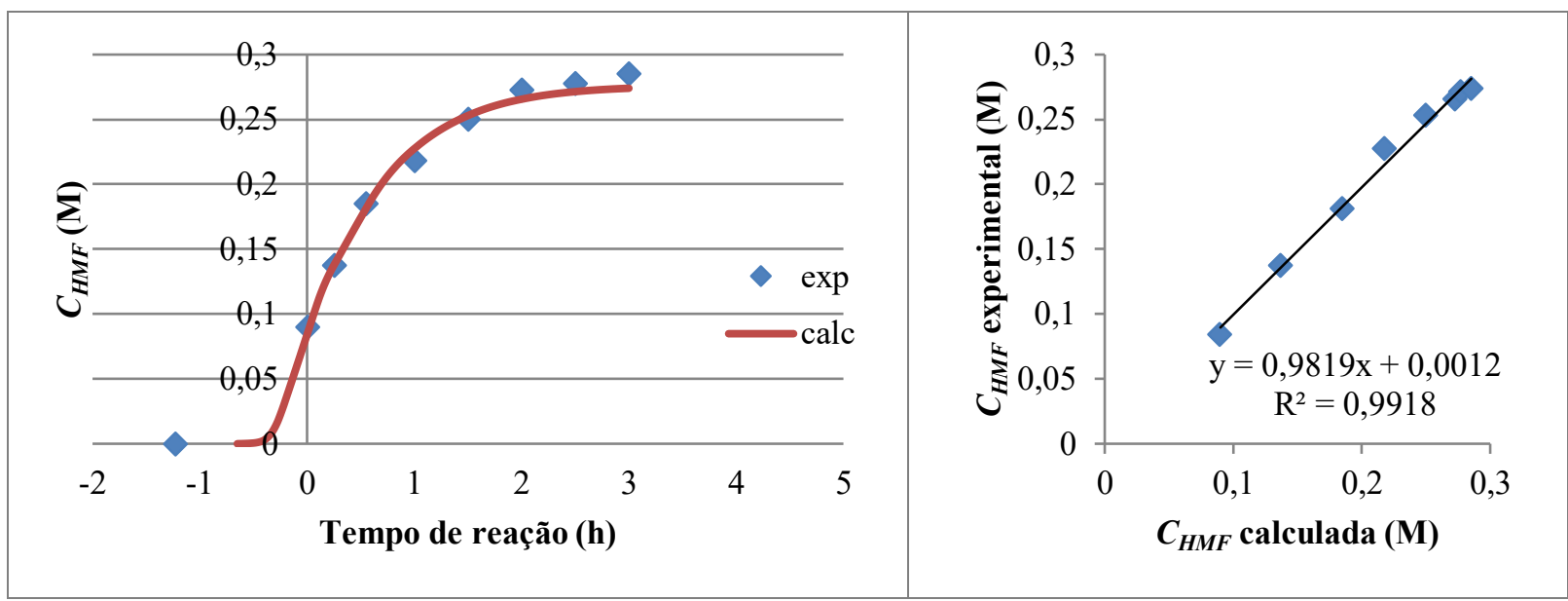

Fonte: Autora.

Nota: Ensaios realizados em batelada com resina gelular SGC650H bruta como catalisador e DMSO como solvente.

Figura 58 - Comparação entre dados experimentais e valores calculados para a concentração de HMF no ensaio a $90{ }^{\circ} \mathrm{C}$ com alimentação de $13,5 \%(\mathrm{~m} / \mathrm{m})$ de frutose.

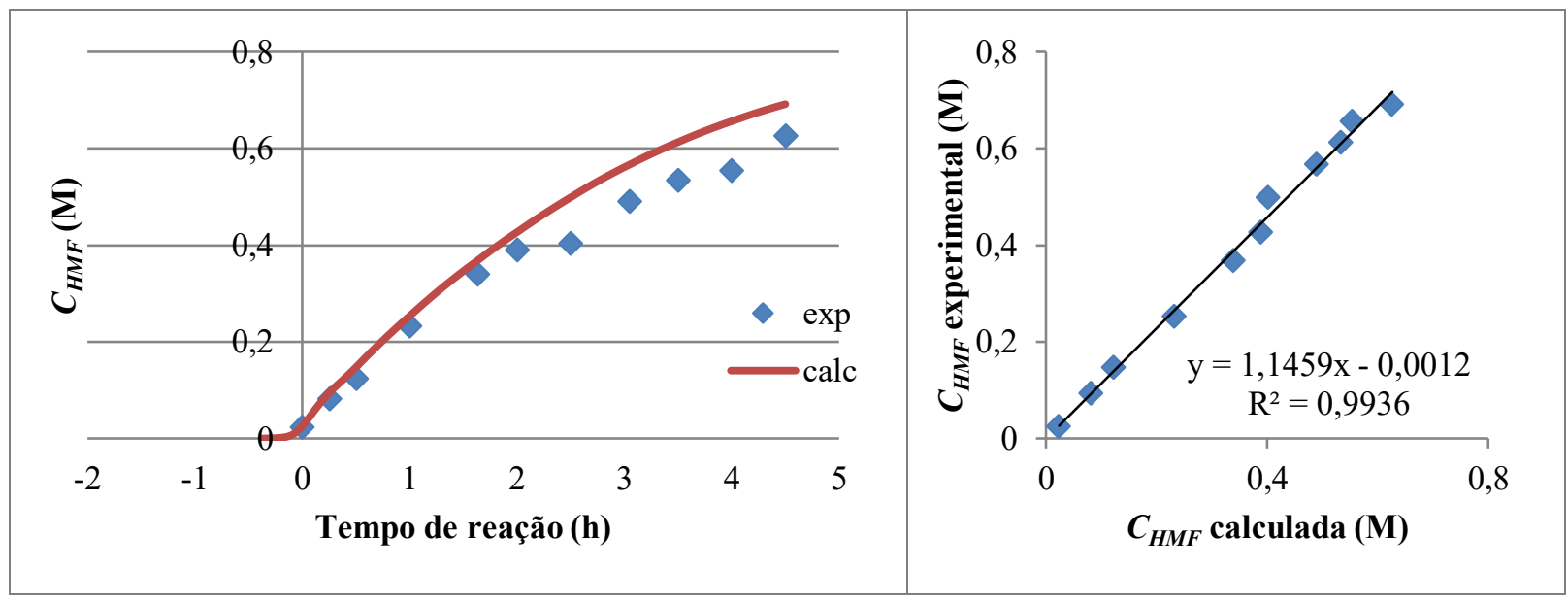

Fonte: Autora.

Nota: Ensaios realizados em batelada com resina gelular SGC650H bruta como catalisador e DMSO como solvente. 
Figura 59 - Comparação entre dados experimentais e valores calculados para a concentração de HMF no ensaio a $100{ }^{\circ} \mathrm{C}$ com alimentação de $13,5 \%(\mathrm{~m} / \mathrm{m})$ de frutose.

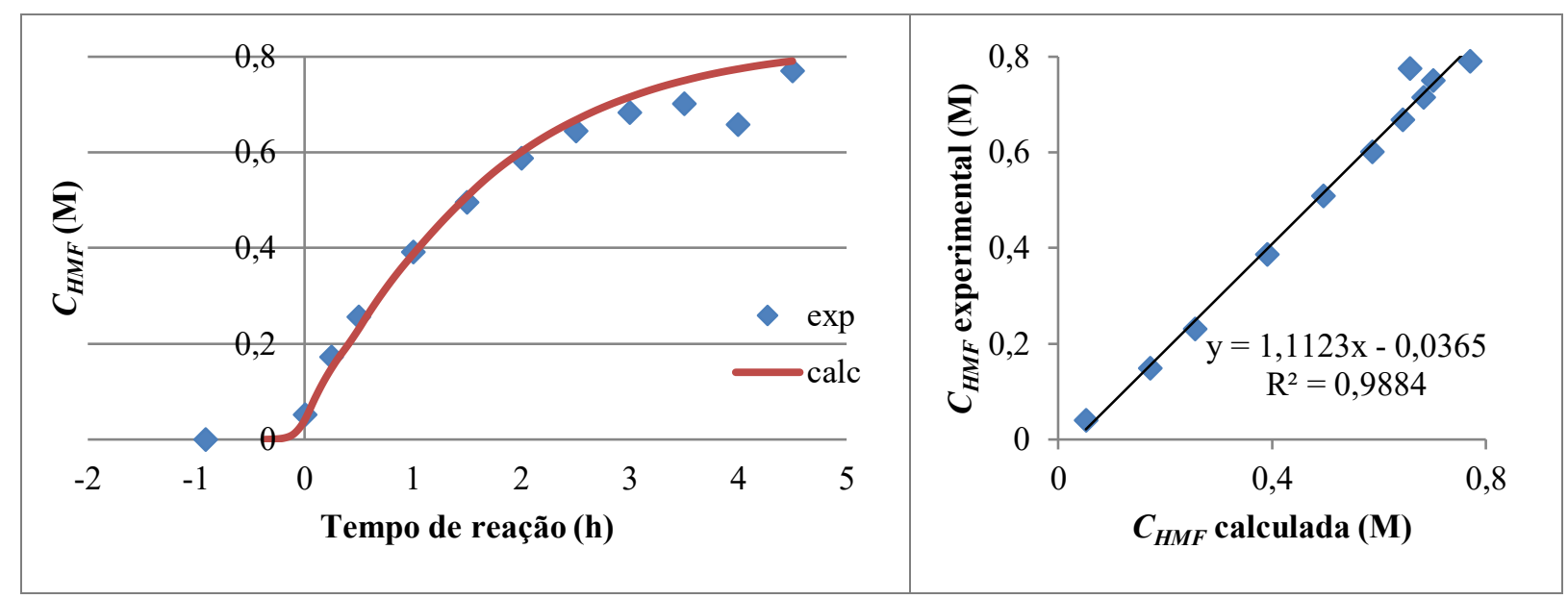

Fonte: Autora.

Nota: Ensaios realizados em batelada com resina gelular SGC650H bruta como catalisador e DMSO como solvente.

Figura 60 - Comparação entre dados experimentais e valores calculados para a concentração de HMF no ensaio a $110{ }^{\circ} \mathrm{C}$ com alimentação de $13,5 \%(\mathrm{~m} / \mathrm{m})$ de frutose.
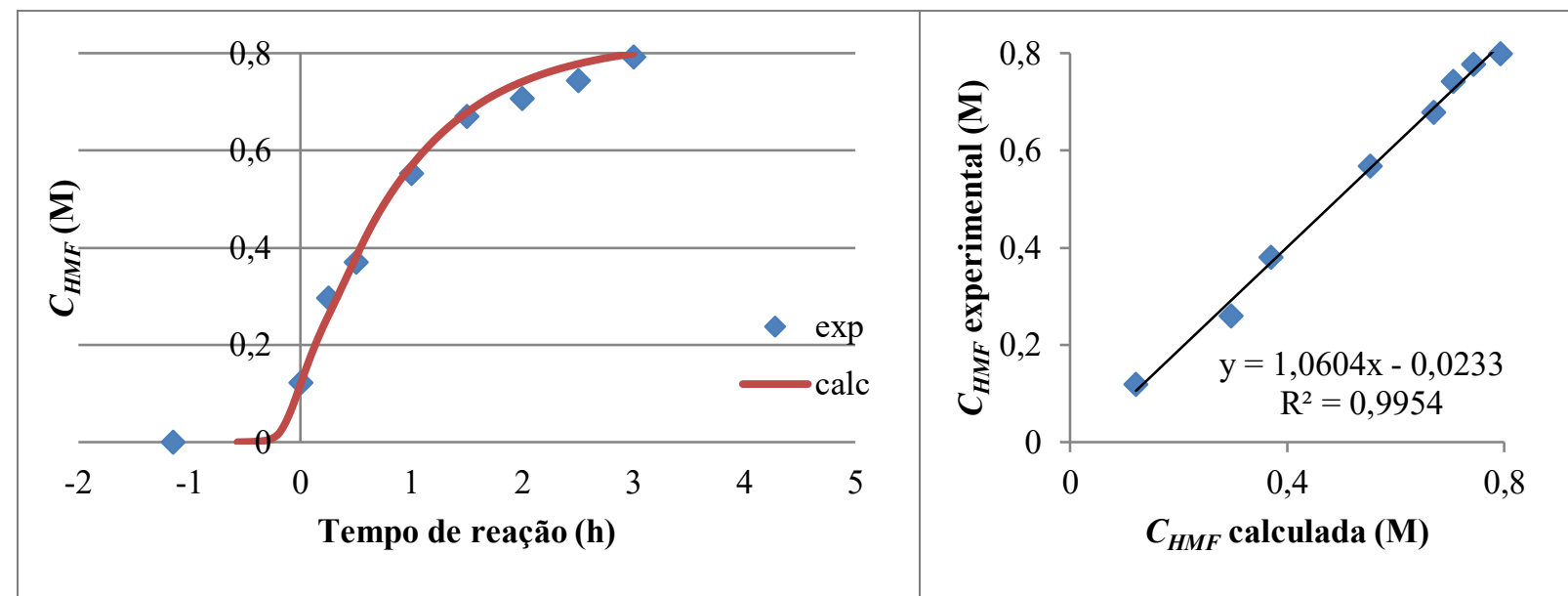

Fonte: Autora.

Nota: Ensaios realizados em batelada com resina gelular SGC650H bruta como catalisador e DMSO como solvente. 
ANEXO A - TABELA DOS GRUPOS QUE COMPÕEM EQUAÇÕES CINÉTICAS CATALISADAS POR SÓLIDOS 


\section{GROUPS IN KINETIC EQUATIONS FOR REACTIONS ON SOLID CATALYSTS}

\section{Driving-Force Groups}

\begin{tabular}{lllcc}
\hline Reaction & $A \rightleftarrows R$ & $A \rightleftarrows R+S$ & $A+B \rightleftarrows R$ & $A+B \rightleftarrows R+S$ \\
\hline $\begin{array}{l}\text { Adsorption of } A \\
\text { controlling }\end{array}$ & $p_{A}-\frac{p_{R}}{K}$ & $p_{A}-\frac{p_{R} p_{S}}{K}$ & $p_{A}-\frac{p_{R}}{K p_{B}}$ & $p_{A}-\frac{p_{R} p_{S}}{K p_{B}}$ \\
$\begin{array}{l}\text { Adsorption of } B \\
\text { controlling }\end{array}$ & 0 & 0 & $p_{B}-\frac{p_{R}}{K p_{A}}$ & $p_{B}-\frac{p_{R} p_{S}}{K p_{A}}$ \\
$\begin{array}{l}\text { Desorption of } R \\
\text { controlling }\end{array}$ & $p_{A}-\frac{p_{R}}{K}$ & $\frac{p_{A}}{p_{S}}-\frac{p_{R}}{K}$ & $p_{A} p_{B}-\frac{p_{R}}{K}$ & $\frac{p_{A} p_{B}}{p_{S}}-\frac{p_{R}}{K}$ \\
$\begin{array}{l}\text { Surface reaction } \\
\text { controlling }\end{array}$ & $p_{A}-\frac{p_{R}}{K}$ & $p_{A}-\frac{p_{R} p_{S}}{K}$ & $p_{A} p_{B}-\frac{p_{R}}{K}$ & $p_{A} p_{B}-\frac{p_{R} p_{S}}{K}$ \\
$\begin{array}{l}\text { Impact of } A \\
\text { controlling }(A\end{array}$ & 0 & 0 & $p_{A} p_{B}-\frac{p_{R}}{K}$ & $p_{A} p_{B}-\frac{p_{R} p_{S}}{K}$ \\
$\begin{array}{l}\text { not adsorbed) } \\
\text { Homogeneous } \\
\text { reaction } \\
\text { controlling }\end{array}$ & $p_{A}-\frac{p_{R}}{K}$ & $p_{A}-\frac{p_{R} p_{S}}{K}$ & $p_{A} p_{B}-\frac{p_{R}}{K}$ & $p_{A} p_{B}-\frac{p_{R} p_{S}}{K}$ \\
\hline
\end{tabular}

\section{Replacements in the General Adsorption Groups}

$$
\left(1+K_{A} p_{A}+K_{B} p_{B}+K_{R} p_{R}+K_{S} p_{S}+K_{I} p_{I}\right)^{n}
$$

\begin{tabular}{|c|c|c|c|c|}
\hline Reaction & $A \rightleftarrows R$ & $A \rightleftarrows R+S$ & $A+B \rightleftarrows R$ & $A+B \rightleftarrows R+S$ \\
\hline $\begin{array}{l}\text { When adsorption of } A \\
\text { is rate controlling, } \\
\text { replace } K_{A} p_{A} \text { by }\end{array}$ & $\frac{K_{A} p_{R}}{K}$ & $\frac{K_{A} p_{R} p_{S}}{K}$ & $\frac{K_{A} p_{R}}{K p_{B}}$ & $\frac{K_{A} p_{R} p_{S}}{K p_{B}}$ \\
\hline $\begin{array}{l}\text { When adsorption of } B \\
\text { is rate controlling, } \\
\text { replace } K_{B} p_{B} \text { by }\end{array}$ & 0 & 0 & $\frac{K_{B} p_{R}}{K p_{A}}$ & $\frac{K_{B} p_{R} p_{S}}{K p_{A}}$ \\
\hline $\begin{array}{l}\text { When desorption of } R \\
\text { is rate controlling, } \\
\text { replace } K_{R} p_{R} \text { by }\end{array}$ & $K K_{R} p_{A}$ & $K K_{R} \frac{p_{A}}{p_{S}}$ & $K K_{R} p_{A} p_{B}$ & $K K_{R} \frac{p_{A} p_{B}}{p_{S}}$ \\
\hline $\begin{array}{l}\text { When adsorption of } A \\
\text { is rate controlling with } \\
\text { dissociation of } A \text {, } \\
\text { replace } K_{A} p_{A} \text { by }\end{array}$ & $\sqrt{\frac{K_{A} p_{R}}{K}}$ & $\sqrt{\frac{K_{A} p_{R} p_{S}}{K}}$ & $\sqrt{\frac{K_{A} p_{R}}{K p_{B}}}$ & $\sqrt{\frac{K_{A} p_{R} p_{S}}{K p_{B}}}$ \\
\hline $\begin{array}{l}\text { When equilibrium } \\
\text { adsorption of } A \text { takes } \\
\text { place with dissociation } \\
\text { of } A \text {, replace } K_{A} p_{A} \text { by } \\
\text { (and similarly for other } \\
\text { components adsorbed } \\
\text { with dissociation) }\end{array}$ & $\sqrt{K_{A} p_{A}}$ & $\sqrt{K_{A} p_{A}}$ & $\sqrt{K_{A} p_{A}}$ & $\sqrt{K_{A} p_{A}}$ \\
\hline $\begin{array}{l}\text { When } A \text { is not } \\
\text { adsorbed, replace } K_{A} p_{A} \\
\text { by (and similarly for } \\
\text { other components that } \\
\text { are not adsorbed) }\end{array}$ & 0 & 0 & 0 & 0 \\
\hline
\end{tabular}




\begin{tabular}{|c|c|c|c|c|}
\hline \multicolumn{5}{|c|}{ Kinetic Groups } \\
\hline \multicolumn{2}{|c|}{ Adsorption of $A$ controlling } & $k_{A}$ & & \\
\hline \multirow{2}{*}{\multicolumn{2}{|c|}{$\begin{array}{l}\text { Adsorption of } B \text { controlling } \\
\text { Desorption of } R \text { controlling }\end{array}$}} & $k_{B}$ & & \\
\hline & & $k_{R} K$ & & \\
\hline \multicolumn{2}{|c|}{$\begin{array}{l}\text { Adsorption of } A \text { controlling with } \\
\text { dissociation }\end{array}$} & $k_{A}$ & & \\
\hline \multicolumn{2}{|c|}{ Impact of $A$ controlling } & $k_{A} K_{B}$ & & \\
\hline \multirow{2}{*}{\multicolumn{2}{|c|}{ Homogeneous reaction controlling }} & - $k$ & & \\
\hline & & Surface R & on Controll & \\
\hline & $A \rightleftarrows R$ & $A \rightleftarrows R+S$ & $A+B \rightleftarrows R$ & $A+B \rightleftarrows R+S$ \\
\hline Without dissociation & $k_{s} K_{A}$ & $k_{s} K_{A}$ & $k_{s r} K_{A} K_{B}$ & $k_{S r} K_{A} K_{B}$ \\
\hline With dissociation of $A$ & $k_{s r} K_{A}$ & $k_{S r} K_{A}$ & $k_{s} K_{A} K_{B}$ & $k_{s r} K_{A} K_{B}$ \\
\hline$B$ not adsorbed & $k_{s r} K_{A}$ & $k_{s} K_{A}$ & $k_{s} K_{A}$ & $k_{S r} K_{A}$ \\
\hline $\begin{array}{l}B \text { not adsorbed, } A \\
\text { dissociated }\end{array}$ & $k_{s r} K_{A}$ & $k_{s} K_{A}$ & $k_{s} K_{A}$ & $k_{s r} K_{A}$ \\
\hline
\end{tabular}

\section{Exponents of Adsorption Groups}

\begin{tabular}{|c|c|c|c|c|}
\hline $\begin{array}{l}\text { Adsorption of } A \text { controlling } \\
\text { without dissociation }\end{array}$ & $n=1$ & & & \\
\hline Desorption of $R$ controlling & $n=1$ & & & \\
\hline $\begin{array}{l}\text { Adsorption of } A \text { controlling } \\
\text { with dissociation }\end{array}$ & $n=2$ & & & \\
\hline $\begin{array}{l}\text { Impact of } A \text { without } \\
\text { dissociation } A+B \rightleftarrows R\end{array}$ & $n=1$ & & & \\
\hline $\begin{array}{l}\text { Impact of } A \text { without } \\
\text { dissociation } A+B \rightleftarrows R+S\end{array}$ & $n=2$ & & & \\
\hline \multirow[t]{2}{*}{ Homogeneous reaction } & $n=0$ & & & \\
\hline & & & Surface Reaction Controlling & $A+B \rightleftarrows R+S$ \\
\hline No dissociation of $A$ & 1 & 2 & 2 & 2 \\
\hline Dissociation of $A$ & 2 & 2 & 3 & 3 \\
\hline $\begin{array}{l}\text { Dissociation of } A \text { ( } B \text { not } \\
\text { adsorbed) }\end{array}$ & 2 & 2 & 2 & 2 \\
\hline $\begin{array}{l}\text { No dissociation of } A \text { ( } B \\
\text { not adsorbed) }\end{array}$ & 1 & 2 & 1 & 2 \\
\hline
\end{tabular}

Fonte: Yang; Hougen (1950) apud . Froment; Bischoff; De Wilde (2011).

Nota: $p_{i}$ simboliza as pressões parciais da espécie $i ; K$, a constante de equilíbrio da reação; $K_{j}$, as constantes de equilíbrio de adsorção da reação $j$ (adsorção de $A$, adsorção de $B$ ou reação na superfície $s r$ ); e $k_{j}$, as constantes de velocidade da reação $j$. 